\title{
METABOLISM OF IODOACETIC ACID BY ORANGE LEAVES
}

By

TIMOTHY JOSEPH FACTEAU

\begin{abstract}
A DISSERTATION PRESENTED TO THE GRADUATE COUNCIL OF THE UNIVERSITY OF FLORIDA

IN PARTIAL FULFILLMENT OF THE REQUIREMEINTS FOR THE DEGREE OF DOCTOR OF PHILOSOPHY
\end{abstract}

UNIVERSITY OF FLORIDA

December, 1967 
Digitized by the Internet Archive in 2010 with funding from

University of Florida, George A. Smathers Libraries with support from Lyrasis and the Sloan Foundation 


\section{ACKNOWLEDGEMENTS}

The author wishes to express his sincere appreciation and gratitude to Dr. C. H. Hendershott, Division Chairman and Head, Department of Horticulture, University of Georgia, and chairman of the student's supervisory committee, for his valuable assistance and guidance of the research and preparation of this manuscript. He also wishes to express his gratitude to Dr. R. H. Biggs, Associate Biochemist, Department of Fruit Crops, and co-chairman of the student's supervisory committee, for his assistance during the research and preparation of this manuscript. Appreciation is extended to $\mathrm{Dr}$. A. H. Krezdorn, Chairman, Department of Fruit Crops; Dr. J. F. Gerber, Associate Professor, Department of Fruit Crops; and Dr. T. E. Humphreys, Associate Biochemist, Department of Botany for their constructive criticism and assistance in the presentation of this manuscript.

The author also wishes to express his deepest gratitude to his wife, Alice, for her help and thoughtfulness during the course of this study and the preparation of this manuscript. 
TABLE OF CONTENTS

ACKNOWLEDGEMENTS $\ldots \ldots \ldots \ldots \ldots \ldots \ldots \ldots \ldots \ldots \ldots \ldots \ldots \ldots \ldots \ldots \ldots \ldots$

LIST OF TABLES $\ldots \ldots \ldots \ldots \ldots \ldots \ldots \ldots \ldots \ldots \ldots \ldots \ldots \ldots \ldots \ldots \ldots \ldots \ldots \ldots$

LIST OF FIGURES $\ldots \ldots \ldots \ldots \ldots \ldots \ldots \ldots \ldots \ldots \ldots \ldots \ldots \ldots \ldots \ldots \ldots \ldots$

INTRODUCTION $\ldots \ldots \ldots \ldots \ldots \ldots \ldots \ldots \ldots \ldots \ldots \ldots \ldots \ldots \ldots \ldots$

LITERATURE REVIEW $\ldots \ldots \ldots \ldots \ldots \ldots \ldots \ldots \ldots \ldots \ldots \ldots \ldots \ldots$

MATERIALS AND METHODS $\ldots \ldots \ldots \ldots \ldots \ldots \ldots \ldots \ldots \ldots \ldots \ldots \ldots \ldots$

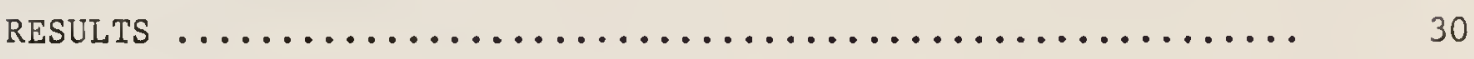

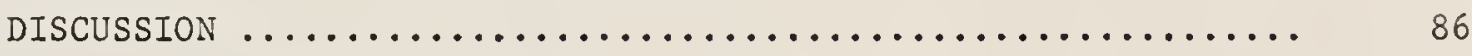

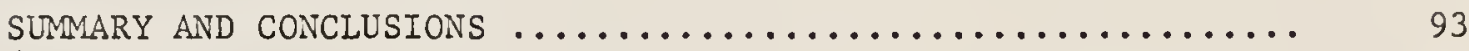

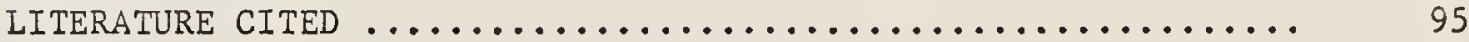




\section{LIST OF TABLES}

1. Effect of the time of exposure to IOAC on the rate of abscission of 'Pineapple' orange explants.............

2. Effect of various chemicals on the rate of abscission

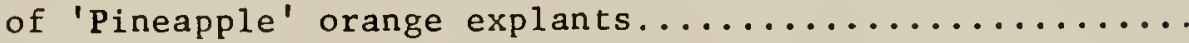

3. Ethanol extractable radioactivity in 'Pineapple' orange leaf disks treated in $2 \mathrm{ml}$ of $5 \times 10^{-4} \mathrm{M}$ IOAC-1-14 C for

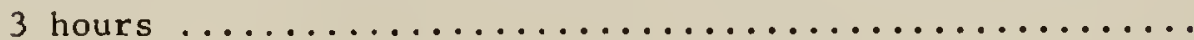

4. Ethanol extractable radioactivity in extracts of 'Valencia' orange leaf disks treated in $2 \mathrm{ml}$ of

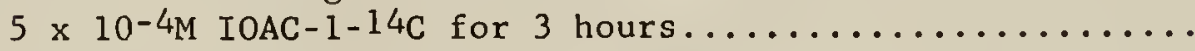

5. Radioactivity remaining after ethanol extraction in 'Pineapple' orange leaf disks after treatment in $2 \mathrm{ml}$

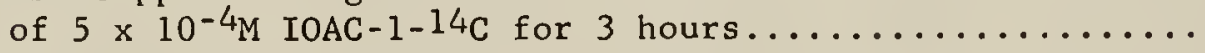

6. Radioactivity remaining after ethanol extraction in 'Valencia' orange leaf disks after treatment in $2 \mathrm{ml}$

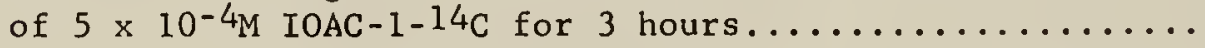

7. Distribution of radioactivity in fractions from water extracts of 'Pineapple' orange leaves treated with

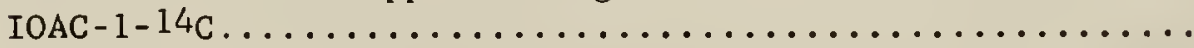

8. Distribution of radioactivity in fractions from water extracts of 'Valencia' orange leaves treated with

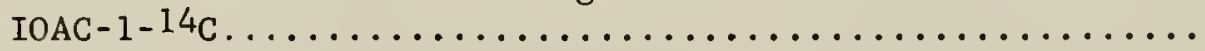

9. Distribution of radioactivity in fractions of a water extract of 'Pineapple' orange leaves treated with IOAC $-1-14 \mathrm{C}$

10. $R_{f}$ values from paper chromatograms of ${ }^{14} \mathrm{C}$-metabolites formed by 'Pineapple' and 'Valencia' orange leaves treated with either IOAC $-1-14 \mathrm{C}$ or IOAC $-2-1{ }^{4} \mathrm{C} \ldots \ldots \ldots \ldots . .$.

11. Distribution of radioactivity in fractions from water extracts of 'Pineapple' orange leaves treated with either IOAC $-2-14 \mathrm{C}$ or acetate $-1-1{ }^{4} \mathrm{C} \ldots \ldots \ldots \ldots \ldots \ldots \ldots$

12. $R_{f}$ values from paper chromatograms of labeled metabolites formed by 'Pineapple' orange leaves treated with IOAC $-1-14 \mathrm{C}$. 
13. Distribution of radioactivity in ethanolic ammonium and water fractions collected from a Dowex 50-X8

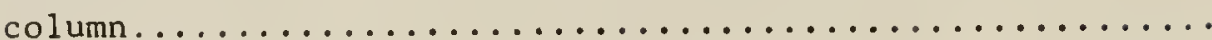

14. Rf values from paper chromatograms (developed in butanol solvent) of metabolites formed by 'plneapple' and 'Valencia' orange leaves treated with either IOAC $-1-1{ }^{4} \mathrm{C}$ or IOAC $-2-14 \mathrm{C} \ldots \ldots \ldots \ldots \ldots \ldots \ldots \ldots \ldots \ldots \ldots \ldots \ldots \ldots . \ldots \ldots$

15. Rf values from paper chromatograms (developed in methanol solvent) of metabolites formed by

'Pineapple' and 'Valencia' orange leaves treated with either IOAC $-1-14 \mathrm{C}$ or IOAC $-2-14 \mathrm{C} \ldots \ldots \ldots \ldots \ldots \ldots$

16. Rf values from paper chromatograms (developed in phenol solvent) of metabolites formed by 'Pineapple' and 'Valencia' orange leaves treated with either

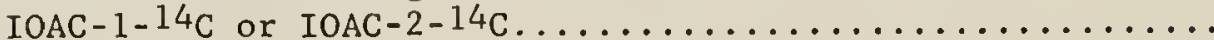

17. Rf values from paper chromatograms (developed in butanol solvent) of metabolites formed by 'Pineapple' orange leaves treated with either IOAC-1-14C or

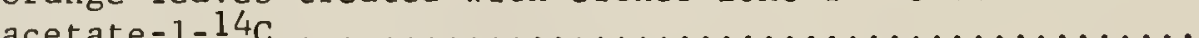

18. $R_{f}$ values from paper chromatograms (developed in methanol solvent) of metabolites formed by 'Pineapple' orange leaves treated with either

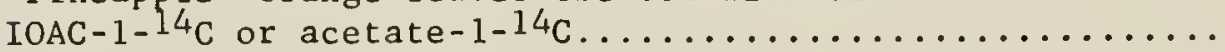

19. $R_{f}$ values from paper chromatograms (developed in phenol solvent) of metabolites formed by 'Pineapple' orange leaves treated with either IOAC-1-14 C or

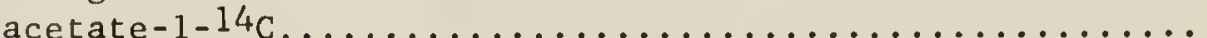

20. $R_{f}$ values from paper chromatograms of metabolites formed by 'Pineapple' orange leaves treated with either

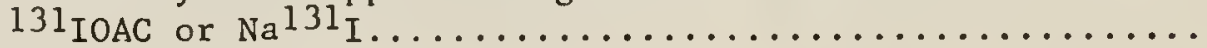

21. Distribution of radioactivity in fractions from 'Pineapple' orange leaves treated with sodium $131_{\text {iodide }}$ and eluted from a Dowex $50-X 8$ column.......... 


\section{LIST OF FIGURES}

1. Effect of the time of exposure to IOAC on the rate of abscission of 'Pineapple' orange explants............

2. Effect of various chemicals on the rate of abscission

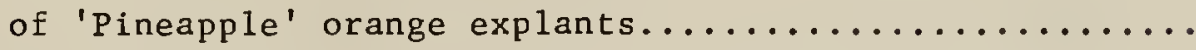

3. ${ }^{14} \mathrm{CO}_{2}$ production from attached 'Pineapple' orange

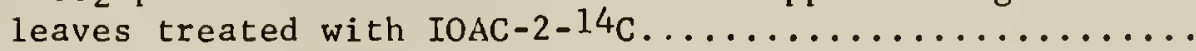

4. ${ }^{14} \mathrm{CO}_{2}$ production from detached 'Pineapple' orange leaves treated with IOAC-1-14C or IOAC-2-14C.........

5. Autoradiogram of thin-layer separated ether-acidicpartitioned-fraction of 'Pineapple' orange leaves

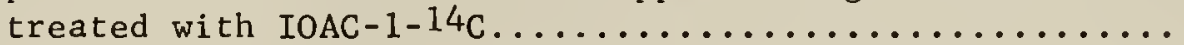

6. Autoradiograms of paper chromatographic separation of ${ }^{14} \mathrm{C}$-metabolites fram 'Pineapp $1 \mathrm{e}^{\prime}$ and 'Valencia' orange leaves treated with IOAC-1-14C..............

7. Autoradiogram of electrophoretic separation of ${ }^{14} \mathrm{C}$-metabolites from 'Pineapple' orange leaves treated with IOAC $-1-14 \mathrm{C} \ldots \ldots \ldots \ldots \ldots \ldots \ldots \ldots$

8. Autoradiogram of ${ }^{14} \mathrm{C}$-metabolites from 'Pineapple' and 'Valencia' orange leaves treated with IOAC-1-14 C....

9. Electrophoretic separation of $14 \mathrm{C}$-metabolites resulting from drop application of IOAC-1-14C to 'Pineapple' orange leaves....................

10. Electrophoretic separation of $14 \mathrm{C}$-metabolites resulting from drop application of IOAC-1-14C to 'Valencia' orange leaves.....................

11. Electrophoretic separation of $14 \mathrm{C}$-metabolites resulting from drop application of IOAC-2-14C to 'Pineapple' orange leaves.....................

12. Electrophoretic pattern of $5 \times 10^{-4} \mathrm{M}$ IOAC $-1-14 \mathrm{C} \ldots \ldots \ldots$

13. Electrophoretic separation of ${ }^{14} \mathrm{C}$-metabolites resulting from drop application of IOAC-1-14C to 'Pineapple' orange leaves..................... 
14. Autoradiogram of polyamide thin-layer sheet separation of ${ }^{14} \mathrm{C}$-metabolites formed by 'Pineapple' orange leaves

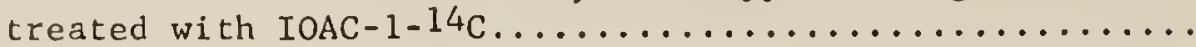

15. ${ }^{14} \mathrm{C}$-metabolites from 'Valencia' orange leaves treated with IOAC $-2-14 \mathrm{G} \ldots \ldots \ldots \ldots \ldots \ldots \ldots \ldots \ldots \ldots . \ldots \ldots$

16. ${ }^{14} \mathrm{C}$-metabolites from 'Pineapple' orange leaves treated with IOAC $-2-14 \mathrm{C} \ldots \ldots \ldots \ldots \ldots \ldots \ldots \ldots \ldots . . \ldots \ldots$

17. ${ }^{14} \mathrm{C}$-metabolites from 'Pineapple' orange leaves treated with either IOAC-1-14C or acetate-1-14C............

18. ${ }^{14} \mathrm{C}$-metabolites from 'Pineapple' orange leaves treated with IOAC $-1-14 \mathrm{C} \ldots \ldots \ldots \ldots \ldots \ldots \ldots \ldots \ldots \ldots . . . \ldots \ldots$

19. ${ }^{14} \mathrm{C}$-metabolites from 'Pineapple' orange leaves treated with either IOAC $-1-14 \mathrm{C}$ or acetate $-1-14 \mathrm{C} \ldots \ldots \ldots \ldots \ldots$

20. ${ }^{14} \mathrm{C}$-metabolites from 'Pineapple' orange leaves treated

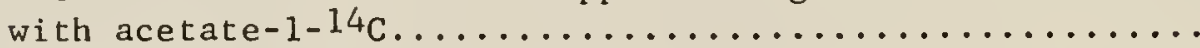

21. ${ }^{14} \mathrm{C}$-metabolites of a combined sample of IOAC-1-14C and acetate-1-14C each applied by petiole uptake to 'Pineapple'

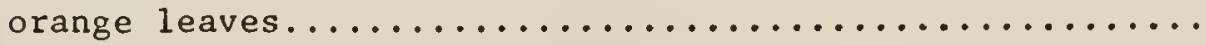




\section{INTRODUC TION}

Increase in citrus production, complicated by a decrease in available manpower, has resulted in an attempt to develop a mechanical means of harvesting citrus fruits. The citrus fruit, however, is not readily adaptable to mechanical harvesting. A major difficulty is the bonding force between the stem and the fruit which is quite strong, especially during the early part of the harvesting season. Thus, investigations into the physiology of abscission were initiated in an attempt to determine ways to accelerate the abscission processes in Citrus sinensis cv. Pineapple and Valencia.

It has been shown that field applications of iodoacetic acid (IOAC) to whole trees resulted in a loosening of the fruit $(76,77)$. The IOAC was effective only on early and mid-season varieties ('Hamlin', 'Parson Brown', and 'Pineapple') and not on the late season variety ('Valencia') $(76,77)$. However, both 'Pineapple' and 'Valencia' oranges could be induced to abscise by IOAC if the compound was absorbed directly through the stem (168). An investigation of absorption of IOAC by 'Pineapple' and 'Valencia' orange leaves showed that there was no difference between these varieties in the amount or rate of uptake (152). Thus, it would seem that the failure of the 2 varieties to respond in a similar manner was associated with a difference in metabolism of the compound. The purpose of the work reported here was to follow the metabolism of IOAC by 'Pineapple' and 'Valencia' orange leaves in an effort to determine why the 2 varieties varied in their 
susceptibilities to IOAC. It was also hoped that the study would offer some clue as to how IOAC acts as a promoter of orange abscission. Another phase of the study involved the use of an explant test to screen various chemicals for thelr effects on rates of abscission. These chemicals were used because they might offer some ideas as to the mechanism of abscission.

There are 3 possibilities as to how IOAC could act as an abscission agent. First, IOAC could act as an enzyme inhibitor since it has been reported as a sulfhydryl enzyme inhibitor in many systems (88). Second, some metabolite of IOAC, if it were metabolized, could be the active agent. Finally, the iodine molecule could be the effective part since it has been shown to be a promotor of abscission (78). This last possibility would depend on whether or not the I-C bond in IOAC was broken during metabolism. 


\section{LITERATURE REVIEW}

\section{Introduction}

The process of abscission controls the active shedding of plant organs. In describing abscission, Esau (53) wrote that the periodic defoliation of perennial plants is a complex phenomenon which involves the development of features bringing about the separation. This occurs without injury to the living tissues and gives protection to the newly exposed surface from desiccation and invasion by microorganisms.

The morphological and biochemical changes occurring during abscission are very complex and not completely understood. Also, many variations in the abscission processes occur among the various plant species. Some plants form abscission layers, others do not. However, most plants usually have a distinct zone of specialized cells where separation occurs $(53,54,80)$.

\section{Morphology}

The abscission zone is generally located at the base of the subtended organ such as a fruit, leaf, or flower. The cells within this zone are usually quite different from the cells in the surrounding areas. They are usually smaller, denser, and more compact. Intercellular spaces are absent and there is a conspicuous lack of lignin $(3,53)$. The cells usually contain little or no suberin (3) and may or may not be high in starch $(24,27,42,80,99,109,168)$.

Two layers may be descernible in the abscission zone: a separation layer, in which structural changes facilitate separation, and a protective layer, usually believed to protect the plant from desiccation and 
pathogenic invasion (53). Not all plants form a separation layer prior to abscission $(27,61)$. An abscission layer was not formed in certain plants (poinsettia, cotton, pepper) when abscission was accelerated by ethylene, even though these plants did form a layer prior to abscission if allowed to develop normally (61). Likewise, in normal abscission of bean leaves, cell division occurred and an abscission layer was formed; when abscission was accelerated by ethylene, no cell division took place and no separation layer was formed (27).

The actual separation process usually requires 2 processes, 1 mechanical and the other biochemical. The actual separation may take any one of 3 forms: dissolution of the middle lamella, dissolution of the middle lamella and part of the primary wall, or dissolution of entire cells (4).

\section{Environmental Factors}

Abscission of plant parts appears to be largely a matter of biochemical processes. The processes can be modified, and in some cases initiated, by environmental factors.

\section{Temperature}

Abscission processes appear to be temperature dependent since both high and low temperatures can induce abscission (3). Very high day or night temperatures have been reported to be detrimental to fruit set of tomatoes, even with applications of 2-napthoxyacetic acid to inhibit abscission. It was suggested that the lack of set and subsequent drop were due to a lack of photosynthates (127). High temperatures also hastened development of the abscission zones of 'Starking', 'Golden Delicious', and 'Jonared' apple varieties (146). Low temperatures have been shown to retard the rates of abscission of bean explants (136). The response to temperature is thought to be biochemical in nature 
since it was shown with the bean explant test that the maximum rate of abscission occurs at temperatures between $25^{\circ}$ and $30^{\circ} \mathrm{C}$ (174).

Water

Water strees has been shown by many investigators to affect the abscission processes $(44,81,113,146,165)$. Early season shedding of 'Washington' navel oranges was reported to be caused by daily water deficits in young developing fruits (44). However, too much water can also lead to abscission, since cotton boll shedding was reported excessive if the root zone became flooded (51).

\section{Light}

Light intensity, duration, and quality have been shown to effect abscission and some investigators (71) are of the opinion that abscission is not entirely an auxin-mediated response. With light-grown seedlings, chemical treatments had a more pronounced effect upon abscission than did dark-grown seedlings. Light quality was shown to have just as significant an affect upon abscission as it did with dark-grown seedlings. It was suggested that high light intensity reduced abscission probably because of rapid dehydration and enzyme inactivation (71). Other workers (15) showed that light had an inhibitory effect on the rate of abscission of young bean explants. However, the effect diminished as the plants aged.

\section{Internal Factors}

\section{Effects ui Auxins on Abscission}

The role of auxin in abscission of leaves had been recognized ever since Laibach (94) found that auxin-rich orchid pollinia would both accelerate and retard the abscission of debladed petioles. LaRue (97) and Portheim (130) were also instrumental in establishing that auxins applied to leaf petioles delayed abscission. Since then, there have 
been many reports on the action of auxin in relation to the abscission proceas $(1,3,4,13,15,16,102,136,155)$.

One of the early theories on the action of auxin was the "auxingradient" theory (144). Work with beans established the facta that levels of leaf auxin were higher than levels of stalk auxin and this "gradient" decreased with age. From these facts, the idea arose that an auxin gradient controlled abscission. The theory received criticism from various workers $(16,60,119,150,153)$ who found that auxin applicationseither distal or proximal to the abscission zone were effective in delaying abscission.

The concentration applied to plants has been shown to influence abscission. High concentrations of auxin applied to coleus and bean explants have been shown to inhibit and low concentrations to accelerate abscission. Whether the applications were proximal or distal to the abscission zone made no difference.(60). These results were confirmed $(13,16)$ and the two-phase theory of the action of auxin on abscission was proposed.

Further work revealed the existence of a time factor (41, 102, 136, 138, 141). Auxin applied, in any concentration, within 6 hours after deblading delayed abscission. After this, all concentrations of auxin accelerated abscission proportionally to the concentration applied. The initial period (delayed by auxin) was called Stage $I$, and the second (accelerated by auxin) was called Stage II.

Effects of Auxins on Pectin Substances

Since abscission involves dissolution of pectin compounds and/or cell walls, investigations have been made of the effects of auxins on these materials. The pectic substances are primarily polymers of galacturonic acid and act as cellular cementing agents. They are the 
basic components of the middle lamella (53). The carboxyl groups present are bonded through calcium and magnesium ions to other chains, thus binding one cell to another. Methylation of the carboxyl groups probably reduces the bonding strength of the pectic substances (23, 56 , $122,154)$.

The literature regarding pectin enzymes is confusing. There are a number of enzymes involved with pectic compounds; i.e., pectinase which hydrolyzes pectic acid, but not methylated pectic acid (175); polygalacturonidase which hydrolyzes pectin chains (175); and pectin methylesterase (PME) that de-esterifies carboxyl groups (102).

It has been noted that soluble pectins increased as apple fruits ripened and this was attributed to the action of PME and/or polygalacturonidase (102). Both enzymes have been found in the abscission zones of debladed bean petioles and it was suggested that PME was necessary for free carboxyl groups so that polygalacturonidase could split the long pectin chains (133). High PME activity has been reported (171173) in the abscission regions of tobacco pedicles. From tests with indoleacetic acid (IAA) and methionine (methyl donor), it was concluded that abscission was prevented by high PME activity and increased by low PME activity. In agreement with this, highest PME activities have been found to occur in the abscission zones of non-abscissing leaves (95). Thus, PME activity may be associated with leaf age since high PME activity has been reported to occur in young bean abscission zones and to decrease with age. When abscission was stimulated by ethylene, a decrease in PME activity occurred. Moreover, treatment with 2,4-dichlorophenoxyacetic acid (2,4-D) inhibited abscission and the PME activity remained high. It was suggested that the de-esterification of methyl groups caused by the high PME activity in the presence of 2, 4-D would 
serve to make sites available for calcium binding, thereby strengthening the cell walls and inhibiting abscission (126).

The addition of IAA has resulted in an accelerated rate of methyl esterification of pectic substances in cell walls of Avena coleoptles, but has not resulted in a net change in the final degree of pectic esterification (89). Also, IAA increased PME activity in tobacco pith cells and these results were used to explain the increase in growth. The suggestion was that removal of methyl groups by PME allowed a polygalacturonase to further break down pectin, thus producing elasticity and, thereby, an increase in cell enlargement (29). Furthermore, IAA may promote the bonding of PME to the cell wall, thus tending to immobilize the enzyme and favor the methylation of pectates (or prevent de-esterification), which would decrease the amount of calcium bridging, thereby, causing softening of cell walls (65). Auxin applications have been reported (124) to increase the incorporation of the methyl group from methionine into pectins of Avena coleoptile cell walls, thus softening them. Moreover, anti-auxins have been found to inhibit the IAA effect of loosening cell walls (43). Effects of Ethylene on Abscission

The ability of ethylene to accelerate abscission has long been recognized $(1,3,13,27,32,61,67,68,72,108,116,137,139,147)$. However, other unsaturated hydrocarbons can produce the same effects as ethylene, but are generally required in higher concentrations ( 3 ). Whether ethylene, per se, is the cause of naturally occurring abscission processes is not known. It may be a by-product of catabolism and does not initiate the abscission process, but may simply speed it. If the biosynthesis of ethylene were known, the problem would be simpler. For instance, if pectin substances are sources of precursors to ethylene 
production as suggested (67), then ethylene would probably be a byproduct of pectin breakdown.

Effect of Chemical Treatments on Ethylene Production

The discovery that leaves produced ethylene, that this production increased as abscission advanced, and that exogenous IAA could inhibit this increase, led to the auxin-ethylene balance hypothesis of foliar abscission as proposed by Hall $(67,68)$. It was shown that arabinose, ethanol, pectin, pectic acid, pyruvic acid, fructose, and galactose yielded ethylene (67).

However, 2,4-D and IAA have also been reported to stimulate the release of ethylene by cotton plants (117, 118) and from bean explants $(1,137)$. Yet these compounds, under certain circumstances, retard abscission. Addicott (3) also concluded that ethylene probably functions in abscission through its effects on auxin.

Many compounds are known to influence abscission, auxin being an endogenous regulator. Besides auxin, treatment of bean explants with endothol, potassium iodide, and some amino acids result in increased rates of abscission plus an increase in ethylene production $(1,137)$. In fact, all chemical agents that stimulated abscission only did so if applied during Stage II. Ethylene, the most potent chemical, had no effect except during Stage II (137). Conditions in which ethylene would not build up were used and decreased rates of abscission were found. These facts led to the conclusion that ethylene was involved in the abscission process (137).

\section{Possible Mechanisms of Ethylene Biosynthesis}

One of the more basic problems involved with ethylene is the mechanism of its synthesis in living plants. Ethylene can be found in most plant parts, especially ripening fruits $(31,33,34,104,105,110,114)$. It 
has been shown to be increased by additions of auxin $(1,3,67,70)$, abscission agents $(1,137)$ and to be formed from many substrates present in plants, including pectin compounds $(67,70)$.

The search for the pathway of ethylene production has led to the separation of various sub-cellular systems. This search was instigated because it was observed that intact tissues respond to treatment with solutions of varying tonicity as though the ethylene-producing system was located in a particle having a semi-permeable membrane. Cytoplasmic particles that would evolve ethylene in the presence of thiomalic and thioglycolic acids have been isolated. The system had many characteristics of an enzyme system in that ethylene production was proportional to the concentration of particles, the reaction was stopped by heat, and increased by phosphorous. Ethylenediaminetetraacetic acid (EDTA) inhibited the reaction and this inhibition was partly reversed by adding copper (104).

Attempts to repeat this work have led to the conclusion that the substances emanating from the cytoplasmic particles was not ethylene and, hence, ethylene production by a sub-cellular system had not yet been found. The gas that was found reacted similarly to that previously isolated, but it did not co-chromatograph with ethylene. Neither bromine nor mercuric perchlorate solutions removed the substance from air, whereas, these reagents were found consistently to eliminate comparable quantities of ethylene from synthetic air-ethylene mixtures. The gas chromatographed between ethane and ethylene and might have been a 2 carbon compound (31).

Still other workers concluded that the gas in question was ethane (105). This ethane-producing particulate system required the presence of an unsaturated fatty acid. Saturated fatty acids gave little to no 
production of ethylene, while linoleate and linolenate resulted in a marked production of ethylene. It was not clear whether these acids were acting as co-substrates or co-factors. Under normal conditions apples usually produce more ethylene than ethane, and if apple tissue was homogenized and incubated in buffer, the 2 were produced in equal amounts. Under these same conditions, ethane was produced from thiomalic acid. From these relations it was suggested that a possible relationship existed between ethylene and ethane biosynthesis and that present information suggests either one may be a precursor of the other, or they are derived from a common source (105).

Mitochondria may be involved in the synthesis of ethylene since 2,4-D treated cotton plants responded by an increase in both $\mathrm{CO}_{2}$ and ethylene production, al1 of which occurred in the mitochondria (117). Buhler et al. (30) subjected various fruits to ethylene-14 C and found that avocados and pears incorporated $14 \mathrm{C}$ from ethylene, but oranges did not. The amount of $14 \mathrm{C}$ incorporated, in any case, was very small. The majority of the radioactivity was in the organic acid fraction, suggesting that ethylene was metabolized through the organic acid cycle.

However, mitochondria preparations from both tomato and apple fruits did not produce ethylene, indicating that ethylene production and the Krebs cycle were not connected (114). Other workers (104) also concluded that ethylene synthesis was not involved with the Krebs cycle since preparations which evolved ethylene were not mitochondria fractions and would not oxidize Krebs cycle substrates.

Apple slices have been shown to produce labeled ethylene when treated with tritium labeled water. The optimum temperature for the process was $320 \mathrm{C}$ and above this temperature ethylene production decreased rapidly. The inactivation caused by heat slowly disappeared when the 
tissues were exposed to lower temperatures. Also, ethylene synthesis ceased almost immediately under anaerobic conditions, but a precursor accumulated that could be rapidly oxidized in air to yield ethylene (33). Effects of Gibberellins on Abscission

Gibberellic acid (GA) has been noted to affect abscission. Increased abscission rates after application of GA have been obtained by numerous investigators $(1,2,13,24,39,40,79,93,119)$ and some (38) hypothesized that 3 hormones, auxin, GA, and an abscission-accelerating hormone, interact to control the process. The mechanism of a GA-auxin interaction, if present, is unknown. Treatment with GA has been shown to increase levels of endogenous auxin in plants, possibly by influencing the IAA degradation enzymes, peroxidase and IAA oxidase, either directly or through the action of an inhibitor (66). That GA directly or indirectly controls the endogenous level of auxin has also been concluded by others (128). However, based on the facts that GA promotes growth under optimal concentrations of auxin and that GA and auxin have opposite effects on cell walls, Leopold (102) suggested that GA and auxin act through distinct and separate systems.

GA has been shown to stimulate abscission in Stages I and II of bean explants (40), but it was most active in Stage I. However, GA also exerts the same two-phase concentration action as does auxin as it prevents abscission at high concentrations, but stimulates abscission at low concentrations (38). GA also has been shown to stimulate ethylene production (1).

Effects of Kinins on Abscission

The opinion exists (162) that kinins are the predominant regulators in the early part of fruit development following fruit set. It has been suggested (101, 102) that kinins influence cell division and synthesis of protein, deoxyribonucleic acid (DNA) and ribonucleic acid (RNA). 
Furthermore, kinins can influence the abscission process $(40,128)$. Some investigators (40) found that kinetins exerted the same two-phase action as did auxin and delayed abscission in Stage $I$. However, after Stage II was reached, it too stimulated abscission. Others (128) have shown that applications of kinetin to the abscission zone inhibit abscission, but either proximal or distal applications accelerate abscission. Applications of kinetin to the abscission zone caused cellular activity and movement of metabolites into that region, thus preventing senescence and abscission. Other investigators (143) have confirmed that mobilization of metabolites into the abscission zone could defer senescence. Increases in dry weight, chlorophyl1 content, protein, DNA, and free and total phosphates were found proximal to the abscission zone in bean explants and whole leaves when kinetin was applied proximal to the abscission zone (143). Effect of Endogenous Abscission Regulators on Abscission

It has been noted (125) that as bean leaves became senescent and approached abscission, the diffusate into agar blocks from these leaves was progressively more effective in accelerating abscission. Subsequent work by various investigators $(13,14,69,87,108,163)$ revealed the presence of other abscission regulators in other plants. In 1961, Liu and Carns (107) crystallized an abscission accelerating material from the cotton burr which they named "abscisin". This regulator was readily translocated and inhibited the retardation of abscission induced by IAA. Others (5) have extracted 2 different regulators from cotton; 1 from young bolls (abscisin II) and 1 from older bolls (abscisin I). Further work with abscisin II revealed that this regulator accelerated petiole abscission of beans, citrus, and coleus, as well as cotton (6). It also accelerated senescence (yellowing) in detached radish leaves. 
Furthermore, the regulator also counteracted the effects of IAA in the Avena curvature and straight-growth test, and GA in the dwarf maize, dwarf pea, and barley endosperm bioassays.

Effects of Carbohydrates and the $\mathrm{C}-\mathrm{N}$ Balance in Relation to Abscission

It has long been thought that a low content of carbohydrates leads to leaf, flower bud, and fruit abscission (4). Various investigators have reported that the addition of sucrose $(13,15,27,96,108)$ or high tissue levels of carbohydrates resulted in delays in abscission $(41,49,74,108)$.

In contrast to these findings, Eaton and Ergle (52) concluded that the nutritional theory of boll shedding of cotton was not valid with regards to carbohydrate and nitrogen relations. Within varieties and environments, the number of bolls/100 $\mathrm{g}$ fresh stems and leaves remained constant even though nutritional factors caused marked differences in plant growth.

Effects of Anino Acids on Abscission

Methionine and certain other methyl group donors have been shown to be effective in accelerating abscission of tobacco flowers and petioles of cotton and coleus $(112,161,172,173)$. The use of ${ }^{14} \mathrm{C}$ labeled methionine and phenylalanine indicated (161) that methionine and phenylalanine might promote abscission by serving as sources of methyl or other groups which could be incorporated into the cell wall and middle lamella in the separation zone. The D forms of alanine, aspartic acid, glutamic acid, and serine were found to be effective as promotors of abscission (161). Also, both the D and $\mathrm{L}$ forms of leucine, metrionire and phenylalanine had some activity (161). However, other work has shown that the most efficient methyl donating compounds were, in general, far less effective in accelerating abscission than were some other compounds $(140)$. 
Alanine has been reported to increase abscission (41, 136, 137, 140) and alanine and some other amino acids can result in increased ethylene production in the bean explant test (137). It has also been suggested that as a leaf ages, the decline in auxin along with a concomitant rise in amino acid concentrations could promote abscission (41). Since kinetin increases the synthesis of DNA, RNA, and protein, and since it will inhibit abscission when placed on the abscission zone of bean explants (128), it would seem that amino acids could conceivably play a part in the abscission process. Amino acid extracts from various aged leaves do suggest a relationship with the abscission process as extracts trom older leaves accelerated the rate of abscission (140).

\section{Biochemistry of Abscission}

Deficiencies of oxygen $(39,108)$, carbohydrates $(13,15)$, water $(69)$, and growth regulators $(3,139)$ can promote the initiation of the processes leading to separation. The exact nature of the functioning of any one of the factors in unknown. Furthermore, the processes leading to senescence may in some way be connected to the processes of abscission. Generally, in the literature, the 2 terms are difficult to separate. Abscission of plant parts can occur from relatively young plants. However, this does not mean that the part abscissed was, in turn, physiologically young. The results of experiments utilizing kinins, suggest that senescence and abscission are interrelated. Kinetin causes a mobilization of organic compounds and an increase in protein, DNA, and RNA synthesis. Abscission is generally associated with a loss of carbohydrates and a mobilization away from the abscission region. Also, as leaves approach senescence, the inhibitory effects of auxin are lost.

The physical changes occurring in senescent (or abscissing) leaves are very evident, i.e., chlorophyll and water loss, and anthocyanin 
appearance. The chemical changes include exit of nitrogen, potassium, phosphorous, iron, and magnesium, changes in form or disappearance of carbohydrates, and a decrease in the auxin level (3). Just exactly why these changes occur is unknown, but many theories have been advanced, among which are the accumulation of some inhibitor or deleterious substance, the accumulation and deposition of calcium, and permeability changes in membranes (164). Changes in Glucose Metabolism as Tissues Age

There is evidence which indicates that as plants grow older, a shift in their various metabolic pathways may occur. Differences in sensitivities to metabolic inhibitors have been found between young and old plants, which would imply at least a difference in basic metabolism (111). Also, in young tissues and in undifferentiated tissues, the glycolytic pathway was of major importance. However, as the tissues aged the pentose shunt was favored (12). Changes of sufficient magnitudes in certain enzymes have been reported to provide a convincing explanation for the change in pathways as tissues age (64). Moreover, the presence of the pentose shunt in fruits of peppers (50), tomatoes, cucumbers, limes, and oranges has been demonstrated, but the authors did not study changes with age (7).

Thus, workers have provided evidence that a shift in the method of glucose degradation occurs as plants age. In contrast, there are indications that shift from the pentose shunt to the glycolytic pathway occurs in ripening banana fruits (151).

Possible Relationships of the Pentose Shunt and the Abscission Processes

Glucose catabolism appears to shift from the glycolytic pathway to the pentose shunt as tissues age $(12,111)$. Since leaf senescence and abscission are closely related, with abscission possibly being the 
terminal process, the pentose shunt may be associated with these processes. Auxins $(82,83,141)$, as well as IOAC (8-10, 55, 90), influence the pathway of glucose catabolism; moreover, both are involved with abscission $(3,4,37,73,76,77,98,102,136,167-169)$.

It has been suggested that IOAC-induced abscission of orange fruits might involve a shift to the pentose shunt (168). IOAC blocks glycolysis at the triosphosphate dehydrogenase (TPD) step (11, 23, 35, $55,63,90)$ and it would seem likely that an inhibition at this point could cause increased activity of the pentose shunt. This has been shown to be the case in chlorella (90) and in apple slices (55), but not the case for strawberry leaves $(8-10)$.

Auxins, especially 2,4-D have been found to influence the pathway of glucose catabolism. An increase in the pentose shunt with 2,4-D treatment has been reported; but IAA had no effect $(82,83)$. Others (142) found that IAA or kinetin reduced the activity of gluconate-6phosphate dehydrogenase and transketolase to only $1 / 3$ to $1 / 4$ that of the controls. The activities of enolase, malate dehydrogenase, and isocitrate dehydrogenase were not affected by the presence of IAA or kinetin. So, with increasing growth rate (tumor tissue), there was a decrease in the activities of the pentose shunt. However, it has also been reported that additions of auxin resulted in an increase in glucose6-phosphate dehydrogenase activity (91).

\section{Effects of IOAC on Abscission}

Iodoacetic acid has been shown to accelerate abscission in oranges (76, 77, 168, 169), olives (73), bean plants (167), and cotton explants (37). Weintraub et al. (167) surveyed over 500 compounds on bean plants to see if they would accelerate abscission. Triodobenzoic acid was used as a standard. The activity of related compounds was influenced 
by the halogen, I>Br>Cl (in order of the most to the least effective inducing abscission) and by specific position occupied ( $3>2$ or 5 ). Iodoacetic acid was also found to cause abscission but to a lesser extent than triiodobenzoic acid.

Effects of IOAC on Biochemical Systems

Iodoacetic acid is known as an inhibitor of certain enzymes, particularly sulfhydral (SH) enzymes (23, 88, 100, 103, 115, 156, 157). In some cases, the primary enzyme affected was TPD (88), but others (35) found that IOAC would inhibit $\mathrm{CO}_{2}$ fixation but did not inhibit TPD. In contrast, it was reported that IOAC inhibited both $\mathrm{CO}_{2}$ fixation and TPD activity in chlorella (90). Under conditions of darkness, increased levels of fructose 1,6-diphosphate (FDP), dihydroacetone phosphate (DAP), and glyceraldehyde phosphate (GAP) resulted. However, when the chlorella were treated with IOAC in the light, the effects of IOAC disappeared. It was suggested that in darkness, IOAC inhibited TPD while FDP, DAP, and GAP accumulated. In the light, FDP was converted to ribulose 1,5diphosphate (RUDP) with the help of cyclic phosphorylation and by carboxylation to the $\beta$ keto acid in the pentose shunt. IOAC, therefore, induced a new pathway of hexose degradation via RUDP (90). IOAC also has been shown to promote an increase in anthocyanin in 'McIntosh' apples. It was postulated that IOAC decreased glycolysis and increased glucose metabolism via the pentose shunt, thereby increasing the shikimic acid concentration and leading to the production of more anthocyanins.

However, it was shown that IOAC stimulates glycolysis to a much. greater extent than it stimulates the pentose shunt. Strawberry leaves, when treated with IOAC, responded by large increases in $\mathrm{CO}_{2}$ production which was not completely accounted for by losses of sugars and starches. This increase in $\mathrm{CO}_{2}$ production, however, was associated with a rise in the concentrations of pyruvate and oxaloacetate $(9,10)$. 
Further studies of the $\mathrm{C}_{6} / \mathrm{C}_{1}$ ratio in strawberry leaves treated with IOAC indicated that increased glycolysis accounted for the major part of the stimulation of $\mathrm{CO}_{2}$ output. Glucose-6-phosphate (G6P), fructose-6-phosphate (F6P), and FDP increased greatly. The incrcases in G6P and F6P, caused by iodoacetate, were attributed to increased cell wall permeability such that there was an increase in the accessibility of enzymes to substrates. It was suggested (10) that some of the increased $\mathrm{CO} 2$ production was partly caused by uncoupling of oxidative phosphorylation since Contreiras (47) postulated that IOAC acted as an uncoupler of high-energy phosphate bonds.

Iodoacetamide, 2,4-dinitrophenol (DNP), fluoride, arsenite, sodium bisulfite, and fluoroacetate all were shown to inhibit ethylene production and respiration in apple tissues (34). The inhibitions caused by DNP were partially reversed by adenosine triphosphate (ATP). The evidence suggested that at least 1 step in the synthesis of ethylene required energy which was supplied by respiration. Another step might involve a sulfhydryl enzyme since high-energy compounds failed to reverse the inhibitory effects of iodoacetamide.

Whether IOAC, as do other abscissing agents including potassium iodide (137), causes an increase in ethylene production which initiates abscission; or whether IOAC inhibits ethylene production and, therefore, abscission accelerated by ethylene, remains to be investigated. Also, IOAC might act as a SH inhibitor. Michaeles and Schubert (115) postulated that the reaction $\mathrm{R}-\mathrm{SH}+\mathrm{ICH}_{2} \mathrm{COOH} \rightarrow \mathrm{R} \mathrm{S}-\mathrm{CH}_{2} \mathrm{COOH}-\mathrm{HI}$ was the mechanism by which IOAC affects SH enzymes. However, Wilson (168) tried unsuccessfully to histologically determine the effects of IOAC on SH enzymes in the orange fruit abscission zone. 
Sweet orange leaves are able to decarboxylate IOAC-1-14 C. It was not ascertained: a) whether the IOAC acted before the carboxyl group was split off; b) whether the iodine, per se, induced abscission; c) or whether the methyl carbon alone as the ICH3 moiety was the effective part (152).

Effects of Potassium Iodide on Abscission

Potassium iodide has been shown to be capable of accelerating abscission of bean leaves. Moreover, applications of IAA inhibited the effects of the iodide ion. It was also shown that iodine also would accelerate bean leaf abscission. Defoliation of immature cotton required 1000 times as much iodide ion as did beans, indicating that the concentration required to accelerate abscission varies with species (78). The effectiveness of other halogen ions with respect to accelerating abscission has been tested. It was shown that iodine was more effective in accelerating abscission of bean leaves (167) and orange fruit (76, 168) than was bromine, chlorine, or fluorine. Potassium iodide also is active on deciduous plants (98).

Whether the iodine in potassium iodide functions, in abscission in a similar manner as does the iodine of IOAC is not known. Rubinstein and Abeles (137) showed that potassium iodide accelerated the abscission of bean explants, but an increase in ethylene production occurred before tissue separation. This led to the conclusion that potassium iodide and other abscission promoters acted through their effects on ethylene production. The effects of IOAC on ethylene production are not known, but iodoacetamide has been shown to inhibit ethylene production in apple slices (34).

Effects of Oxidation-Reduction Agents in Relation to Abscission

Growth promotion of stem tissues of cucumbers, induced by auxin, 
has been associated with an increase in ascorbic acid and a more reduced state; whereas growth inhibition of leaf tissue has been associated with a decrease in ascorbic acid and a more oxidized system (91). The auxin treatments resulted in an increase in glucose-6-phosphate dehydrogenase activity and also an increase in nicotinamide adenine dinucleotide phosphate (NADP) production. It was suggested that the NADPH2 produced could lead to a more reduced state of the glutathione and ascorbic acid systems. Several workers $(112,145,159)$ believe that these 2 systems are important factors in growth.

In contrast, however, no significant connection was found (106) between the effects of auxin and the ascorbic acid-dehydroascorbic acid. These same investigators found no increase or decrease in ascorbic acid or dehydroascorbic acid with additions of auxin. Therefore, the dehydroascorbic acid was not the factor that resulted in the reduced growth.

Ascorbic acid has been reported to induce abscission of oranges when applied in high (2-5\%) concentrations to the leaves as a dip ( 48 ). The ascorbic acid only promoted abscission when applied to the leaf tissue, not when applied to the fruit itself, suggesting that some metabolite or change in the ascorbic acid was responsible for the action. A difference in uptake might also have been involved since leaf tissue would probably absorb more ascorbic acid than would the orange fruit. Reducing agents, such as bisulfite, cupric and ferric ions, have been shown to promote orange abscission. It was thought that possibly the process of abscission was involved with keeping tissues in a reduced state $(168,169)$. However, it has been proposed (145) that the onset of senescence is controlled by an unfavorable pile-up of oxidants (electron acceptors) upsetting an endogenous antioxidant-oxidant balance (acceptor/donor ratio). This suggests that abscission, a 
manifestation of leaf senescence, might be retarded by conditions that tend to favor the preservation of a more juvenile and less oxidized (more reduced) state. This idea is contrary to the previous one concerning abscission (168, 169). As evidence, it was reported that IAA and other antioxidants (electron donors) inhibit lignin synthesis which is usually a process carried out in older tissues (145).

Auxins are known to be effective in either inhibition or accelerating abscission of many plants. Whether or not auxin is effective in enhancing orange fruit abscission is uncertain, but 2,4-D definitely acts as an inhibitor (168). Whether the action of auxin on abscission is through the oxidation-reduction state of the tissues is not known.

\section{Acetate Metabolism}

Aromatic Synthesis

Acetate has been shown to be involved in the biosynthesis of many aromatic compounds $(120,121,135,158,160)$. There appear to be 3 general modes of incorporation: a) from acetic acid by head-to-tail placement in a straight chain with additions of $\mathrm{C}_{1}$ units from the $\mathrm{C}_{1}$ pool, b) from head-to-tail placement via condensation, and c) from the isoprene route similar to b), but with an intermediate similar to or being mevalonic acid (18). However, the shikimic acid pathway also is a major pathway of aromatic biosynthesis (120). Protocatechuric, gallic, cinnamic acid derivatives, coumarins, and others have been shown to be formed from a shikimic acid pathway (120). Also, there are other aromatics that are formed by a combination of acetate and shikimate pathways, among which are flavonoids, isoflavones, and isocoumarins (12, 121).

Birch et al. (17) were the first to show that fungal cultures could form an aromatic compound from acetate-1-14 C according to the head-totail condensation theory proposed by Birch and Donovan (18). Since then, 
others (19-21, 57-59, 120, 134) have demonstrated that many aromatic compounds are derived from a head-to-tail condensation. The mechanism in all these cases seems to be related to fatty acid synthesis (120). However, it was reported (20) that methyl groups in 7-hydroxy-4, 6dimethylphthalide were derived both from methionine and from the methyl carbon of acetate. Formic acid also contributes $\mathrm{C}_{1}$ units to some phenolic compounds $(20,21)$.

Another pathway by which acetate is incorporated into aromatic rings is via mevalonic acid (120, 121). Some benzene rings are formed thusly, but assimulated acetate also goes into side chains. Heinstein et al. (75) studied incorporation of labeled acetate into gossypol in excised cotton roots and concluded that the mevalonate pathway was probably the pathway of biosynthesis.

It has been suggested (120) that shikimic acid could serve as a precursor to many types of aromatic compounds. Evidence to support this comes from many sources $(120,121)$. The synthesis of the B ring of quercetin, synthesized in buckwheat (Fagopyrum tataricum), was found to be derived from shikimic acid (160) while the A ring and carbons 2, 3 , and 4 of $\mathrm{C}_{15}$ flavonoid compounds were derived from acetate $(62,166)$. Caffeic acid in buckwheat and tobacco was derived solely from phenylalanine (62). Likewise, phloridzin biosynthesis in Malus (84) and hydrangenol in Hydrangea $(85,86)$ are derived by similar pathways. However, there are groups of aromatics that are derived only from shikimate, since coumarins were reportedly formed by the shikimic acid pathway and acetate was poorly utilized (28). Also cinnamic acid derivatives have been noted to arise mainly from shikimate (120). 
Fatty Acid Synthesis

Acetate is metabolized to fatty acid compounds via malonyl-COA (92, 120, 149). The reactions are now fairly well established and have been demonstrated in cell-free systems (25).

\section{Isoprenoid Synthesis}

Isoprenoid structures are also derived from acetate via a headto-tail condensation $(129,170)$. The pathway has been elucidated, mainly in mammalian tissues, because cholesterol and many animal hormones are formed via this pathway. However, phenolics formed by this pathway have been found in plants (75).

Glyoxylic Cycle

The glyoxylate cycle is another means by which acetate can be metabolized. Acetate feeding experiments, mainly with fatty materials (i.e., castor beans) have shown that acetate is incorporated into citric and malic acids in the Krebs cycle (36). The 2 key enzymes, malate synthetase and isocitritase, occur in many micro-organisms and plants, particularly in high oil seeds. Seeds depending on starches for energy rather than fats do not possess the glyoxylate cycle, so it may not be universally present (46). 


\section{MATERIALS AND METHODS}

\section{Plant Material}

All experiments were conducted with either leaves or fruits from 'Pineapple' and 'Valencia' sweet oranges. Two-year-old trees started from cuttings and grown in containers were used for tests in which the radioactive materials were applied in localized zones. Orchard trees were used in experiments in which a petiole absorption technique was employed.

The orange explant test was used to screen chemicals for their abscission accelerating abilities as described by Wilson (168, 169). Briefly, the explant consisted of an orange fruit with a 3-4 inch stem. The stem was inserted into the test solution for the duration of the test. To determine if abscission was in the final stage, a force was applied to the abscission zone by applying a slight pressure to the side of the stem.

\section{Determination of $\mathrm{CO}_{2}$ Production}

\section{Continuous Flow System}

The production of ${ }^{14} \mathrm{CO}_{2}$ from intact 'Pineapple' orange leaves treated with IOAC-2-14C was determined by trapping $14 \mathrm{CO}_{2}$ in Hydroxide of Hyamine 10-X p-(diisobutyl-cresoxyethoxyethyl)-dimethylbenzylammonium hydroxide (132). The leaf, still attached to the plant, was sealed in a small plexiglass leaf chamber. The method of collecting ${ }^{14} \mathrm{CO}_{2}$ evolved by treated leaves was via a scrubbing train. Air was forced through a train of a scrubbing tower of $10 \%$ sodium hydroxide, a distilled water washing tower, a plexiglass leaf chamber, and, finally, 
through the trapping solution.

\section{$\underline{\text { Closed System }}$}

After treatment with either IOAC-1-14C or IOAC-2-14C, 2 'Pineapple' orange leaves, still attached to approximately 3 inches of $\mathrm{twig}$, were placed so that the proximal inch of the twig was in water. The container plus water and explants were suspended in a $250 \mathrm{ml}$ Erlenmyer flask in which $20 \mathrm{ml}$ of Hydroxide of Hyamine was added to absorb $\mathrm{CO}_{2}$. One $\mathrm{ml}$ of the trapping solution was removed (and $1 \mathrm{ml}$ replaced) with a syringe and hypodermic needle through a vaccine cap attached to a teflon tube leading below the level of the trapping solution.

$\underline{\text { Radioactive Materials and Methods of Determining Radioactivity }}$

Al1 radioactive materials were obtained from the Nuclear Equipment Company at the following specific activities:

$$
\begin{aligned}
& \text { IOAC-1-14C, sodium salt, } 1.4 \mathrm{mc} / \mathrm{m} \mathrm{mole} \\
& \text { IOAC-2-14C, sodium salt, } 6.5 \mathrm{mc} / \mathrm{m} \mathrm{mole} \\
& \text { Acetate-1-14C, sodium sa1t, } 15 \mathrm{mc} / \mathrm{m} \mathrm{mole} \\
& \mathrm{Na} 131 \mathrm{I}, \text { sodium salt, } 555.5 \mathrm{mc} / \mathrm{m} \mathrm{mole}
\end{aligned}
$$

Water was added to make concentrations of $0.1 \mathrm{M}$ IOAC and $3 \times 10^{-3} \mathrm{M}$ acetic acid.

${ }^{131}$ IOAC was prepared essentially as described by Conant and Kirner (45). $\mathrm{Na} 13 \mathrm{II}_{\mathrm{I}}$ was reacted with $100 \mathrm{mg}$ of monochloroacetic acid in $10 \mathrm{mI}$ of refluxed, redistilled acetone. The reaction took place at $40^{\circ} \mathrm{C}$ in a sealed bottle for 20 hours. Acetone was removed under a stream of nitrogen and the residue was washed with $15 \mathrm{ml}$ of carbon disulfide. The remaining residue was dissolved in $0.5 \mathrm{ml}$ of deionized water.

Both liquid scintillation and Geiger-Mueller methods of determining radioactivity were used. A Packard-Tri-Carb liquid scintillation counter series $314 \mathrm{Ex}$ at $-50 \mathrm{C}$ was employed with 2 counting solutions: a) a 
solution for counting the Hydroxide of Hyamine; 2,4-diphenyloxazole (PPO)

$3 \mathrm{~g} ;$ 2,2'-paraphenylene bis 5-phenyloxazole (POPOP) $100 \mathrm{mg}$; toluene $1000 \mathrm{ml} \mathrm{(132);} \mathrm{and} \mathrm{b)} \mathrm{a} \mathrm{solution} \mathrm{for} \mathrm{counting} \mathrm{high} \mathrm{percent} \mathrm{water} \mathrm{samples}$ as described by Bray (26), namely, PPO ( $4 \mathrm{~g})$ POPOP ( $0.2 \mathrm{~g})$ naphthalene $(60 \mathrm{~g})$ methanol (absolute, $100 \mathrm{ml}$ ) ethylene glycol (20 ml) and p-dioxane (to make 1 liter). All planchet counting was conducted with a Nuclear Chicago GM planchet counting system. The instrument used was a model 183-B Count-0-Matic scaler equipped with a model C-111-B time-interval printer, a model C-110-B automatic sample changer and, a model D-47 gas flow detector.

Paper chromatograms and paper electrophoretograms were scanned using an Analytical counter ratemeter model 1620-B, equipped with a Nuclear Chicago model C-100-A Actinograph II and a D-47 window gas flow detector. Recordings of the scan were made with a 1-MA EsterlineAngus chart recorder. Settings used were: slit width, $1 / 4$ inch, time constant 10 seconds, full scale deflection 150 or $300 \mathrm{cpm}$, and chromatogram scan speed of $3 / 4 \mathrm{inch} / \mathrm{min}$.

Radioactive samples eluted from polystyrene column were monitored by passing the effluent through a flow cell in a Nuclear Chicago liquid scintillation counter.

Autoradiograms were made of paper and thin-layer chromatograms, and paper electrophoretograms using Kodak, Royal Blue, no screen, medical $\mathrm{X}$-ray film. Time of film exposure was 28 days.

\section{Extraction and Fractionation Procedures}

Initially, $80 \%$ ethanol was used as an extracting medium. However, - eariy in this work it was found that water removed most of the radioactivity from the tissues. Thus, water was used throughout the study. Two extraction and fractionation procedures were primarily used: a) 
dialysis-solvent fractionation, and b) column fractionation. Where there are deviations from these procedures, they will be stated with the results.

Method of Dialysis and Solvent Fractionation

Water extracts were dialyzed using a cellulose acetate membrane against water at $40 \mathrm{C}$. The radioactive components would pass readily through the membrane. This initial clean-up procedure removed many interfering substances and allowed the resulting solutions to be manipulated through additional fractionational procedures more quantitatively, e.g., decreased the formation of emulsions. The dialyzable portion was then partitioned between various organic solvents from an aqueous solution which was either basic or acidic.

\section{Column Fractionational Procedures}

Water extracts were first freed of most proteins and much of the pigment material by precipitation with a small amount of $95 \%$ ethanol. After settling, the precipitate was removed by centrifugation at 3980 $\mathrm{x} \mathrm{g}$. The supernatant was then percolated through a $1 \times 9 \mathrm{~cm}$ Dowex 50-X8 (100-200 mesh) ion exchange column in the hydrogen form. The column was subsequently washed with water and $0.4 \mathrm{~N}$ ammonium hydroxide in $80 \%$ ethanol. Some of the resulting samples were further fractionated on a Dowex 1-X8 column in the formate form.

A set of samples that had been dialyzed was passed through a waterjacketed $135 \times 0.64 \mathrm{~cm}$ column of polystyrene $\mathrm{SO}_{3} \mathrm{H}$ resin (type A). The resin was converted to the ammonium form by $4 \mathrm{M}$ ammonium hydroxide. The column was operated at $66^{\circ} \mathrm{C}$ with a flow rate of $1.0 \mathrm{ml} / \mathrm{min}$. The UV absorbance at $290 \mathrm{~m} \nu$ of effluent from this column was monitored by a Beckrnan DB spectrophotometer equipped with a Sargent SRL recorder. 
A sample was also passed through a $35 \mathrm{~g}, 2 \mathrm{~cm}$ silicic acid column.

A step-wise elution sequence was used and $10 \mathrm{ml}$ fractions were collected and concentrated.

\section{Paper and Thin-Layer Chromatography}

All radioactive fractions separated were subjected to paper (22) and thin-layer chromatographic techniques $(123,131)$. Specific. parameters are given in the results section.

\section{Paper Electrophoresis}

A Spinco model $R$ electrophoresis system was used at either $\mathrm{pH}$ 8.6 attained with B-2 Veronal buffer, $2.76 \mathrm{~g}$ diethyl barbituric acid, $15.40 \mathrm{~g}$ sodium diethyl barbituate (0.075 ionic strength) or $\mathrm{pH} 2.5$ attained with $0.4 \mathrm{~N}$ acetic acid. 
RESULTS

\section{Citrus Fruit Bioassay for Abscission}

Using the citrus fruit bioassay, it was determined that the maximum time required for uptake of IOAC for the most rapid rate of abscission was approximately 24 hours (Table 1, Fig. 1). From these results it was assumed that whatever the fate of IOAC in the plant, a 24-hour period was an adequate time interval for the changes to occur. Therefore, in all experiments where radioactive IOAC was applied to a limited zone on the leaf surface, a 24-hour uptake period was used. The citrus fruit bioassay was also used to screen additional chemicals for their capacity to promote abscission (Table 2). Malonic acid, 2,4-dinitrophenol, potassium iodide, diodomethane, L-alanine, cysteine, mannitol, sorbitol, glucono-delta-lactone, and ribose all accelerated the rate of abscission of the explants. Sugar compounds, other than the previous ones mentioned, either had no effect or delayed abscission. Ascorbic acid strongly inhibited abscission (Table 2, Fig. 2) under the conditions of these tests.

\section{Patterns of ${ }^{14} \mathrm{CO}_{2}$ Production from Tissues Treated with IOAC}

Both carboxyl and methyl labeled IOAC-14C, when applied to a limited zone on the surface of 'Pineapple' orange leaves, resulted in a production of ${ }^{14} \mathrm{CO}_{2}$. This was the case for either leaves attached to the plant (Fig. 3) or leaves detached from the plant and assayed in a closed system (Fig. 4). ${ }^{14} \mathrm{CO}_{2}$ Production from Attached Leaves

The ${ }^{14} \mathrm{C}_{2}$ production was periodically sampled at 1 -hour intervals 


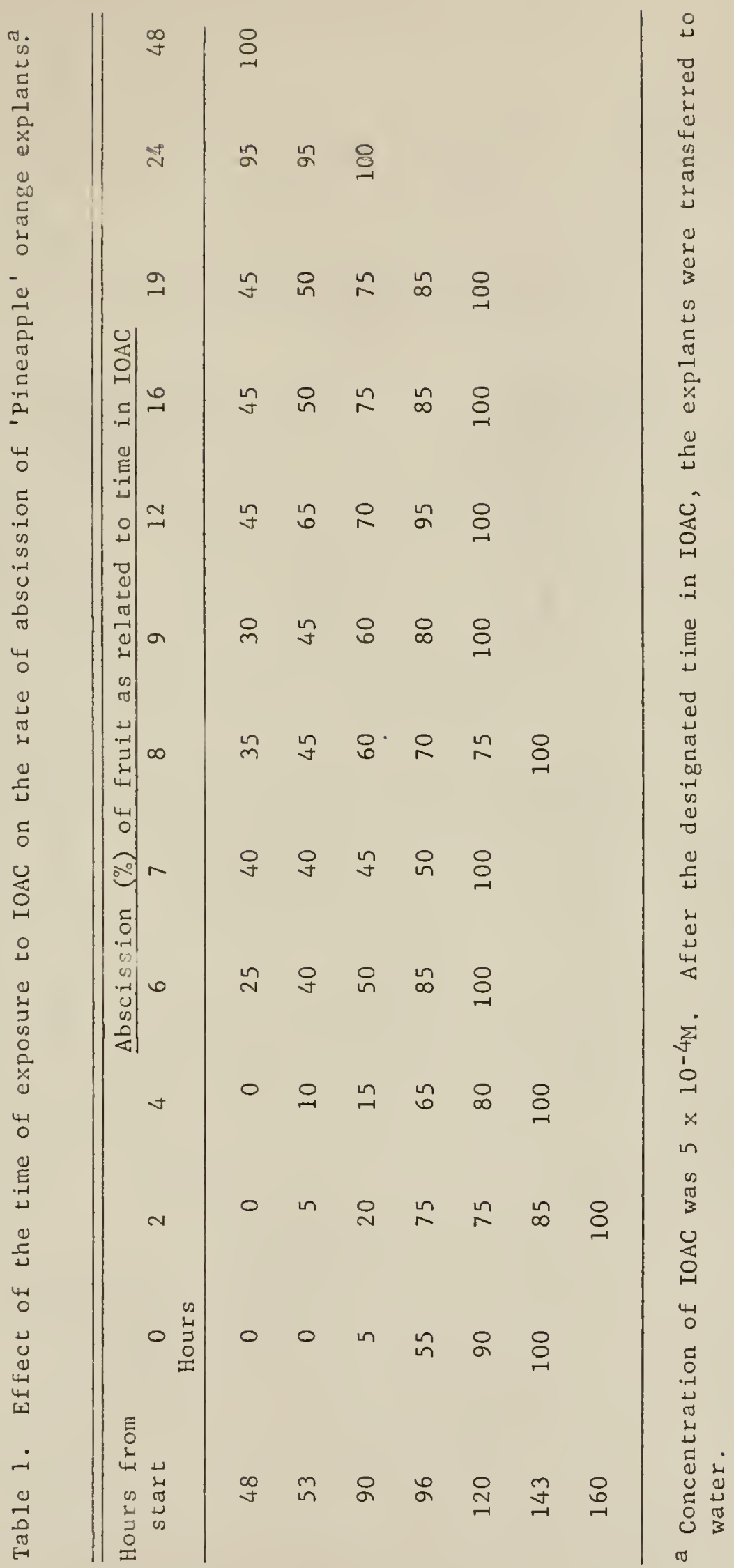




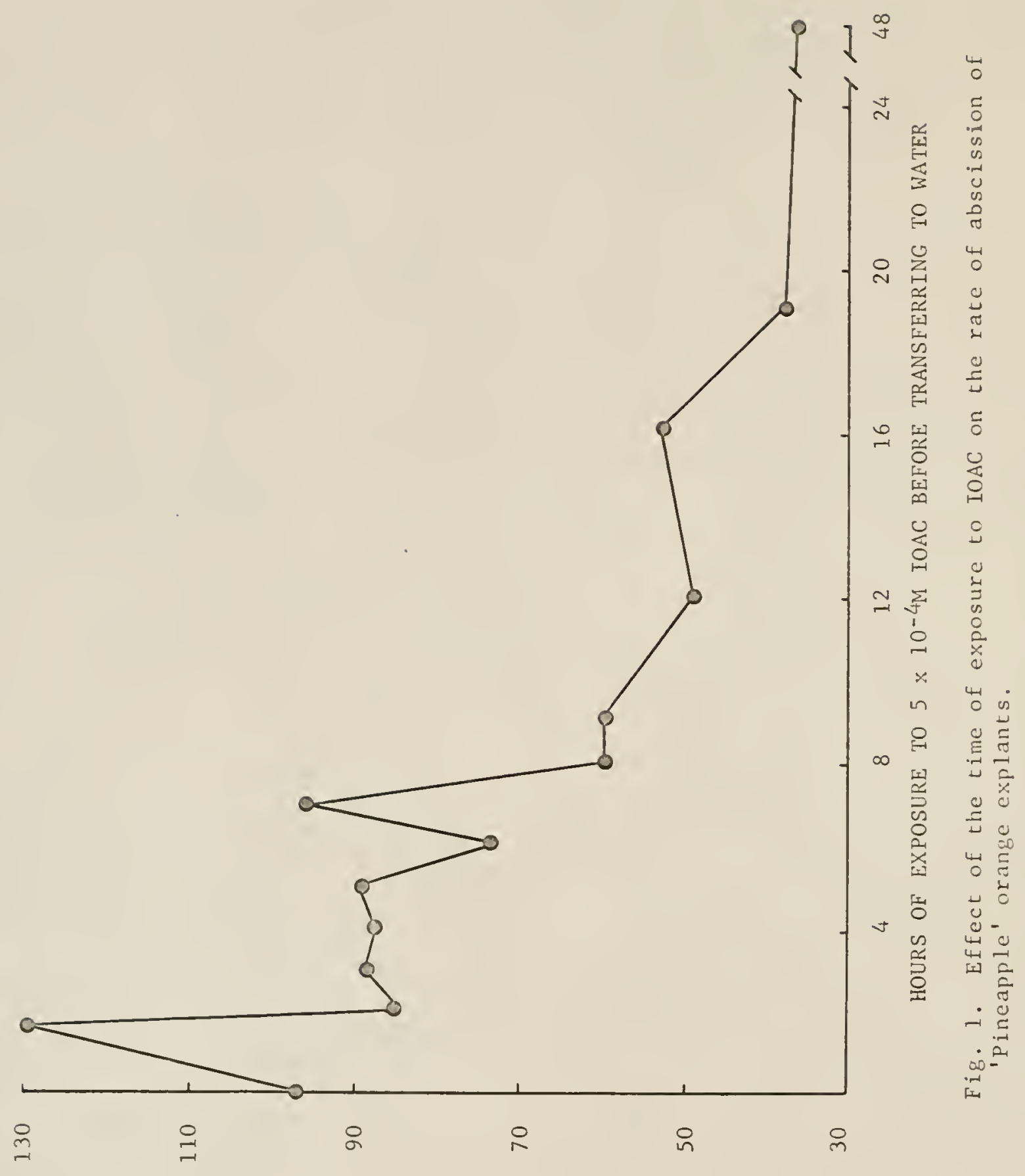

NOISSIJSA $\%$ OS OI SYROH 
Table 2. Effect of various chemicals on the rate of abscission of 'Pineapple' orange explantsa

\begin{tabular}{|c|c|c|c|c|c|c|c|c|}
\hline \multirow[b]{2}{*}{ Chemical } & \multirow{2}{*}{\multicolumn{2}{|c|}{ Molarity }} & \multicolumn{6}{|c|}{ Abscission (\%) } \\
\hline & & & 48 & 72 & 96 & 120 & 144 & $168 \mathrm{Hrs}$. \\
\hline Water control & & & 0 & 10 & 50 & 100 & & \\
\hline Iodoacetic acid & & $\times 10^{-4}$ & 100 & & & & & \\
\hline \multirow[t]{2}{*}{ Mannose } & 5.5 & $\times 10^{-2}$ & 20 & 30 & 40 & 100 & & \\
\hline & 2.8 & $\times 10^{-2}$ & 0 & 0 & 20 & 100 & & \\
\hline \multirow[t]{2}{*}{ Mannitol } & 5.5 & $x \quad 10^{-2}$ & 100 & & & & & \\
\hline & 2.8 & $\times 10^{-2}$ & 100 & & & & & \\
\hline \multirow[t]{2}{*}{ Xylose } & 6.6 & $\times 10^{-2}$ & 10 & 20 & 70 & 100 & & \\
\hline & 3.3 & $x 10^{-2}$ & 10 & 20 & 70 & 100 & & \\
\hline \multirow[t]{2}{*}{ Sorbitol } & 5.5 & $\times 10^{-2}$ & 0 & 100 & & & & \\
\hline & 2.8 & $\times 10^{-2}$ & 0 & 70 & 100 & & & \\
\hline \multirow[t]{2}{*}{ Galactose } & 5.5 & $\times 10^{-2}$ & 10 & 10 & 50 & 70 & 100 & \\
\hline & 2.8 & $\times 10^{-2}$ & 0 & 0 & 40 & 70 & 100 & \\
\hline Glucono-del ta- & 5.5 & $\times 10^{-2}$ & 30 & 100 & & & & \\
\hline lactone & 2.8 & $\times 10^{-2}$ & 20 & 90 & 100 & & & \\
\hline \multirow{2}{*}{ Fructose } & 5.5 & $\times 10^{-2}$ & 0 & 20 & 60 & 80 & 100 & \\
\hline & 2.8 & $\times 10^{-2}$ & 0 & 30 & 80 & 100 & & \\
\hline \multirow[t]{2}{*}{ Ribose } & 6.6 & $\times 10^{-2}$ & 70 & 80 & 80 & 100 & & \\
\hline & 3.3 & $\times 10^{-2}$ & 80 & 100 & & & & \\
\hline \multirow[t]{2}{*}{ Dextrose } & 5.5 & $\times 10^{-2}$ & 0 & 0 & 40 & 40 & 100 & \\
\hline & 2.8 & $\times 10^{-2}$ & 0 & 0 & 30 & 50 & 90 & 100 \\
\hline \multirow[t]{3}{*}{ Ethyl iodide } & & $10^{-3}$ & 5 & 10 & 10 & 45 & 85 & 90 \\
\hline & & $\times 10^{-4}$ & 5 & 20 & 35 & 55 & 75 & 80 \\
\hline & & $10^{-4}$ & 0 & 5 & 5 & 15 & 75 & 100 \\
\hline \multirow{3}{*}{ Methyl iodide } & & $10^{-3}$ & 25 & 55 & 55 & 55 & 55 & 70 \\
\hline & & $\times 10^{-4}$ & 10 & 30 & 30 & 30 & 30 & 40 \\
\hline & & $10^{-4}$ & 0 & 5 & 10 & 15 & 15 & 15 \\
\hline Potassium & & $10-3$ & 80 & 100 & & & & \\
\hline \multirow[t]{2}{*}{ iodide } & & $\times 10^{-4}$ & 30 & 70 & 85 & 100 & & \\
\hline & & $10^{-4}$ & 5 & 25 & 75 & 75 & 100 & \\
\hline Diiodome thane & & $10^{-3}$ & 70 & 100 & & & & \\
\hline Malonic acid & & $10-3$ & 75 & 80 & 100 & & & \\
\hline Cysteine & & $10^{-3}$ & 10 & 70 & 100 & & & \\
\hline Cysteine - & & $10^{-3}$ & & & & & & \\
\hline iodoacetic & & + & 70 & 100 & & & & \\
\hline acid & & $\times 10^{-4}$ & & & & & & \\
\hline 2,4-dinitrophenol & & $10-3$ & 50 & 75 & 100 & & & \\
\hline 2,4-dinitrophenol & & $10^{-3}$ & & & & & & \\
\hline+ iodoacetic & & + & 65 & 100 & & & & \\
\hline acid & & $\times 10^{-4}$ & & & & & & \\
\hline L-alanine & & $10^{-3}$ & 55 & 100 & & & & \\
\hline L-ascorbic acid & 5 & $\times 10^{-4}$ & 15 & 15 & 15 & 15 & 20 & 30 \\
\hline
\end{tabular}

aOranges harvested in January, 1967. 


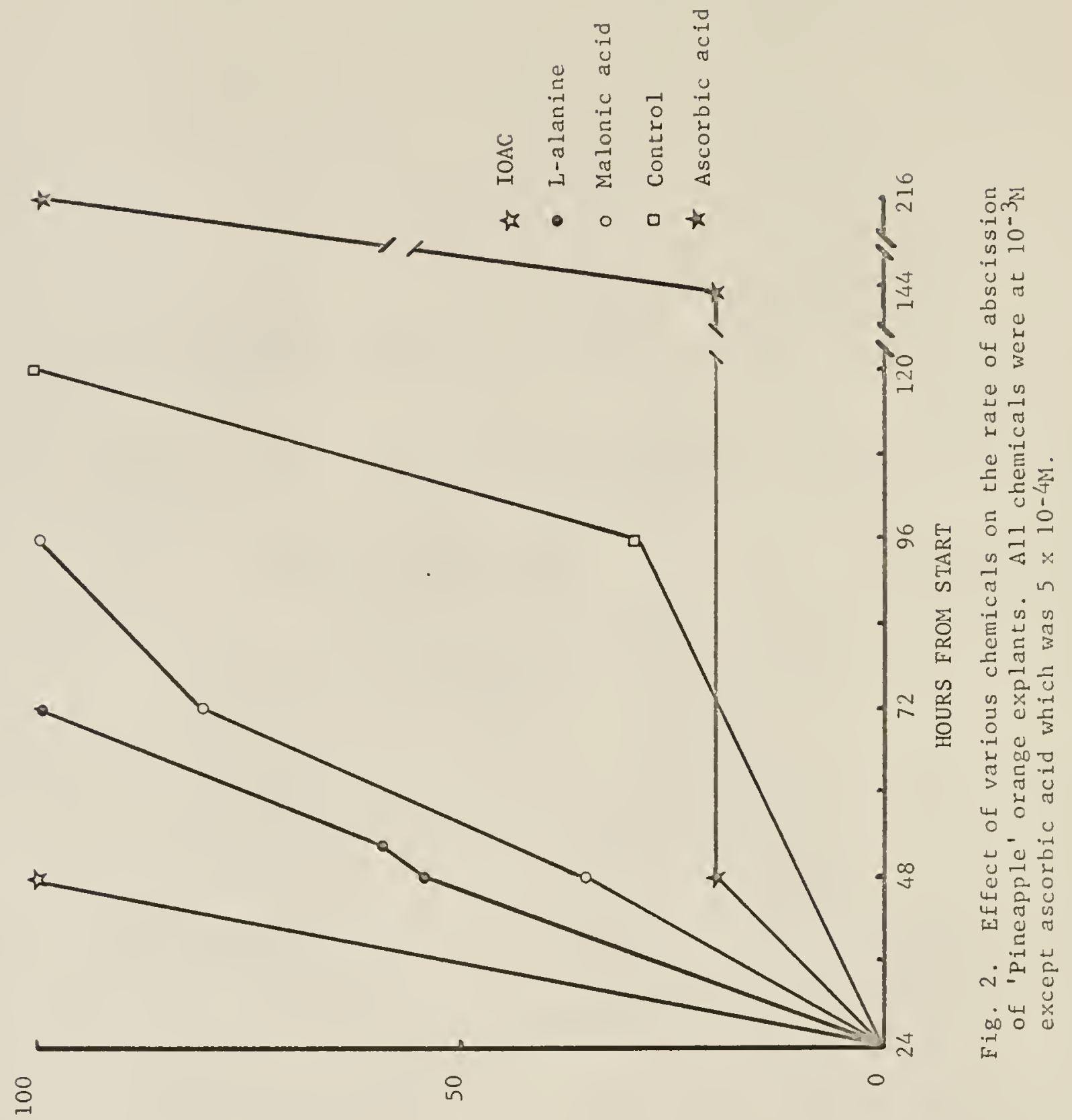

(\%) NOISSIJSgV 


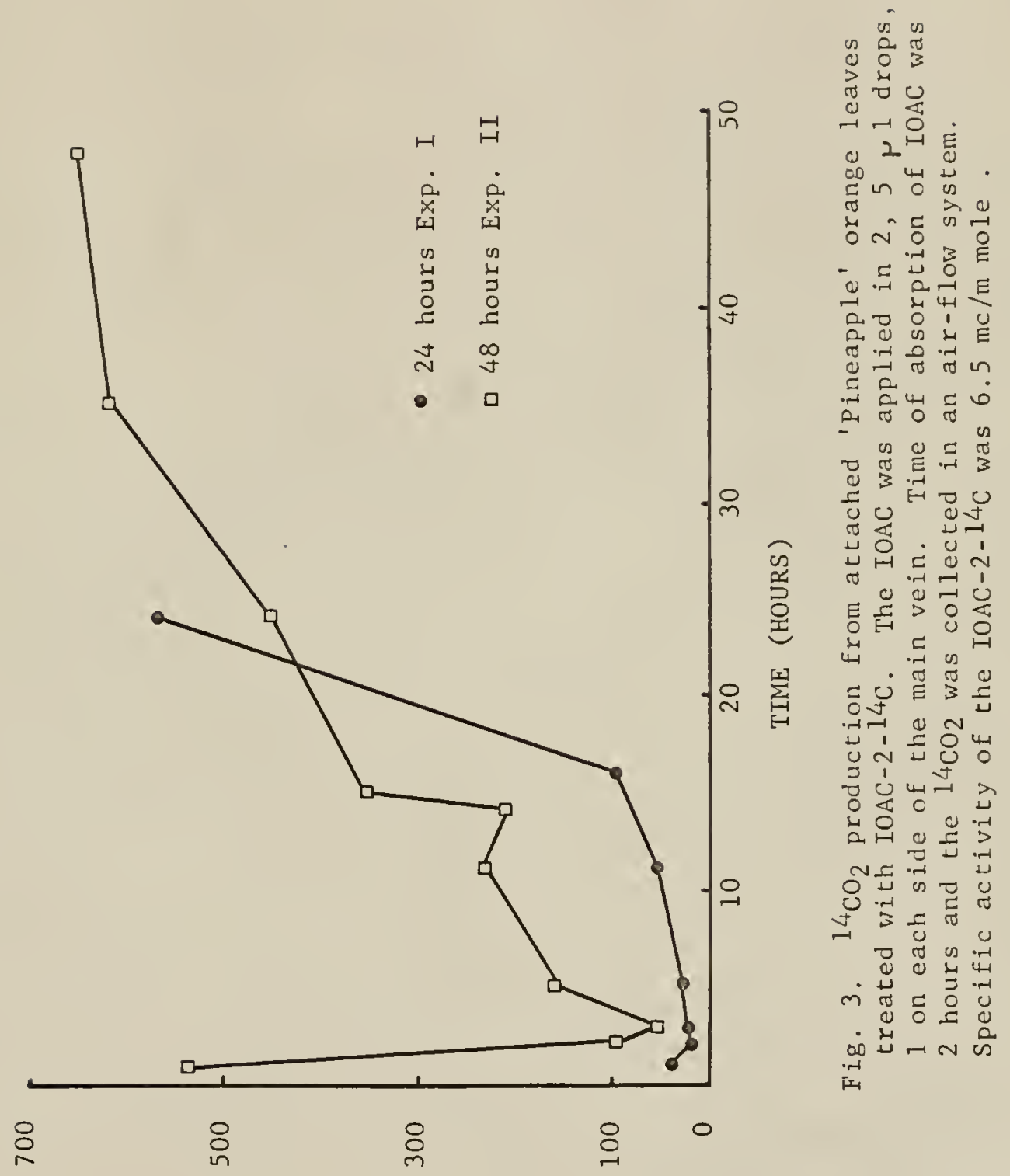

ผลว 


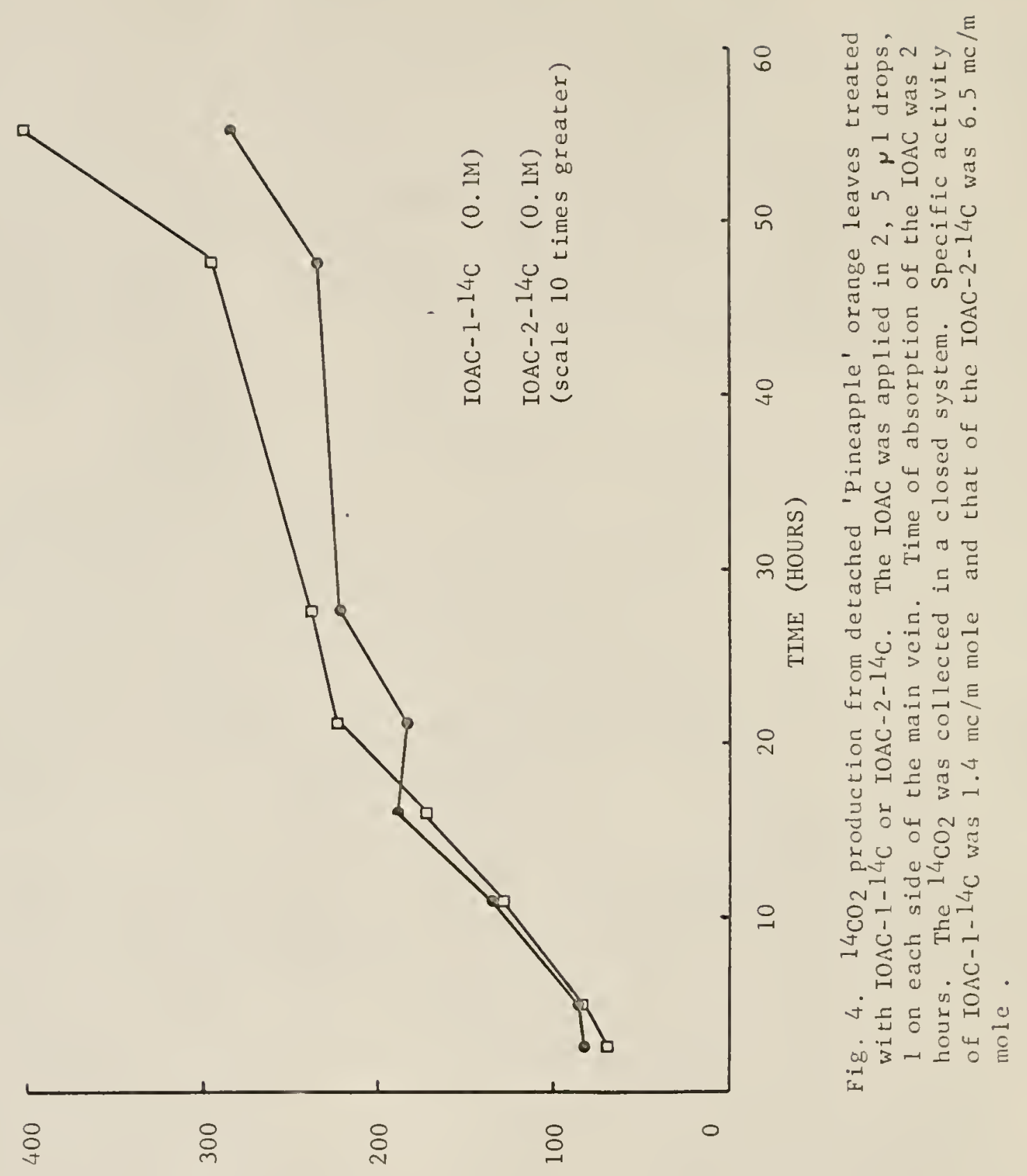

พสว 
for 24 hours in one test and 48 hours in another test (Fig. 3). The release of ${ }^{14} \mathrm{CO}_{2}$ still was increasing over the longer time period. The initial peak at the 1 -hour sample (Fig. 3, Exp. II) was variable and could be the result of trapping any initially volatile components as IOAC is decomposed somewhat by light. However, the level should have been maintained if that were the case. The peak was obtained whether or not the plexiglass chamber was darkened. ${ }^{14} \mathrm{CO}_{2}$ Production from Detached Leaves

The $14 \mathrm{CO}_{2}$ production from detached leaves in a closed system indicated that a small fraction of both IOAC-1-14C and IOAC-2-14 C was metabolized to ${ }^{14} \mathrm{CO}_{2}$ (Fig. 4). Slopes of the ${ }^{14} \mathrm{CO} 2$ production curves show that both the methyl and carboxyl IOAC are metabolized at similar rates.

Effect of Time of Extraction on the Amount of Radioactivity Found in the Extract and Remaining in the Tissues

Treatment of 'Pineapple' (Table 3) and 'Valencia' (Table 4) orange leaves with IOAC-1-14 C showed that in both varieties the amount of radioactivity extracted with ethanol did not diminish over 48 hours. This indicated that the IOAC was not metabolized to cell wall material or any macromolecules that were not soluble in ethanol. It also demonstrated that a large portion of the IOAC was not 10 t as ${ }^{14} \mathrm{CO}_{2}$.

The amount of radioactivity remaining in the 'Pineapple' residue was a very small fraction of the total radioactivity and, again, the amounts were not significantly different with time (Table 5). The amount of radioactivity in the 'Valencia' residue was also a very small portion of the total (Table 6). However, there was a slight drop in the radioactivity remaining in the residue over the 48-hour time interval. This again indicated that there was very little metabolism of IOAC to macromolecules or cell wall material. 
Table 3. Ethanol extractable radioactivity in 'Pineapple' orange leaf disks treated in $2 \mathrm{ml}$ of $5 \times 10^{-4} \mathrm{M}$ IOAC-1 $14 \mathrm{C}$ for 3 hours.

\begin{tabular}{|c|c|c|c|c|c|}
\hline \multirow[b]{2}{*}{ Hours } & \multirow[b]{2}{*}{ Exp. I } & \multicolumn{3}{|c|}{ Radioactivity in ethanol extract $(\mathrm{cpm})^{\mathrm{b}}$} & \multirow[b]{2}{*}{ V } \\
\hline & & II & III & IV & \\
\hline 1 & 11,520 & 12,350 & 11,130 & 8,570 & 7,480 \\
\hline 6 & 9,730 & 10,120 & 8,660 & 6,110 & 8,470 \\
\hline 10 & 11,140 & 12,000 & 8,260 & 8,510 & 9,070 \\
\hline 24 & 12,030 & 10,520 & 9,060 & 9,980 & 8,040 \\
\hline 48 & 11,300 & 10,010 & 9,180 & 8,700 & 7,970 \\
\hline
\end{tabular}

${ }^{a}$ Leaf disks were extracted with $80 \%$ ethanol after $1-, 6 ; 10 ; 24$; and 48hour intervals following treatment. The specific activity of the IOAC $-1-14 \mathrm{C}$ was $1.4 \mathrm{mc} / \mathrm{m}$ mole.

$b_{F}=<.01$ N. S. with respect to time of extraction. 


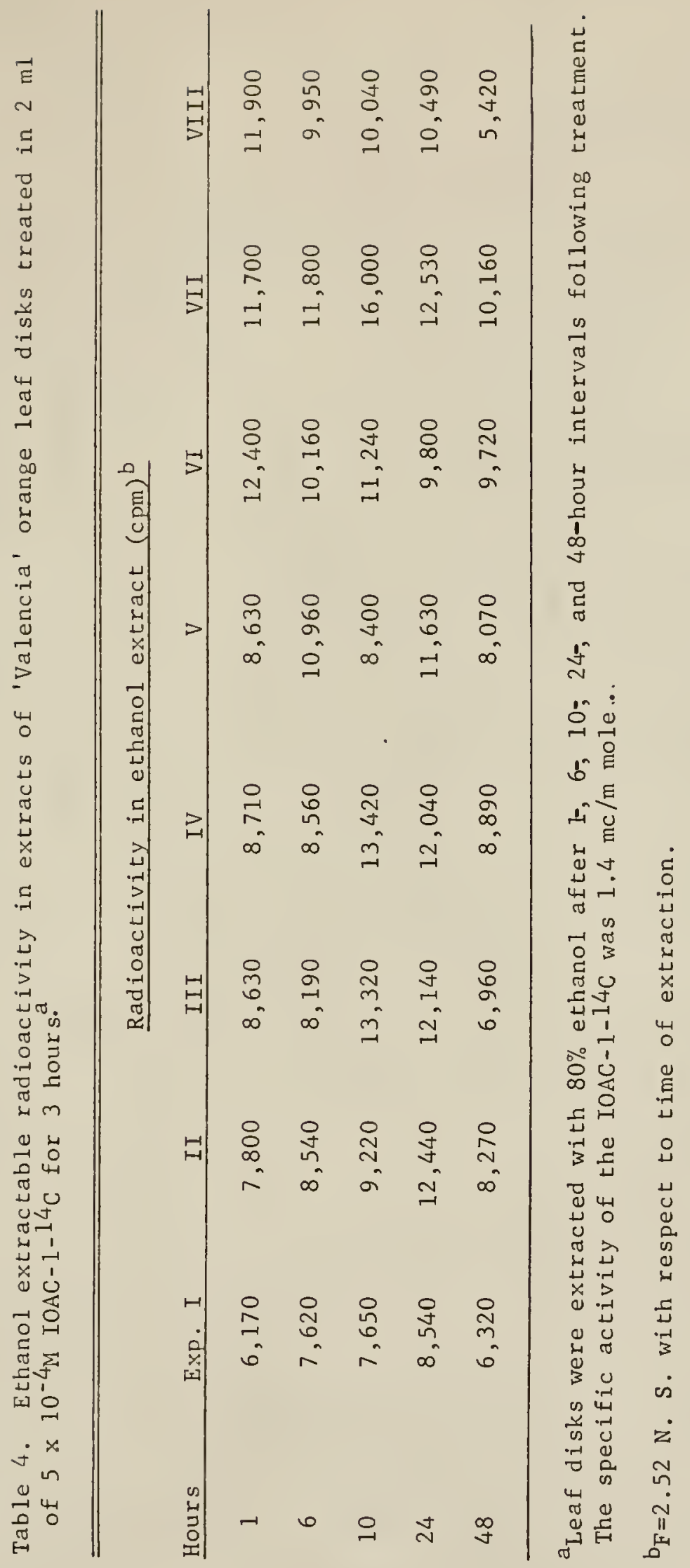


Table 5. Radioactivity remaining after ethanol extraction in

'Pineapple' orange leaf disks after treatment in $2 \mathrm{ml}$ of $5 \times 10^{-4} \mathrm{M}$ IOAC $-1-14 \mathrm{C}$ for 3 hours.

\begin{tabular}{|c|c|c|c|c|c|}
\hline \multirow[b]{2}{*}{ Hours } & \multicolumn{5}{|c|}{ Radioactivity in residue (cpm/mg fresh weight $)^{b}$} \\
\hline & Exp. I & II & III & IV & $\mathrm{V}$ \\
\hline 1 & 2.6 & 3.0 & 1.5 & 1.4 & 2.0 \\
\hline 6 & 1.8 & 3.0 & 1.3 & 1.9 & 1.6 \\
\hline 10 & 3.5 & 2.6 & 1.9 & 1.5 & 1.0 \\
\hline 24 & 2.1 & 1.3 & 1.9 & 0.4 & 1.8 \\
\hline 48 & 1.7 & 2.5 & 0.8 & 1.6 & 0.7 \\
\hline
\end{tabular}

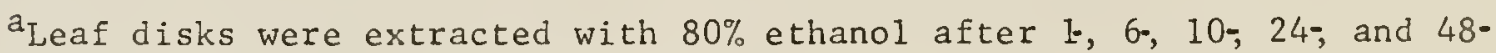
hour intervals following treatment. The specific activity of the IOAC $-1-14 \mathrm{C}$ was $1.4 \mathrm{mc} / \mathrm{m}$ mole.

$b_{F}=\langle 1 N$. S. with respect to time of extraction. 


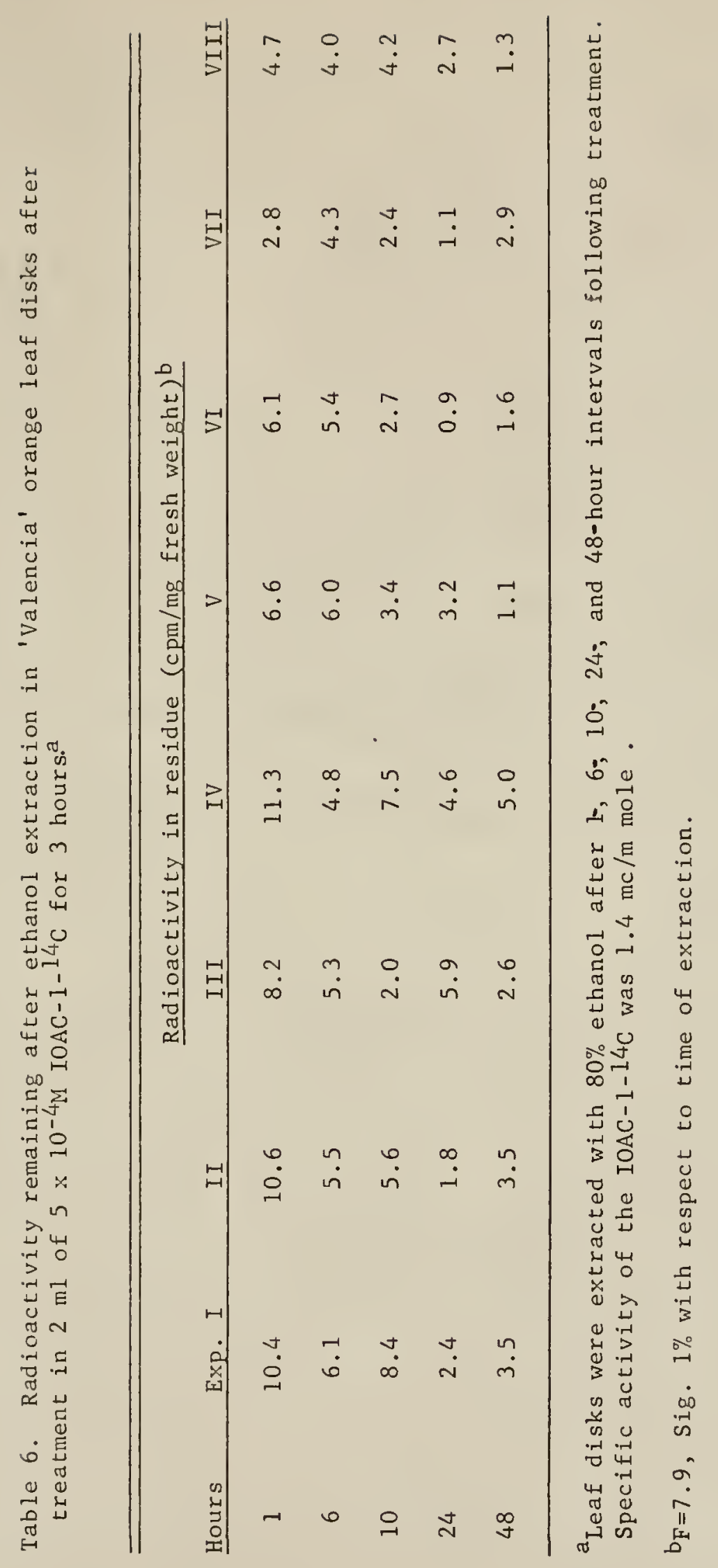


Metabolism of IOAC Applied to Leaves in Drops

Both 'Pineapple' and 'Valencia' orange varieties metabolized labeled IOAC-1-14 C. Approximately 60 to $80 \%$ of the total radioactivity absorbed by the leaves could be extracted with water and was dialyzable (Tables 7 and 8). The average value for the dialyzed components for the 'Pineapple' variety was $77.9 \%$ and that for the 'Valencia' variety was $63.7 \%$. Since most of the radioactive components would pass through a membrane, and since this procedure removed interfering substances that hindered solvent partitioning, this technique was used prior to other fractional procedures.

Solvent partitioning of the dialyzable portion of the radioactivity indicated that less than $10 \%$ of the radioactivity in an acidic water extract was soluble in ether (called the ether fraction) (Tables 7 and 8 ). The aqueous portion from this separation was termed the water fraction and the large percentage of radioactivity remaining in this fraction indicated that the labeled metabolites formed from the IOAC$14 \mathrm{C}$ were polar. This was substantiated by showing that various organic solvents did not partition any radioactivity from this water fraction (Table 9).

Measurement of the Free IOAC in the Tissues After a 24-Hour Uptake Period

Free IOAC-1-14C in the extracts from orange leaves was removed from the dialyzed water extract by partitioning between aqueous HCI ( $\mathrm{pH} 3.0$ ) and diethyl ether. On1y IOAC was detected in the ether fraction (Fig. 5 and Table 10 for $R_{f}$ values of paper chromatography separation) and no further separation was done on this fraction. Both 'Pineapple' and 'Valencia' leaves, after the 24-hour time period, had approximately the same (less than $10 \%$ of activity remaining in the leaf) percent of free IOAC-1-14 C in the partitioned diethyl ether fraction (Tables 7 and 8 ). 


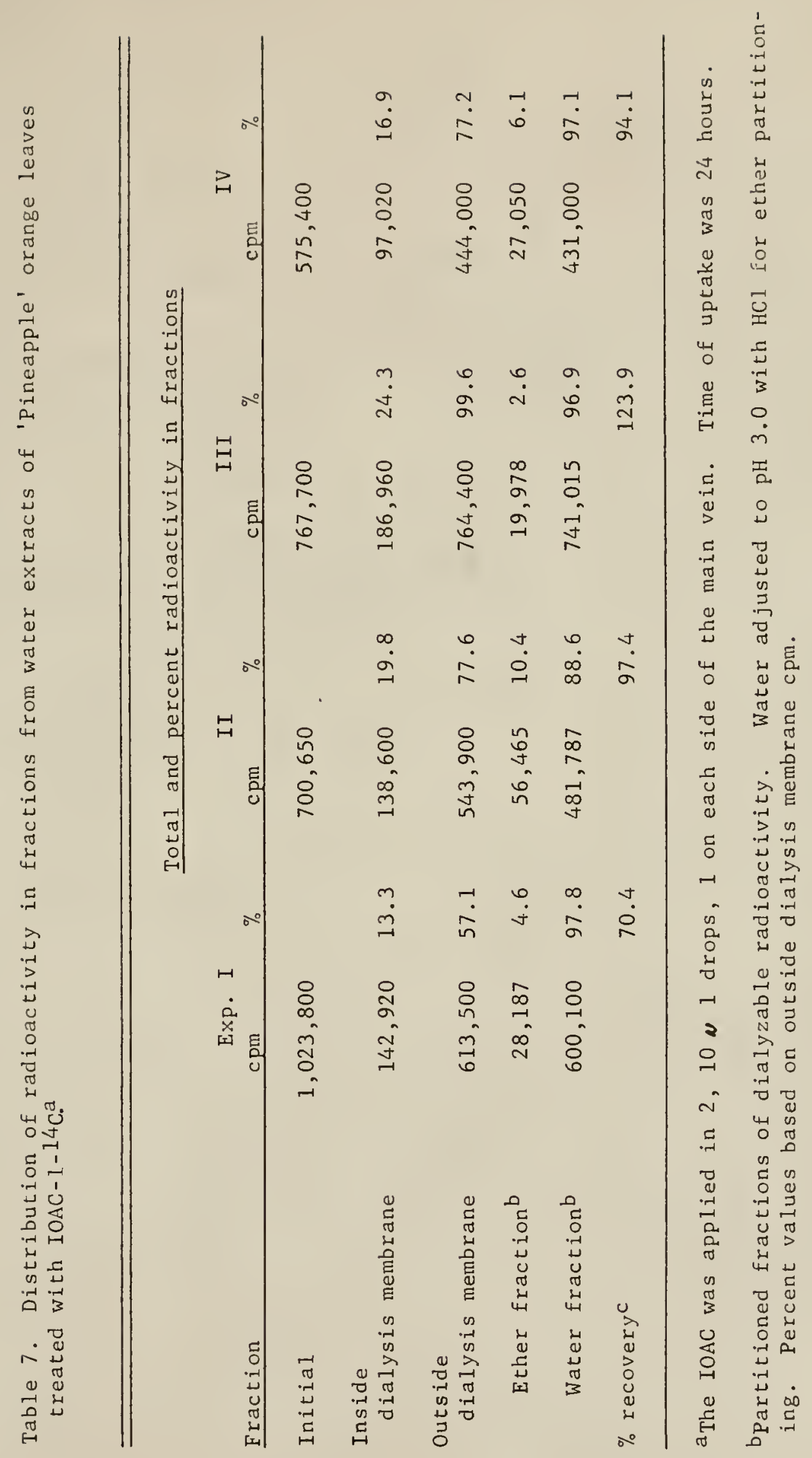




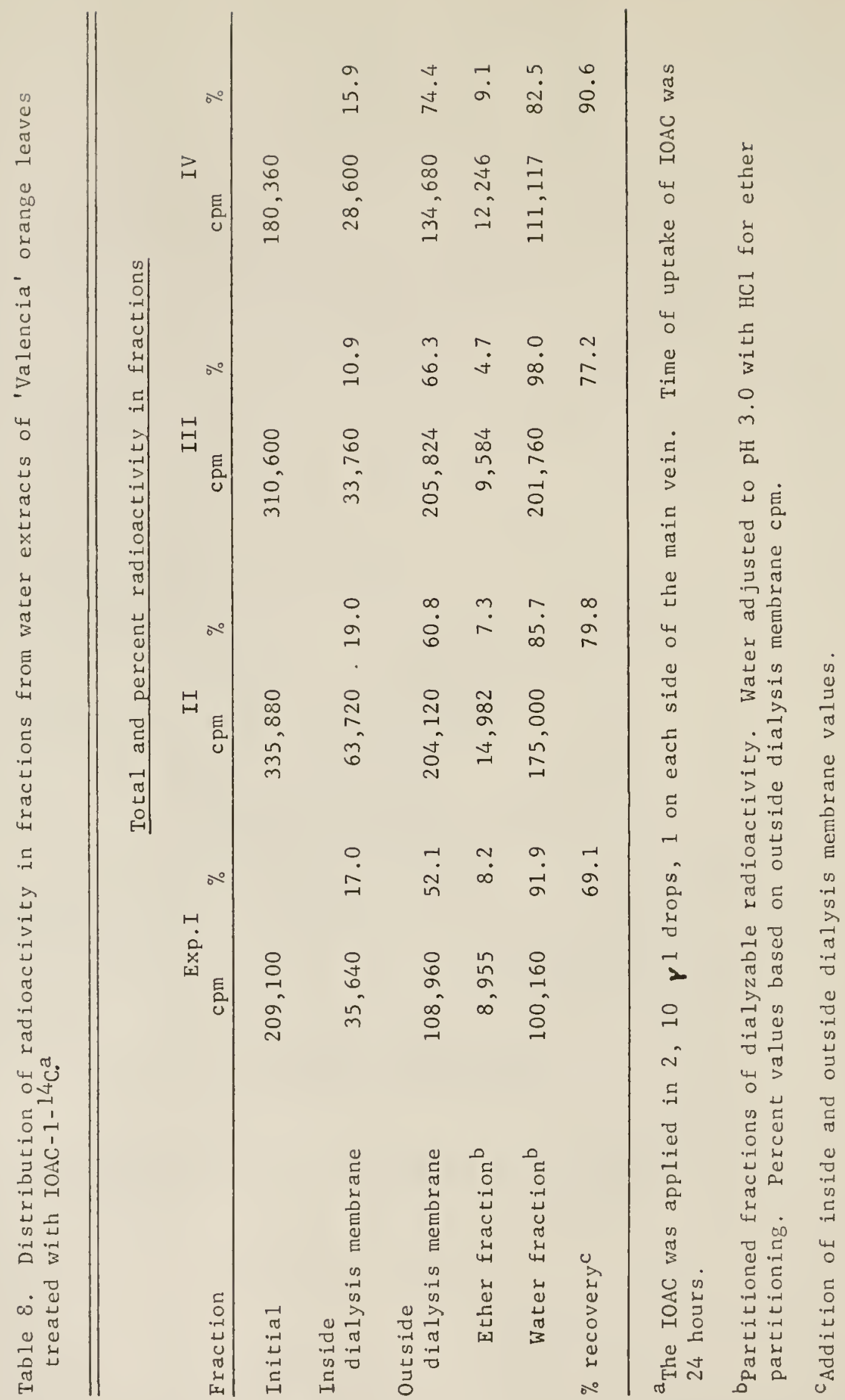


Table 9. Distribution of radioactivity in fractions of a water extract of 'Pineapple' orange leaves treated with IOAC-1-14C.a

\begin{tabular}{|c|c|c|c|}
\hline & Fraction & $\begin{array}{c}\text { Total } \\
\text { cpm }\end{array}$ & $\begin{array}{c}\% \text { of } \\
\text { Inttial value }\end{array}$ \\
\hline \multicolumn{4}{|l|}{ Basic } \\
\hline Solution & Water extract ${ }^{b}$ & 63,700 & - \\
\hline \multirow{4}{*}{$\mathrm{pH} 8.0$} & Carbon tetrachloride & 0 & - \\
\hline & Toluene & 0 & - \\
\hline & Benzene & 0 & - \\
\hline & Ether & 0 & - \\
\hline \multicolumn{4}{|l|}{ Acidic } \\
\hline Solution & Ether ${ }^{c}$ & 2,460 & 3.7 \\
\hline \multirow[t]{5}{*}{$\mathrm{pH} 3.0$} & Carbon disulfide & 0 & - \\
\hline & Carbon tetrachloride & 0 & - \\
\hline & Benzene & 0 & - \\
\hline & Toluene & 0 & - \\
\hline & Water & 67,164 & 105 \\
\hline
\end{tabular}

\footnotetext{
aThe IOAC was applied in 2, $10 \sim 1$ drops, 1 on each side of the main vein. Time of uptake of IOAC was 24 hours. The water extract was made basic ( $\mathrm{pH} 8.0$ ) with $\mathrm{NaHCO}_{3}$, then adjusted to $\mathrm{pH} 3.0$ with $2 \mathrm{~N} \mathrm{HCl}$.

bialyzable portion of extract.

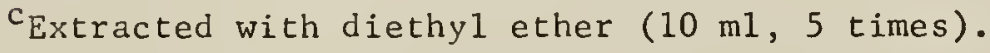




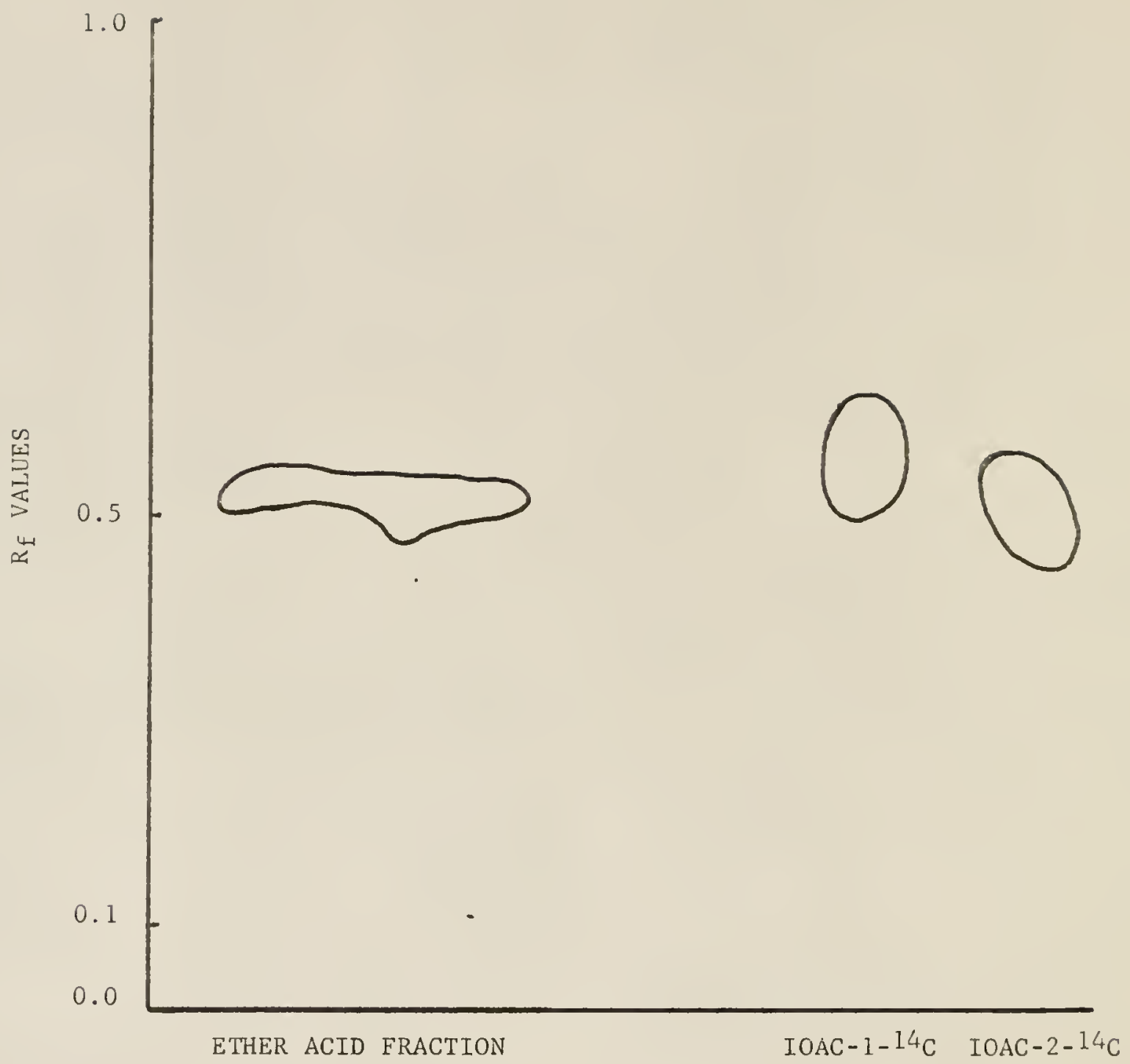

Fig. 5. Autoradiogram of thin-layer separated ether-acidicpartitioned-fraction of 'Pineapple' orange leaves treated with IOAC-1-14C. The IOAC was applied in $2,10 \mathrm{pl}$ drops, 1 on each side of the main vein. Developed in butanol: ethanol:water, 65:10:10, v/v/v, on Eastman chromagram silica gel sheets (type K 301R2). 


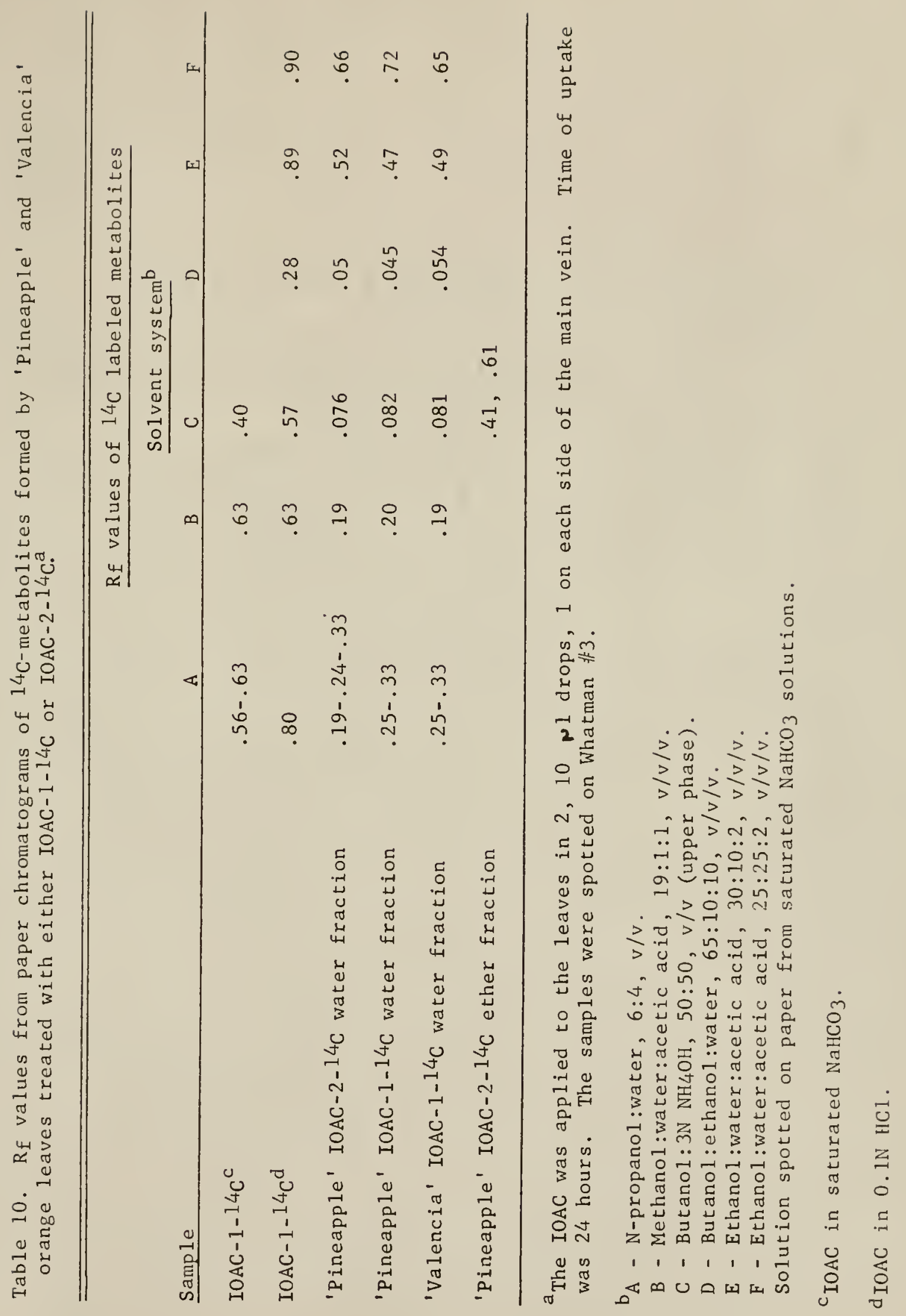


'Pineapple' leaves treated with IOAC-2-14C also had approximately the same percentage of free IOAC in the ether fraction (Table 11). These results indicated that most of the IOAC inside the tissue had been metabolized by both 'Pineapple' and 'Valencia' leaves to a metabolite or metabolites that were extremely polar in nature since the major part of the activity was retained in the water fraction. There was little radioactivity remaining in the leaf residue material. Since both the methyl and carboxyl labeled IOAC resulted in the same ${ }^{14} \mathrm{C}$ distribution pattern, it appeared that the 2 carbons were metabolized similarly. Carboxyl and Methyl $14 \mathrm{C}-1$ abeled IOAC Metabolites

When carboxyl or methyl ${ }^{14} \mathrm{C}$-labeled IOAC was applied to 'Pineapple' and 'Valencia' orange leaves, both metabolized approximately $90 \%$ of the absorbed IOAC to the same metabolites. Paper chromatograms of the water fraction contained $3^{\circ}$ distinct metabolites of which 2 appeared to be positive to ninhydrin (Fig. 6). Referring again to Table 10, paper chromatography of the water fraction in 6 solvent systems showed that 'Pineapple' leaves treated with either IOAC-1-14 C or IOAC-2-14C formed the same metabolites based on $R_{f}$ values. When separated on a paper electrophoretic system, these same compounds in the water phase were shown to be amphoteric (Fig. 7). At least 3 major metabolites and several minor ones were shown by electrophoresis to be formed by both 'Pineapple' and 'Valencia' leaves from IOAC-1-14C and IOAC-2-14C (Figs. 8-11). IOAC moves towards the anode under these same conditions (Fig. 12). These tests indicated that at least 3 major metabolites were formed in both 'Pineapple' and 'Valencia' leaves when treated with either IOAC-1-14 C or IOAC-2-14C. One of the metabolites (III) appeared in greater concentration during the second day of dialysis (Fig. 13). This probably indicated bacterial contamination of the system since this compound (III) accumulated. 


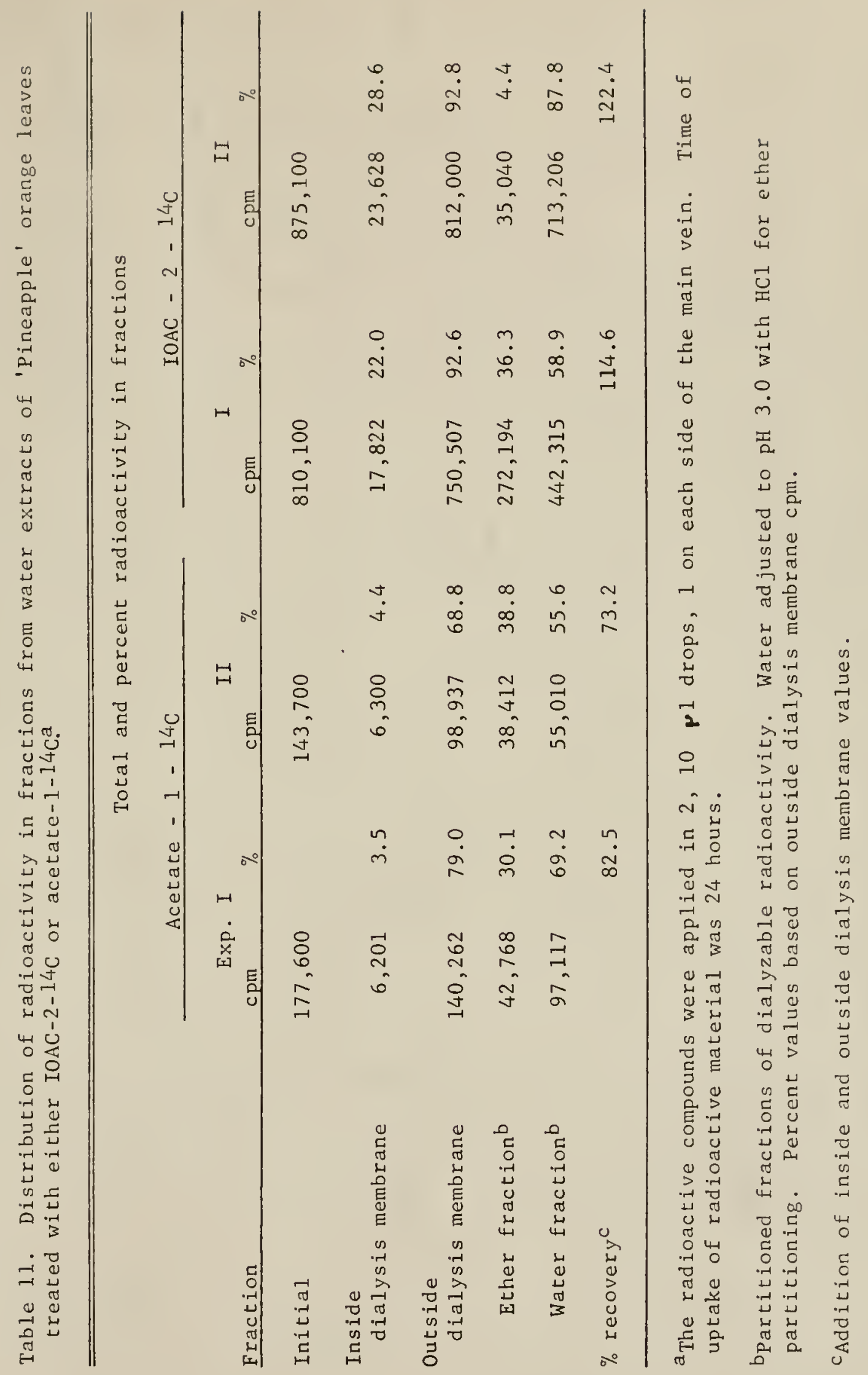




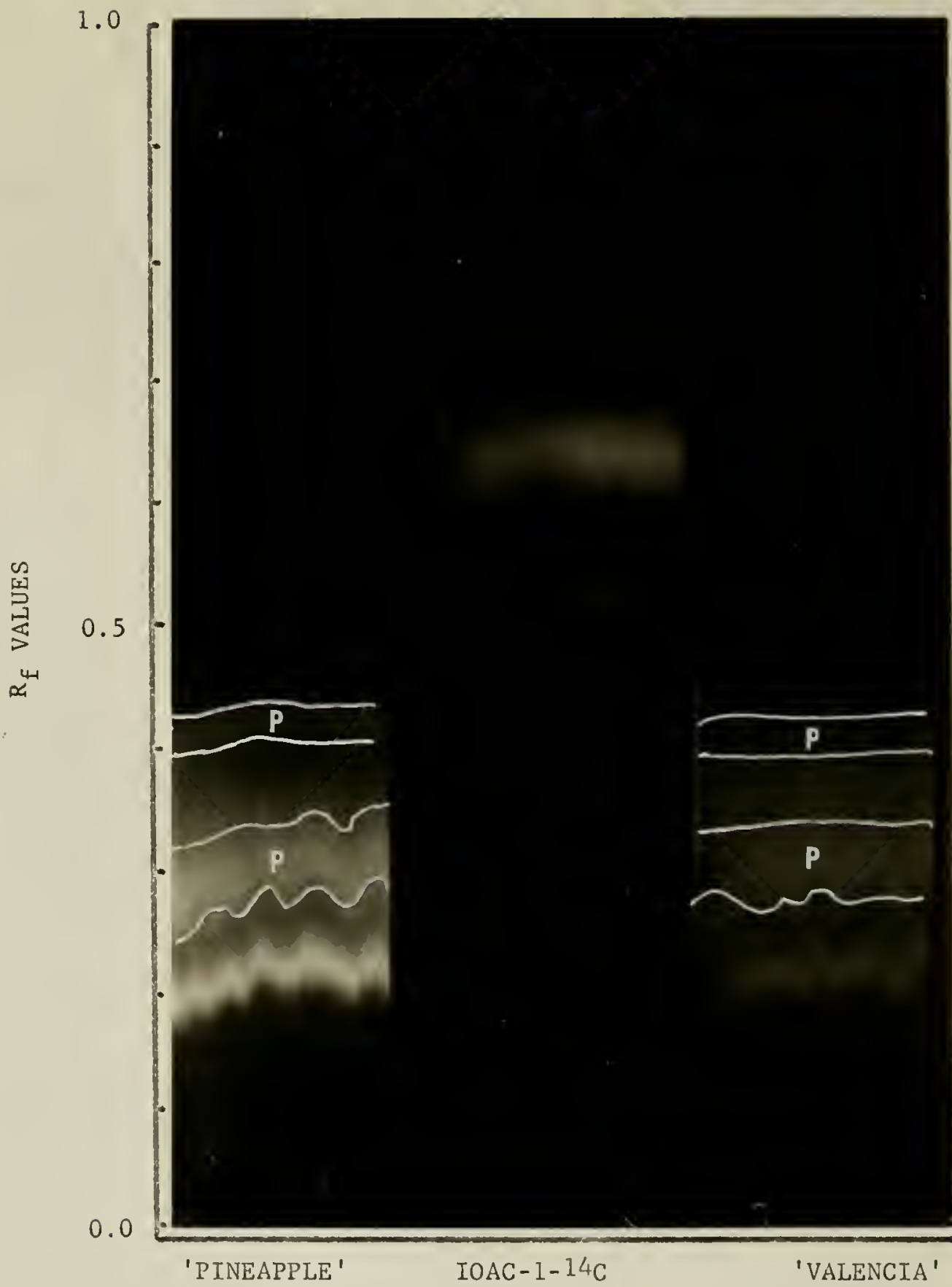

Fig. 6. Autoradiograms of paper chromatographic separation of $14 \mathrm{C}$-metabolices from 'Pineapple' and 'Valencia' orange leaves treated with IOAC $-1-14 \mathrm{C}$. The IOAC was applied in 2, 10 ildrops, 1 on each side of the main vein. Time of uptake of IOAC was 24 hours. Chromatogramed on Whatman 非 3 paper and developed in $\mathrm{N}$-propanol:water, $6: 4, \mathrm{v} / \mathrm{v}$. The letters and lines designate labeled metabolites that were positive to ninhydrin. Color code: $\mathrm{P}=$ purple. 


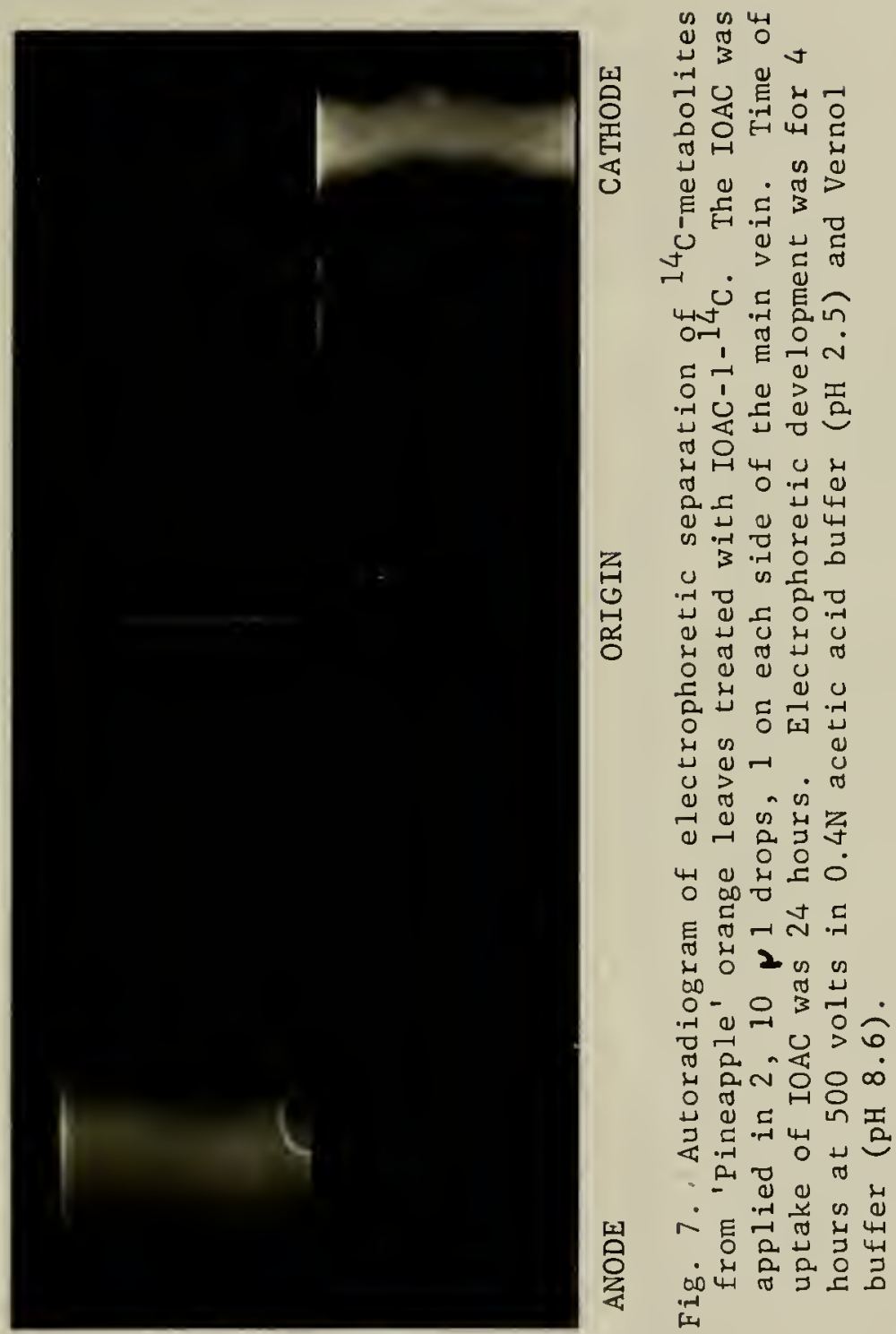

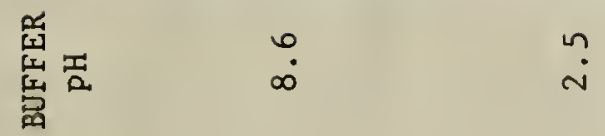


ANODE

ORIGIN

CATHODE

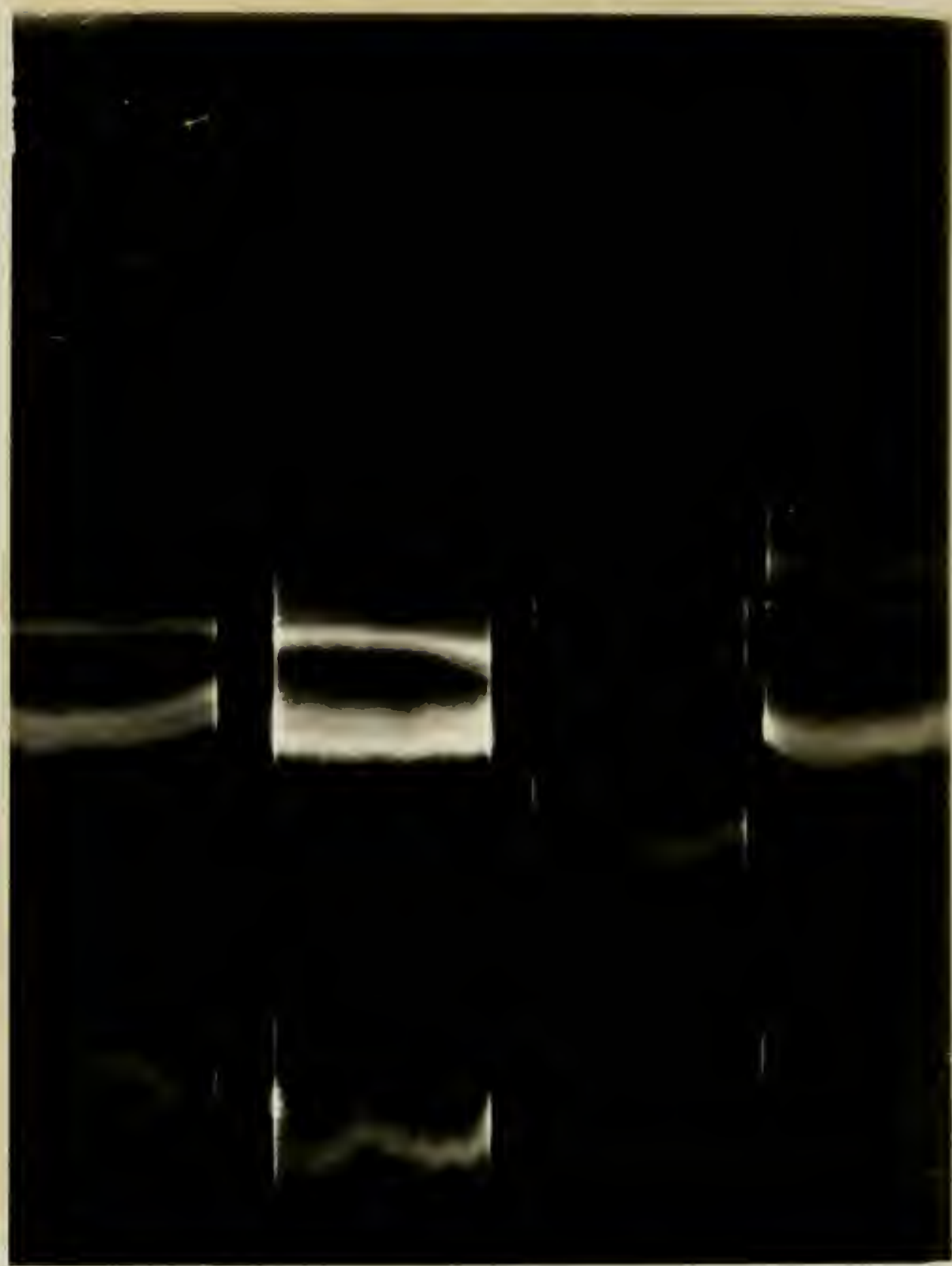

'VALENCIA'

'PINEAPPLE'

'PINEAPPLE'

'PINEAPPLE'

Fig. 8. Autoradiogram of $14 \mathrm{C}$-metabolites from 'Pineapple' and 'Valencia' orange leaves treated with IOAC-1-14C. The IOAC was applied in $2,10 \vee 1$ drops, 1 on each side of the main vein. Time of uptake of IOAC was 24 hours. Separated by paper electrophoresis in $0.4 \mathrm{~N}$ acetic acid buffer, $\mathrm{pH} 2.5$ for 4 hours at 500 volts. 


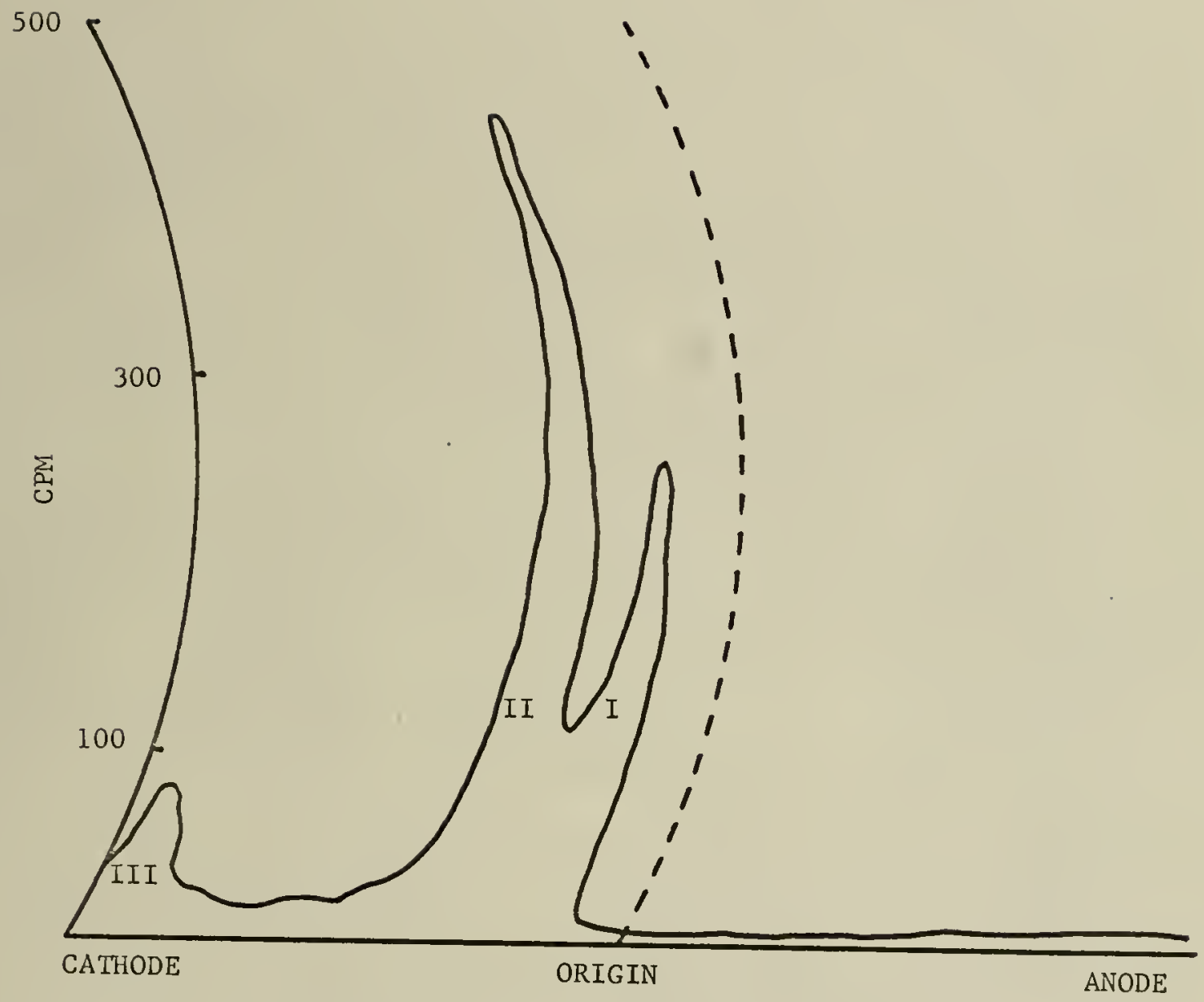

Fig. 9. Electrophoretic separation of ${ }^{14} \mathrm{C}$-metabolites resulting from drop application of IOAC $-1-14 \mathrm{C}$ to 'Pineapple' orange leaves. Developed for 4 hours at 500 volts in $0.4 \mathrm{~N}$ acetic acid buffer,
$\mathrm{pH} 2.5$. 


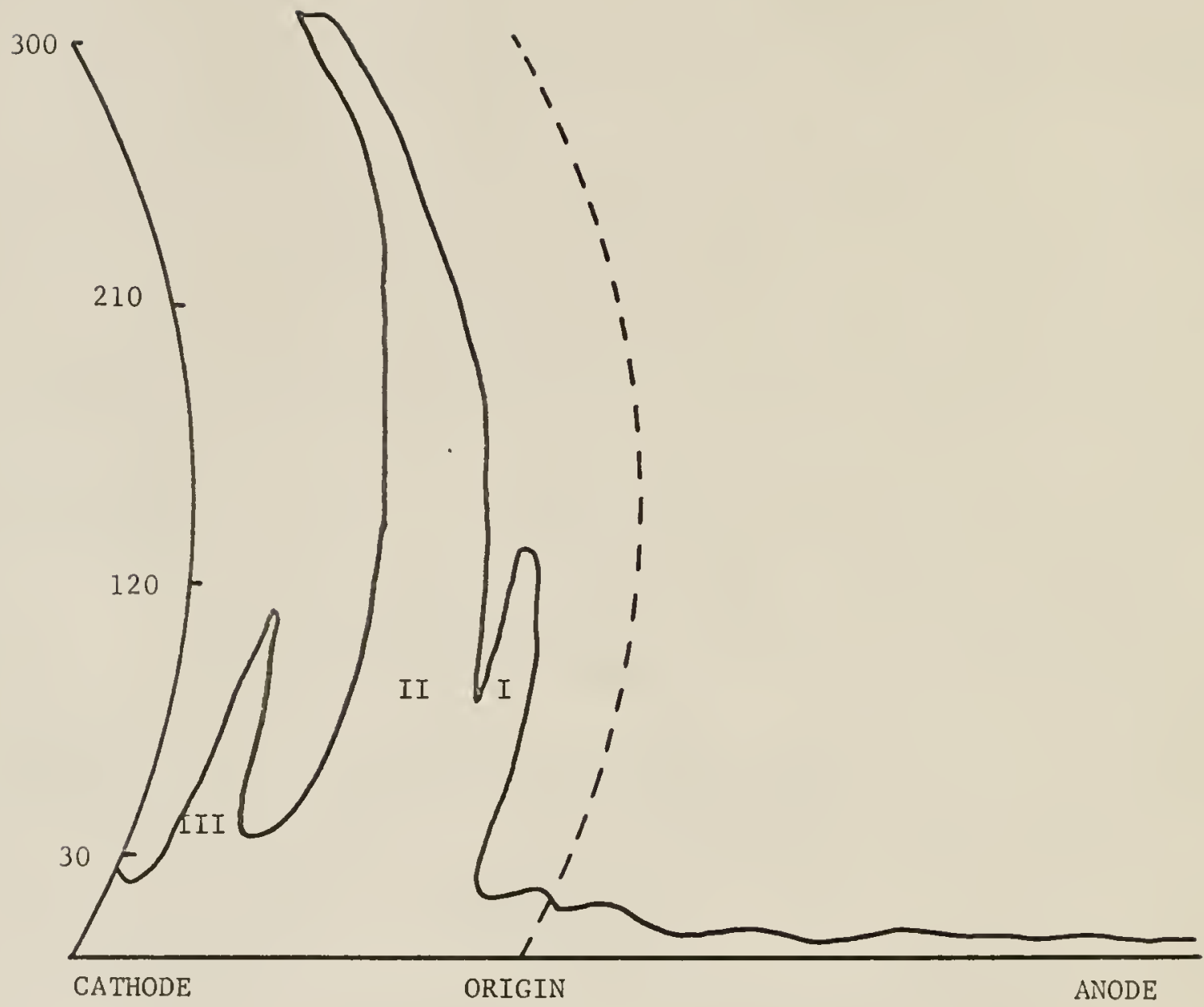

Fig. 10. Electrophoretic separation of ${ }^{14} \mathrm{C}$-metabolites resulting from drop application of IOAC-1-14C to 'Valencia' orange leaves. Developed for 4 hours at 500 volts in $0.4 \mathrm{~N}$ acetic acid buffer, $\mathrm{pH} 2.5$. 
300

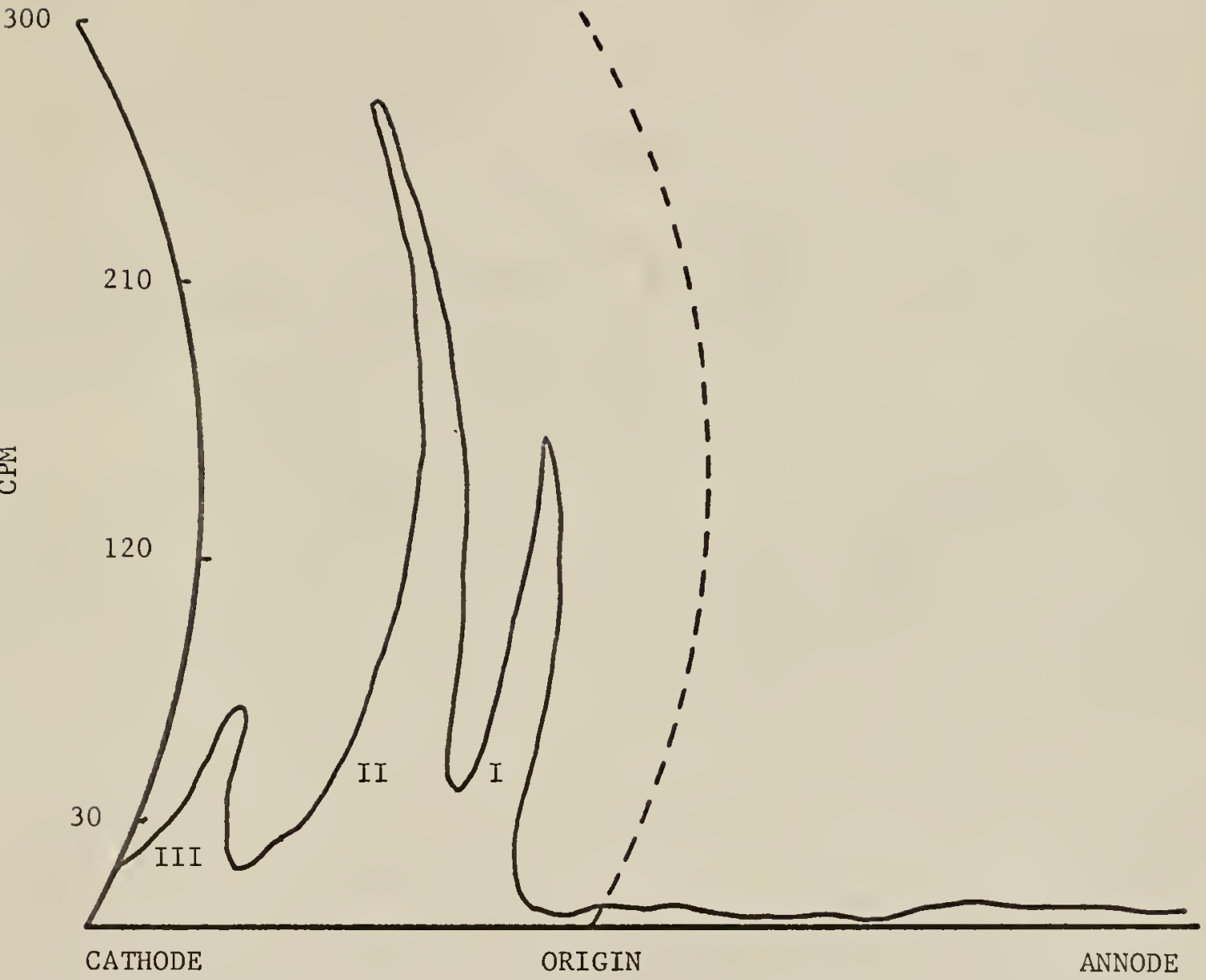

Fig. 11. Electrophoretic separation of ${ }^{14} \mathrm{C}$-metabolites resulting from drop application of IOAC-2-14C to 'Pineapple' orange leaves. Developed for 4 hours at 500 volts in $0.4 \mathrm{~N}$ acetic acid buffer, $\mathrm{pH} 2.5$. 


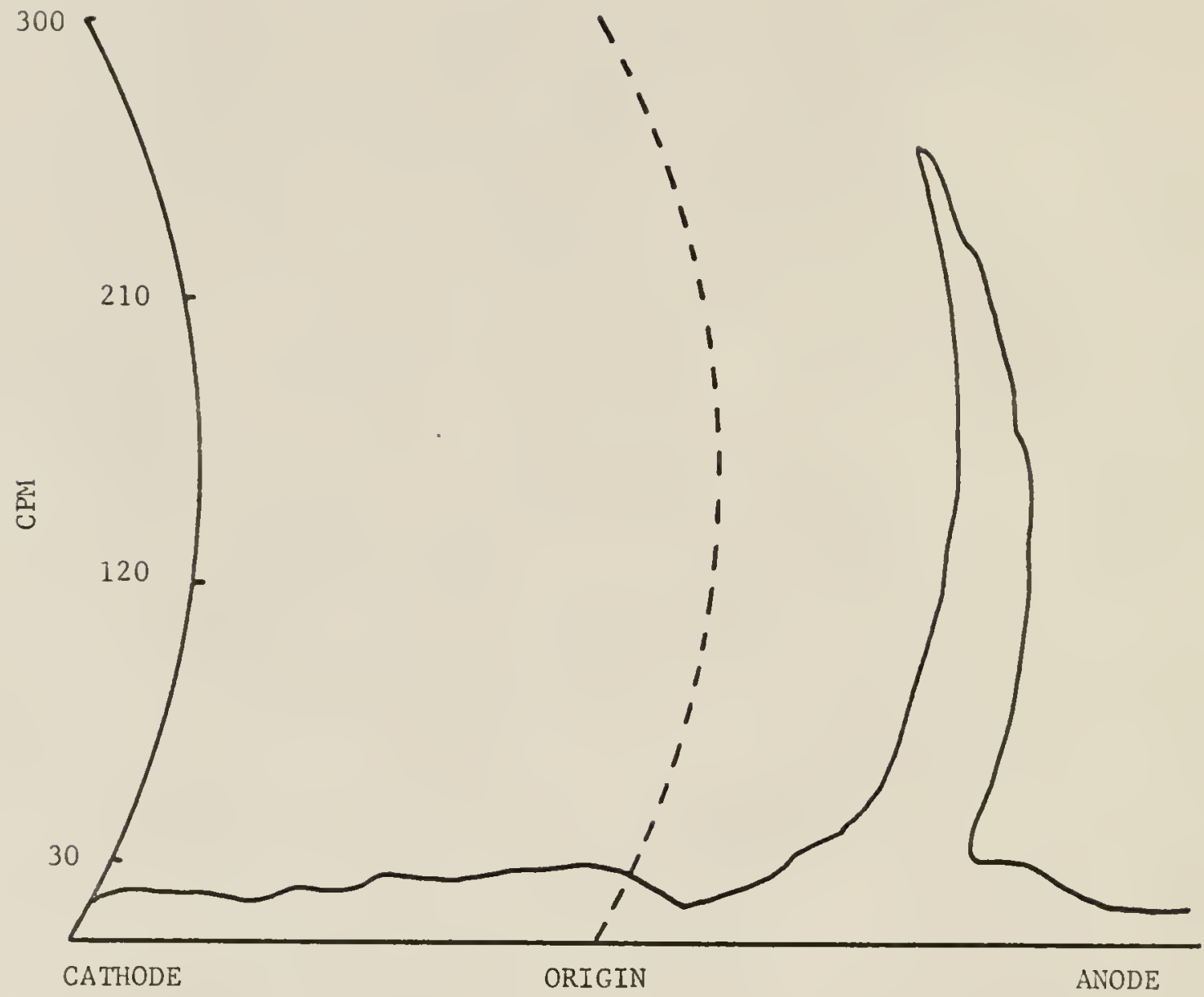

Fig. 12. Electrophoretic pattern of $5 \times 10^{-4} \mathrm{M}$ IOAC-1-14 C. Developed for 4 hours at 500 volts in $0.4 \mathrm{~N}$ acetic acid buffer, $\mathrm{pH} 2.5$. 

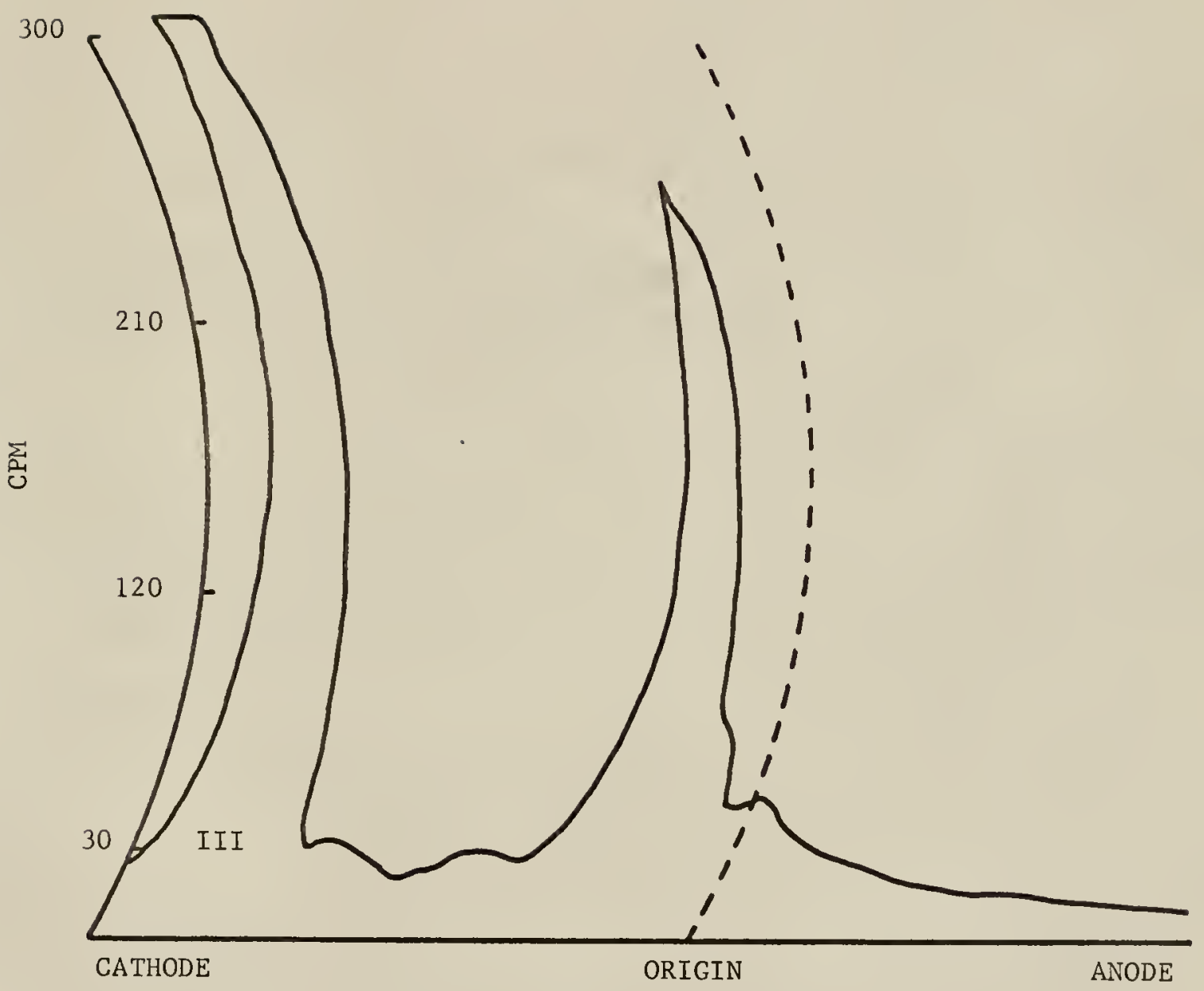

Fig. 13. Electrophoretic separation of ${ }^{14} \mathrm{C}$-metabolites resulting from drop application of IOAC-1-14 C to 'Pineapple' orange leaves. Metabolites appearing during 24-48 hours'dialysis time. Developed for 4 hours at 500 volts in $0.4 \mathrm{~N}$ acetic acid buffer, $\mathrm{pH} 2.5$. 
Initially, an attempt was made to determine whether or not the metabolites would be formed in macerated tissue. Also, tests were conducted to see whether the compounds could be formed either in the supernatant or the residue from macerated leaves. One test was conducted in a phosphate buffer ( $\mathrm{pH}$ 6.2) system, several in water, and 1 in ethanol. In 1 test metabolites were formed from IOAC. However, in 5 subsequent tests, including the phosphate buffer experiment, no labeled metabolites were formed. This indicated that macerating the orange tissues destroyed the capacity to metabolize IOAC. In the 1 test where metabolites were found, some islands of intact living cells might have remained after the maceration.

A sample extracted from 'Pineapple' leaves treated with IOAC-1-14C was subjected to column chromatography on silicic acid in a system designed to separate flavonoid and phenolic compounds. The result was that the labeled metabolites were not readily soluble in ethyl acetate or methanol. The major part of the radioactivity appeared in the first few $10 \mathrm{ml}$ fractions of a methanol:water, $(\mathrm{v} / \mathrm{v})$ eluting solvent. Thus, the compounds that were labeled were polar in nature. Also, further separations by thin-layer chromatography of these radioactive fractions indicated that ${ }^{14} \mathrm{C}$ labeled sugars, flavonoid or phenolic compounds (Fig. 14) were not formed as a result of the metabolism of IOAC. Paper chromatography of 2 of the most radioactive fractions showed the presence of 3 labeled compounds, 2 of which reacted to ninhydrin. These 2 corresponded in $R_{f}$ values to glutamic and aspartic acids (Table 12). This indicated that at least the carboxyl carbon of IOAC is metabolized to amino acids. Electrophoretic separation of the fractions with the highest amount of radioactivity after elution from the silicic acid column showed that only 2 of the 3 major metabolites had been recovered. 
Fig. 14. Autoradiogram of polyamide thin-layer sheet separation of $14 \mathrm{C}$-metabolites formed by 'Pineapple' orange leaves treated with IOAC-1-14C. A sample of the water extract was fractionated on a silicic acid column. These radioactive fractions, appearing at the start of a methanol:water, $v / v$ elution sequence, were developed on a polyamide thin-layer sheet 3 times in methanol:nitromethane, $2: 5, \mathrm{v} / \mathrm{v}$.

The circles depict the compounds visualized with ethanolic aluminum chloride. Tentative identification is given for some of the non-labeled metabolites. Code: P=prunin; $\mathrm{N}=$ naringin; $\mathrm{R}=$ rhoitolin.

\section{Fraction}

$\begin{array}{llllll}1- & 111-114 & 7- & 126-129 & 13- & 143-145 \\ 2- & 115 & 8- & 130 & 14- & 146-147 \\ 3- & 116-119 & 9- & 131-134 & 15- & 148-149 \\ 4- & 120 & 10- & 135 & 16- & 181-182 \\ 5- & 121-124 & 11- & 140 & 17- & \text { Naringin } \\ 6- & 125 & 12- & 141-142 & & \end{array}$




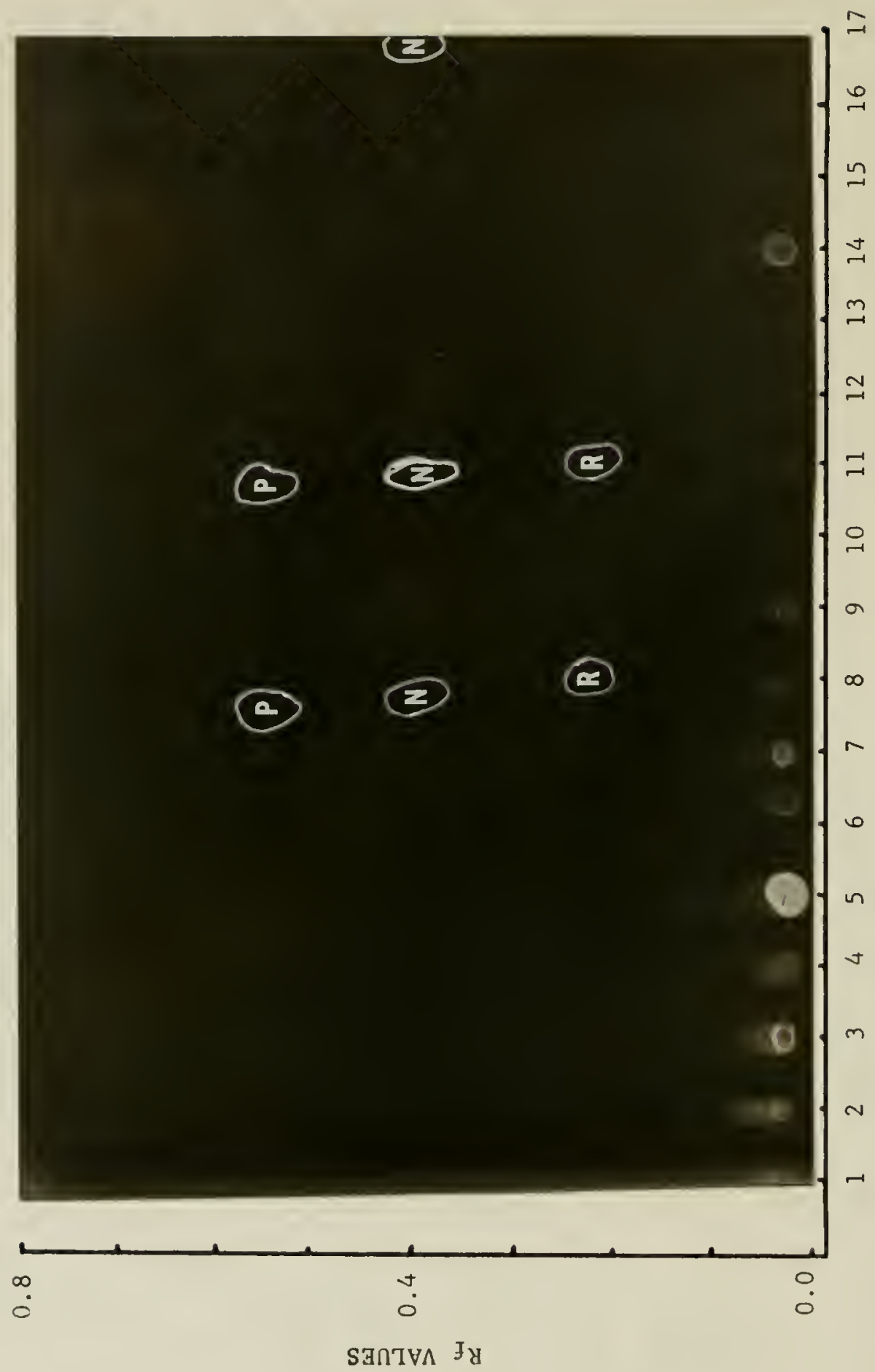


Table 12. Rf values from paper chromatograms of labeled metabolites formed by 'Pineapple' orange leaves treated with IOAC-1-14 C.

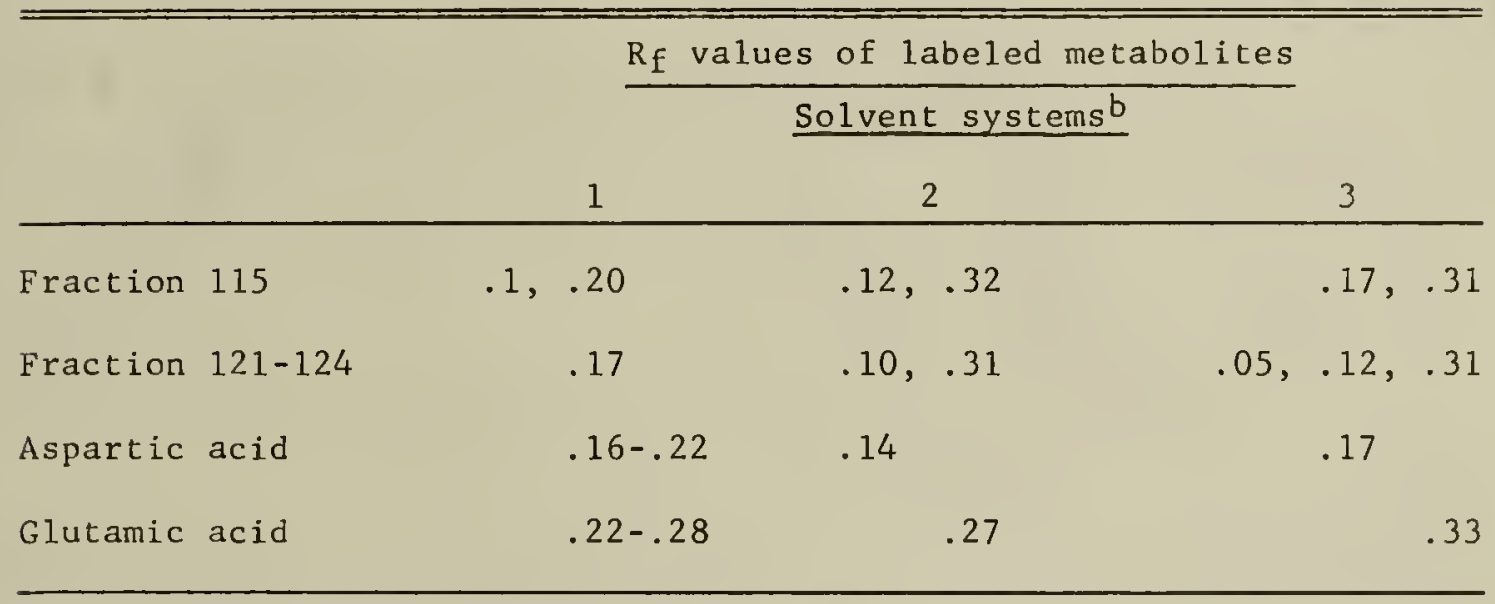

a The IOAC was applied in $2,10 \vee 1$ drops, 1 on each side of the main vein. Time of uptake of IOAC was 24 hours. Fractions were eluted from a silicic acid column with methanol:water, $v / v$, and spotted on Whatman 非 1 .

$\mathrm{b}_{1}$ - Butanol:water:acetic acid, 4:5:1, v/v/v (upper phase).

2 - Methanol:water:acetic acid, 19:1:1, v/v/v.

3 - Phenol:water, $100: 20, \mathrm{v} / \mathrm{v}$ in $0.04 \%$-hydroxyquinoline. 
The other metabolite could have been present in some other fraction or it could have remained on the column. The latter was shown to be more likely because subsequent tests showed that if the extract was dried in the presence of silicic acid, then most of the radioactivity was irreversibly bound to the silicic acid, i.e., could not be removed by water.

'Pineapple' and 'Valencia' orange leaves formed the same metabolites when treated with IOAC-1-14C. However, the amount of radioactivity in 'Pineapple' leaves treated the same as 'Valencia' leaves was approximately 3 times greater (Tables 7 and 8 ). This would seem to indicate that IOAC was either more readily absorbed into 'Pineapple' leaves than it was into 'Valencia' leaves, or that the resulting metabolites were less readily translocated out of 'Pineapple' leaves. Acetate Metabolism by Orange Leaves

'Pineapple' orange leaves treated with acetate-1-14C in the same manner as those treated with IOAC-14 C resulted in a slightly different pattern of metabolites. Less radioactivity remained inside the dialysis membrane with acetate treated leaves (Table 11) than was present in IOAC treated leaves. A greater percentage of the radioactivity extracted by water was partitioned into the acidic ether fraction, indicating either more acetate present or a larger percentage of acidic materials labeled. There was little radioactivity remaining in the leaf residue material, indicating little production of non-water soluble materials. The amount of radioactivity absorbed, however, was not enough to permit separation by either paper chromatography or paper electrophoresis. For this reason, the petiole-absorption technique was used as it resulted in a much greater uptake of the acetate $-1-14 \mathrm{C}$. 
Metabolism of IOAC Applied to the Leaves by Petiole Uptake Amount of Free IOAC Remaining in the Tissues

The amount of unmetabolized IOAC remaining in the 'Pineapple' and 'Valencia' leaves after uptake for 2 hours was found to be not greater than $30 \%$ of the total extractable radioactivity. This was calculated from the total radioactivity in the acidic and neutral fractions(water fraction) from a Dowex 50-X8 column (Table 13). Subsequent separation of this fraction by paper chromatography showed that at least 1 other metabolite was present in both varieties (Figs. 15 and 16). The results indicated that the free IOAC $\left(R_{f} .72-.74\right)$ represented a small fraction of the $30 \%$ radioactivity in the acidic and neutral fraction. This compared favorably with the approximate $5 \%$ free IOAC value obtained in the drop application experiments.

Further fractionation of the water fraction (from the Dowex 50-X8 column) on a Dowex $1-X 8$ column (formate) with subsequent thin-layer separation on Eastman chromagram silica gel films, showed that labeled compounds appeared in the water washes and in the $1 \%$ formic acid elution (Fig. 17, numbers 1 and 3 ). Since these compounds were initially eluted from a Dowex 50-X8 column in the water wash, they were probably either neutral or acidic in nature.

Metabolites Formed as a Result of Petiole Uptake of Carboxyl and MethylLabeled IOAC

'Pineapple' and 'Valencia' orange leaves both metabolized either IOAC $-1-14 \mathrm{C}$ or IOAC $-2-14 \mathrm{C}$ to the same compounds found in either the water or the ammonium fractions eluted from the Dowex 50-X8 column (water fraction metabolites discussed previously): The $\mathrm{R}_{\mathrm{f}}$ values of the various metabolites determined from paper chromatograms in 3 solvent systems clearly show that in all cases the same metabolites were formed (Tables 
Table 13. Distribution of radioactivity in ethanolic ammonium and water fractions collected from a Dowex 50-x8 column.

\begin{tabular}{lcccc}
\hline & \multicolumn{2}{c}{ Percent radioactivity in fractions } \\
\cline { 3 - 5 } Sample & Water & Ammonium & Water & Ammonium \\
\hline 'Pineapple' acetate-1-14 C & 86 & 14 & 80 & 20 \\
'Valencia' acetate-1-14C & 83 & 17 & 89 & 11 \\
'Pineapple' IOAC-1-14C & 59 & 41 & 23 & 77 \\
'Valencia' IOAC-1-14C & 16 & 84 & 29 & 71 \\
'Pineapple' IOAC-2-14C & 21 & 79 & 33 & 67 \\
'Valencia' IOAC-2-14C & 33 & 67 & 16 & 84 \\
'Pineapple' I3lIOAC & 98 & 2 & 98 & 2 \\
\hline
\end{tabular}

aEtracts of 'Pineapple' and 'Valencia' orange leaves in which either IOAC $-1-14 \mathrm{C}$, IOAC $-2-14 \mathrm{C}, 131$ IOAC, or acetate-1-14C were applied by petiole uptake. Uptake time was 1 hour, after which the leaves were placed in water for an additional hour. 


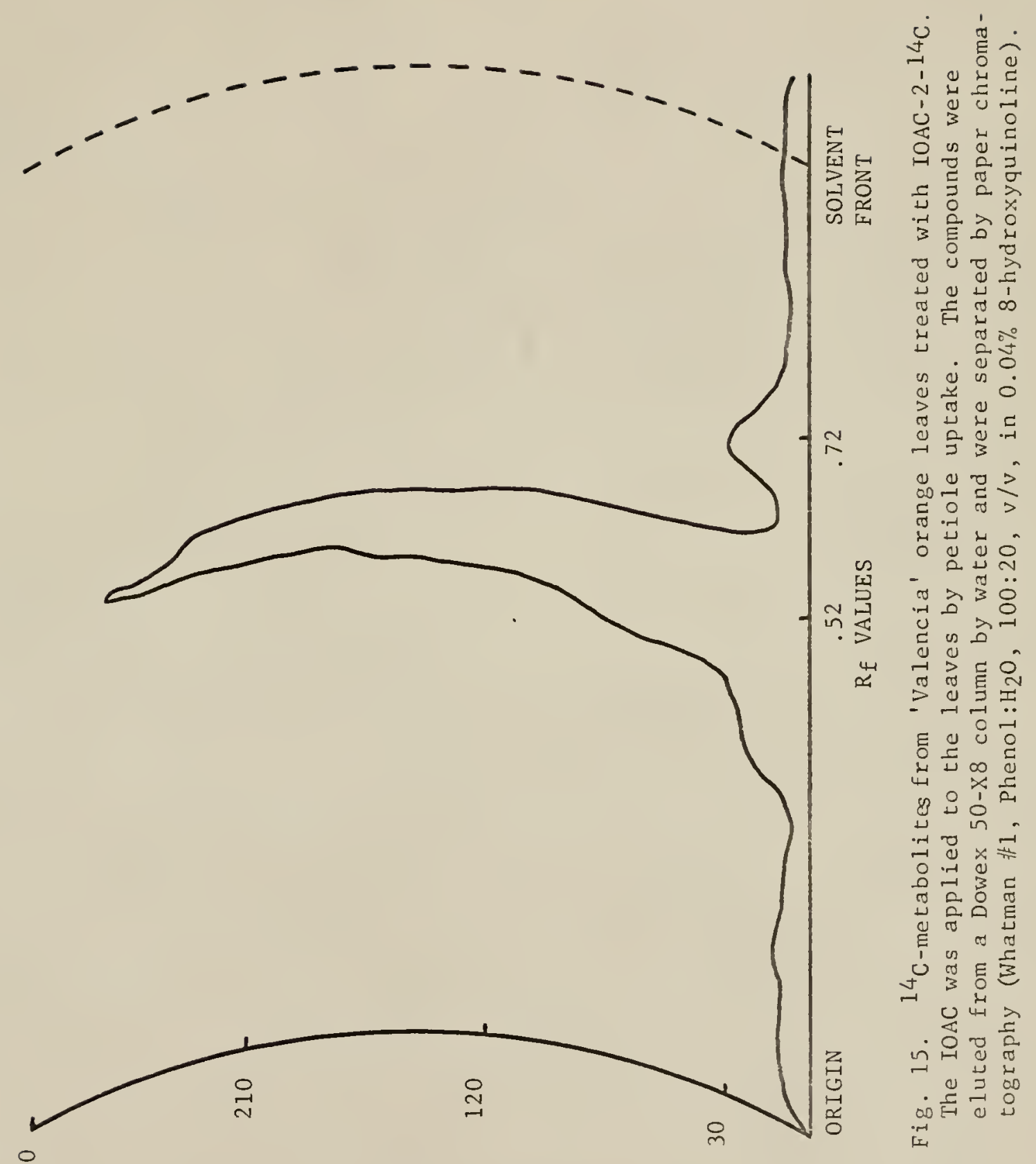

พมว 


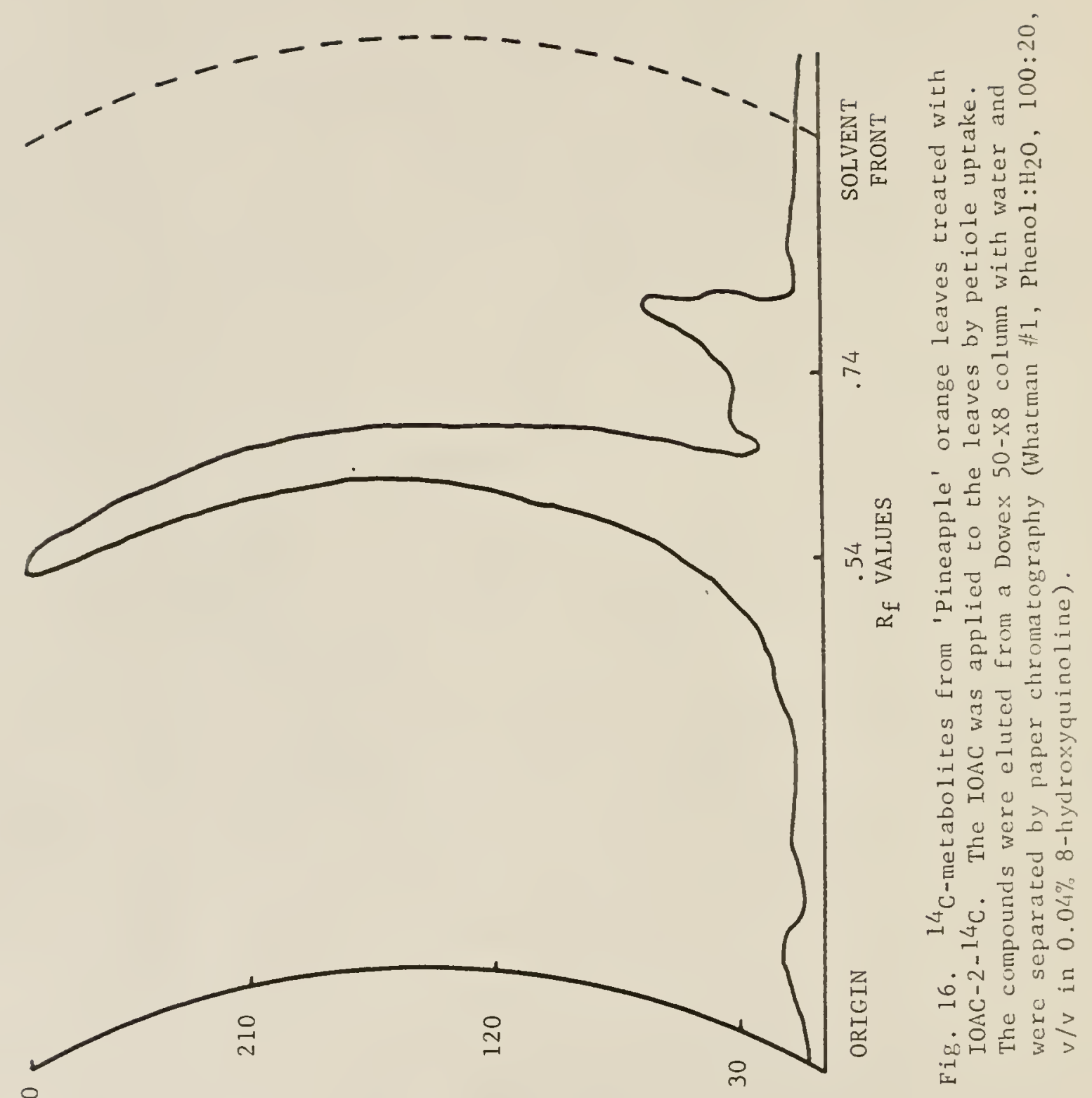

พสว 

Fig. 17. ${ }^{14} \mathrm{C}$-metabolites from 'Pineapple' orange leaves treated with either IOAC-1-14 C or acetate-1-14 C. The radioactive compounds were applied to the leaves by petiole uptake. Time of absorption was 1 hour, after which the leaves were transferred to water for an additional hour. The leaf extracts were eluted from a Dowex 1-X8 column (formate) and separated on Eastman chromagram silica gel thin-layer films. Developing solvent was butanol:water:acetic acid, $4: 5: 1, \mathrm{v} / \mathrm{v} / \mathrm{v}$ (upper phase).

The circles depict compounds positive to bromcresol green .

\section{Fraction}

1 IOAC $-1-14 \mathrm{C}$,

2 acetate $-1-14 \mathrm{C}$,

3 IOAC $-1-14 \mathrm{C}$,

4 acetate $-1-14 \mathrm{C}$,

5 IOAC $-1-14 \mathrm{C}$,

6 acetate $-1-1{ }^{4} \mathrm{C}$,

7 IOAC $-1-14 \mathrm{C}$,

8 acetate $-1-14 \mathrm{C}$, water fraction, water fraction, water fraction, water fraction, water fraction, water fraction, water fraction, water fraction,
$2,3,4$, water washes.

$2,3,4$, water washes.

$1 \%$ formic acid elution.

$1 \%$ formic acid elution.

$5 \%$ formic acid elution.

$5 \%$ formic acid elution.

$40 \%$ formic acid elution. $40 \%$ formic acid elution. 


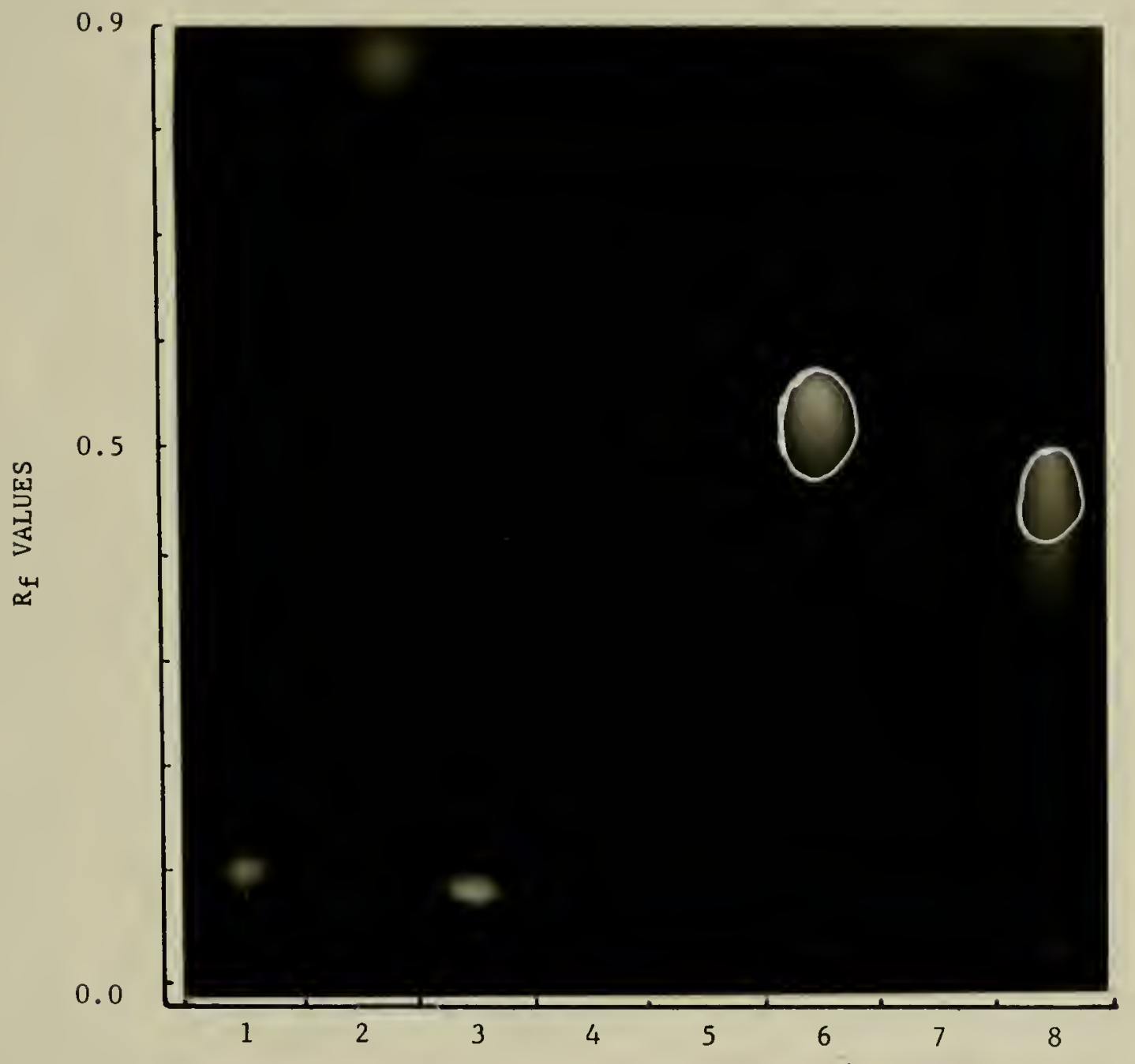


14, 15, and 16). A comparison of these $R_{f}$ values with standard $R_{f}$ values indicated that at least 2 of the components in every solvent system correspond to glutamic and aspartic acids. These unknown compounds were positive to nlahydrin. Thus, they were tentatively identified as being glutamic and aspartic acids. The other metabolites were not identified.

A scan of the ammonium eluted fraction from a polystyrene column shows the presence of 6 labeled metabolites in 'Pineapple' orange leaves (Fig. 18). This is in agreement with the results obtained by paper chromatography in a butanol solvent system in which there were also 6 metabolites. However, the fractions from the polystyrene column were monitored for radioactivity but not collected; therefore, no $\mathrm{R}_{\mathrm{f}}$ values from other forms of chromatography were obtained.

The 'Pineapple' water and ammonium fractions from the hydrogen column, separately, were also eluted from a formate column. These fractions from the formate column were further separated by paper chromatography using 3 solvent systems. Again, in the ammonium fraction sample.from the Dowex 50-X8 column (fractionated on the formate column), 2 of the spots reacted to ninhydrin and these had the same $R_{f}$ values as glutamic and aspartic. In fact, the "fit" of the compounds eluted from the formate column was better than that from the Dowex 50-X8 column ammonium eluted compounds, probably because the extract contained fewer components ( $R_{f}$ values - Tables 17,18 , and 19). These same fractions from the Dowex 1-X8 column (formate) were also separated by thin-1ayer chromatography using Eastman chromagram thin-layer chromatographic films. Again, 2 radioactive, ninhydrin positive spots, corresponding to glutamic and aspartic acids, were separated from the $1 \%$ formic acid elution (Fig. 19, number 3 ). These components also gave the correct ninhydrin colored 


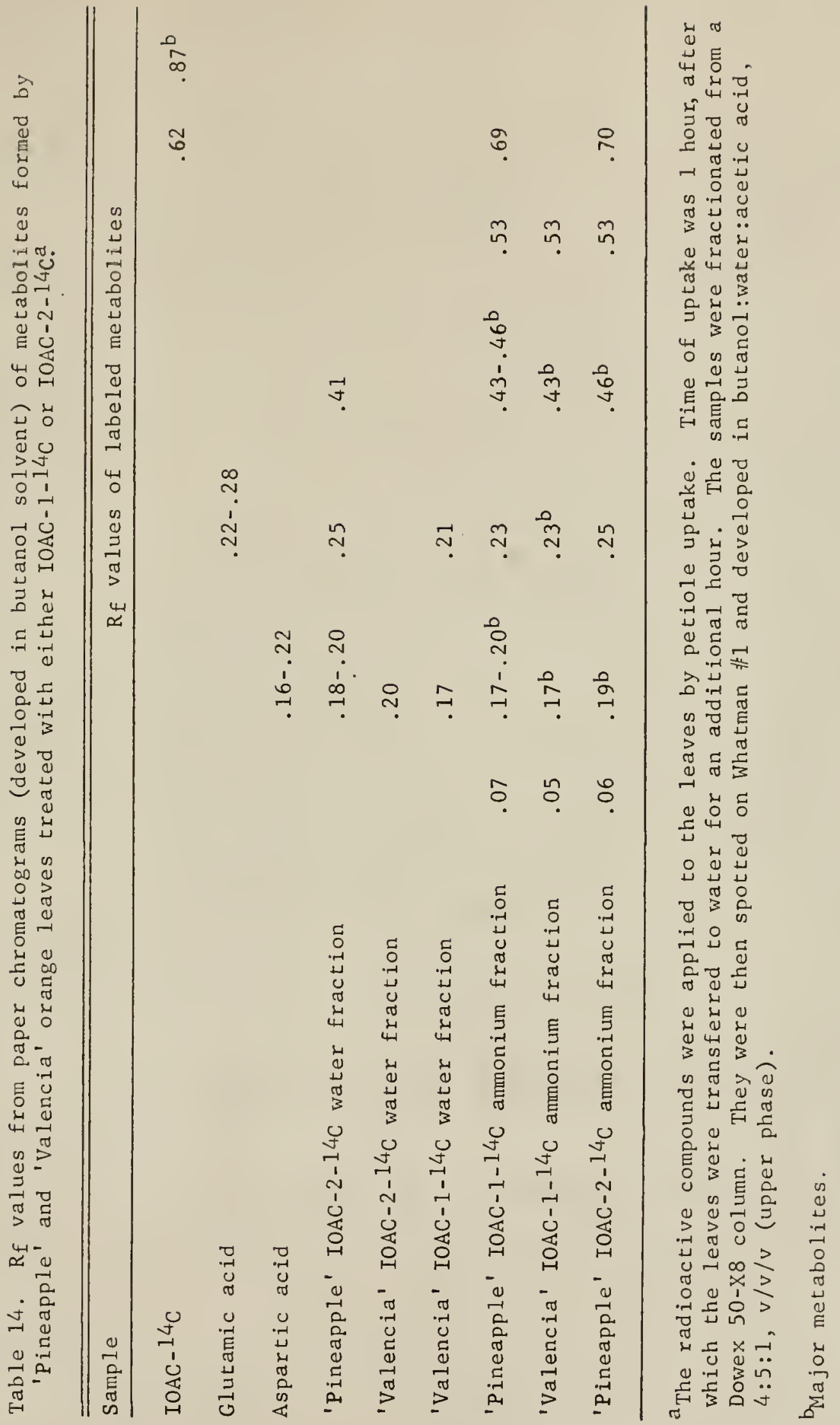




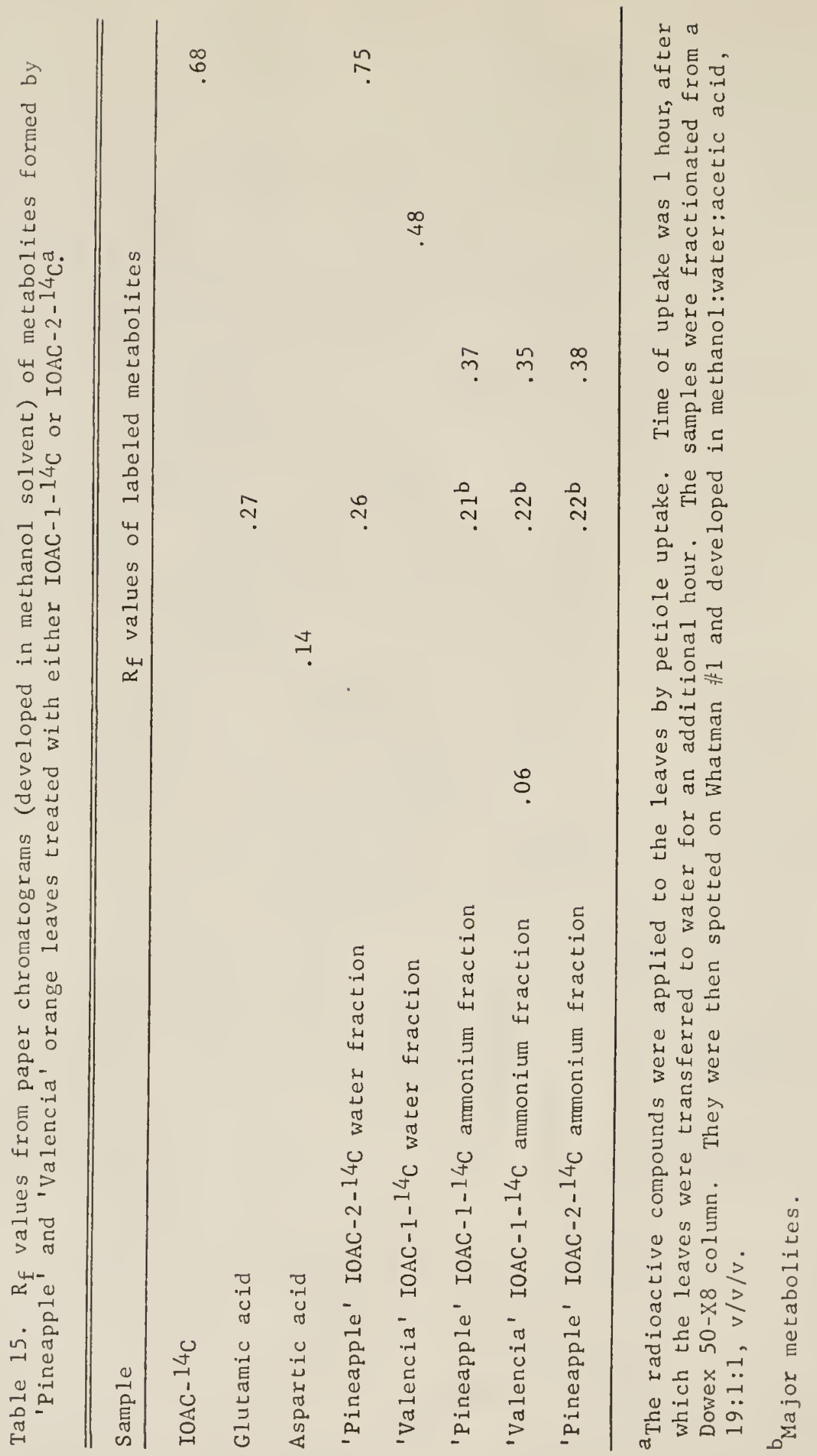




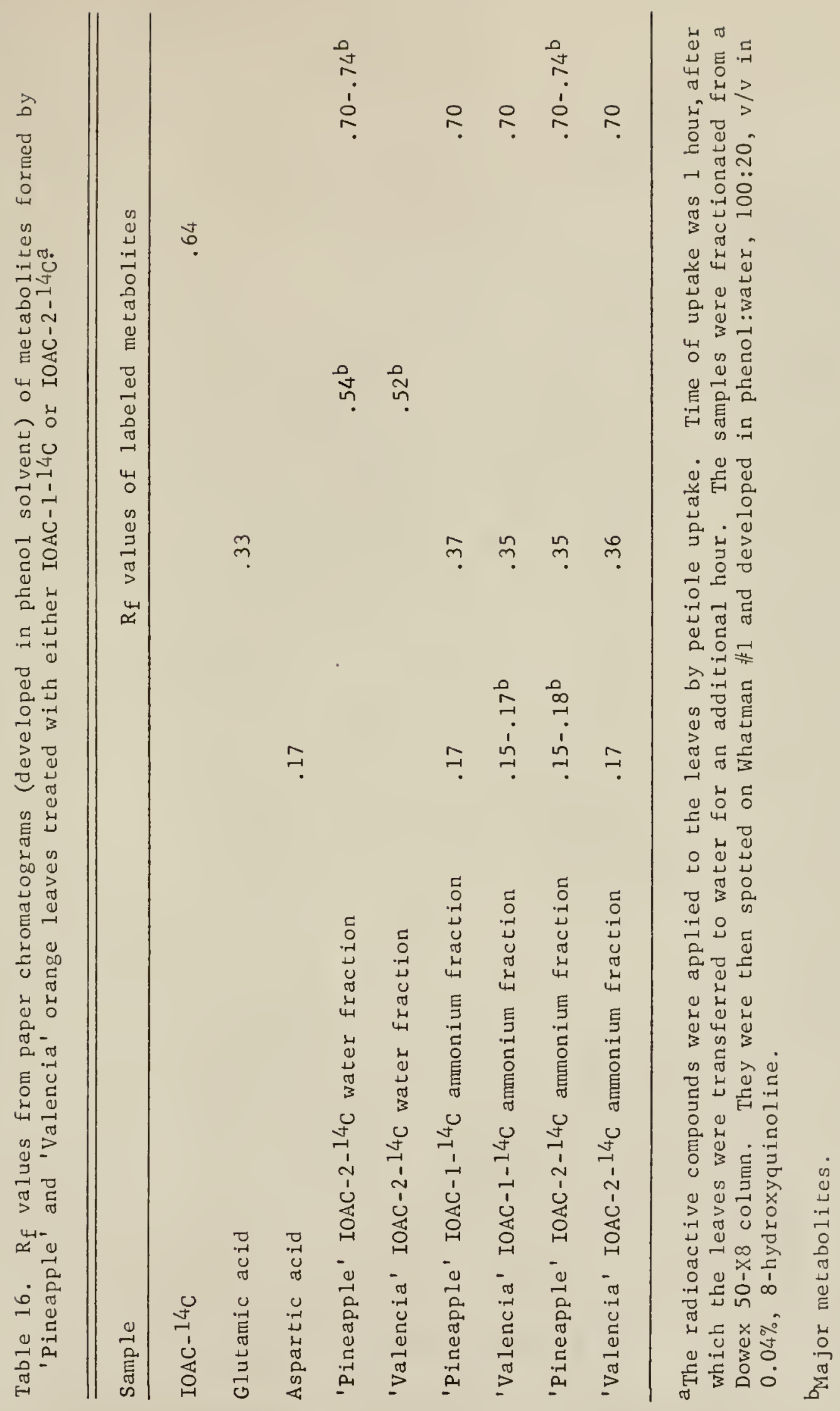




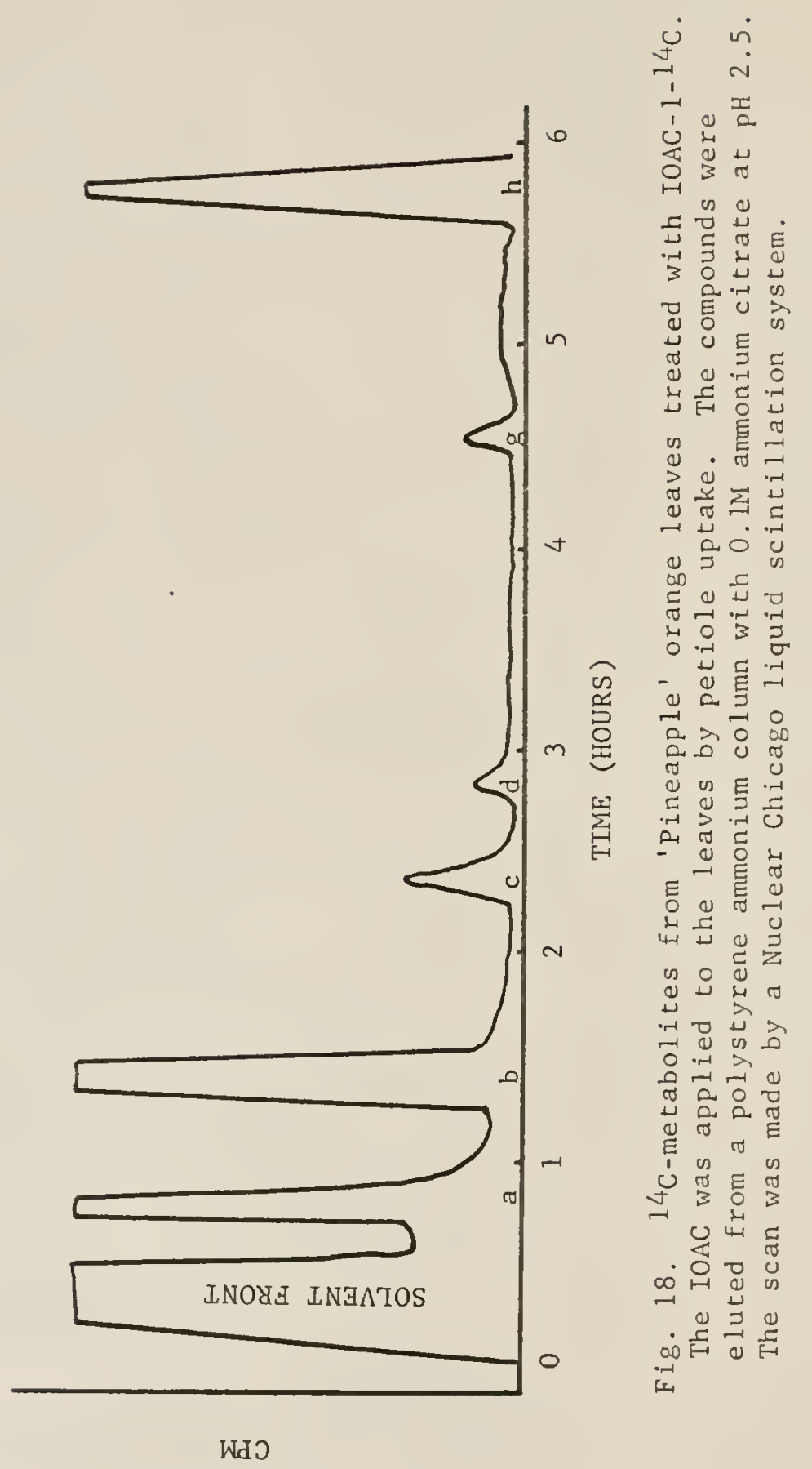




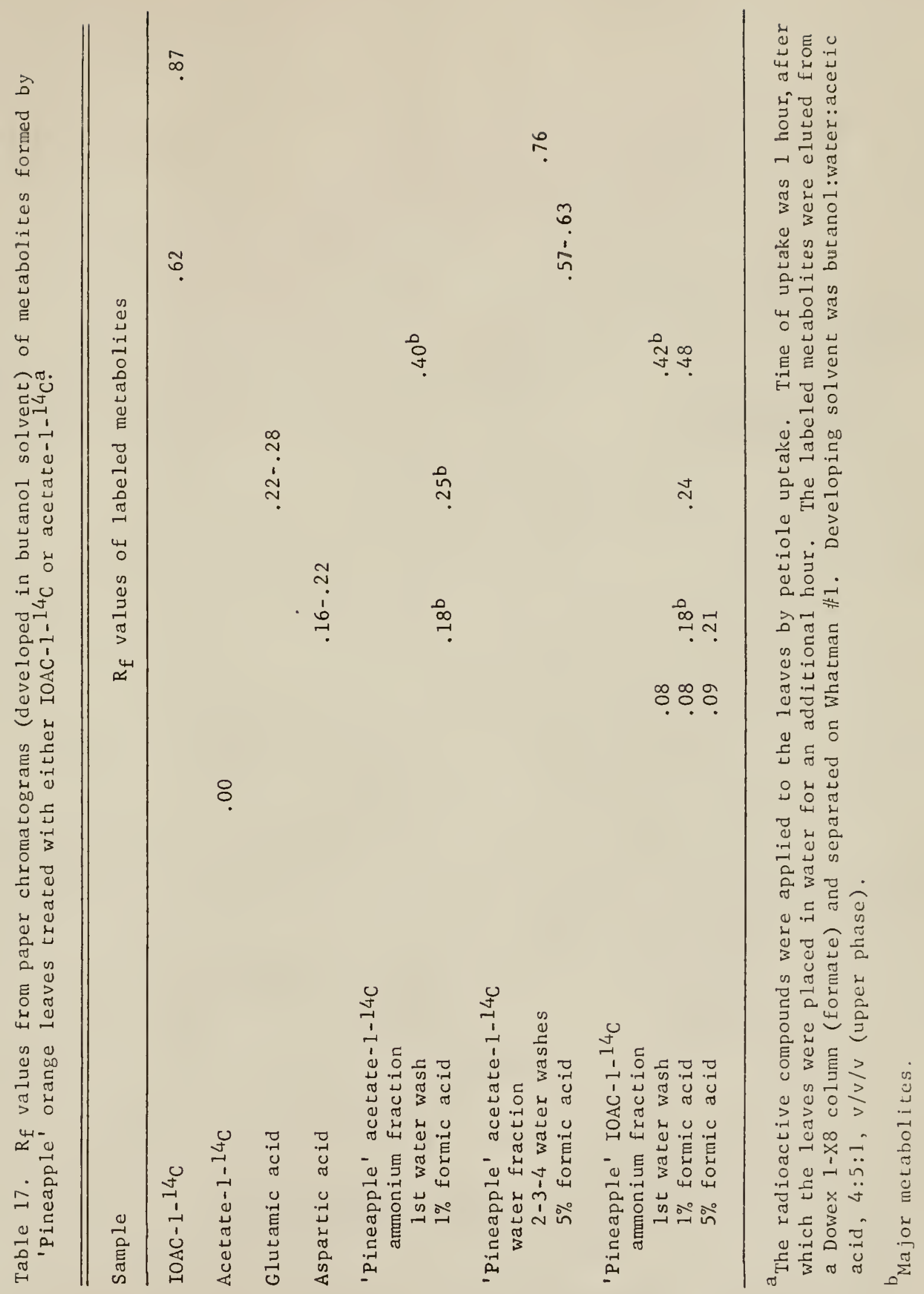




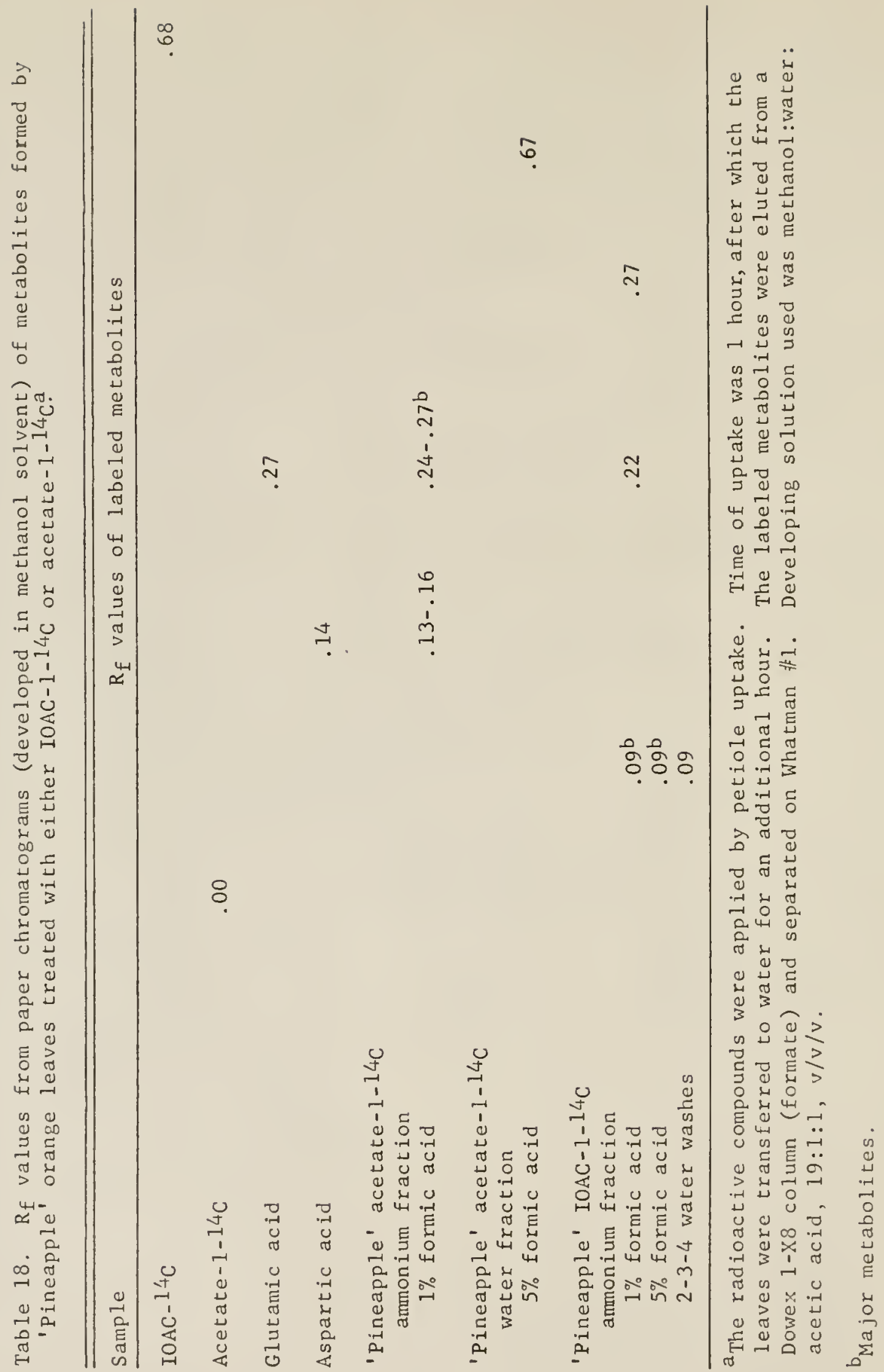




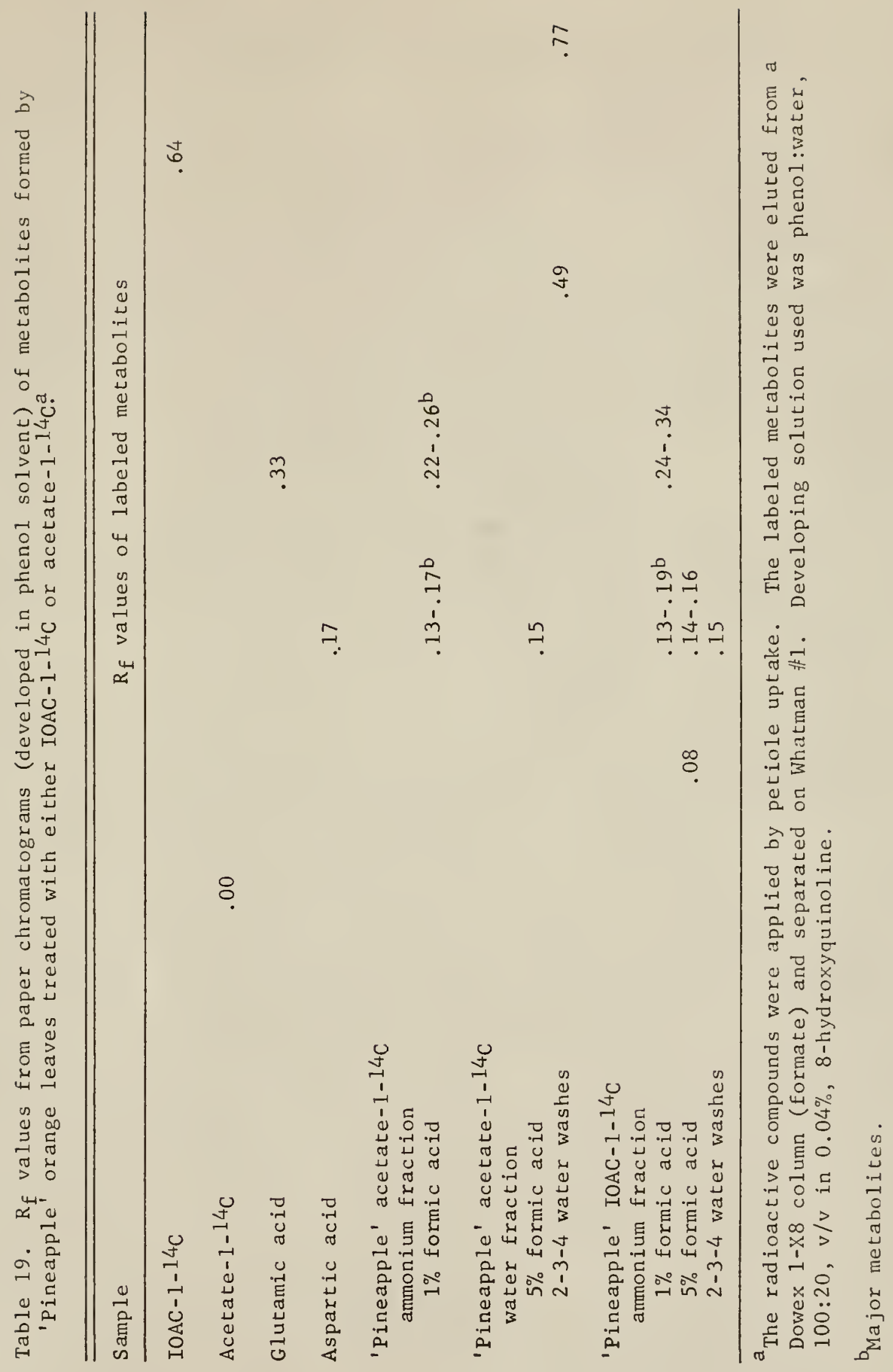


Fig. 19. ${ }^{14} \mathrm{C}$-metabolites from 'Pineapple' orange leaves treated with either IOAC-1-14 C or acetate-1-14 C. The radioactive compounds were applied to the leaves by petiole uptake. Time of uptake was 1 hour, after which the leaves were placed in water for an additional hour. The leaf extracts were eluted from a Dowex 1-X8 column (formate) and separated on Eastman chromagram silica gel sheets. Developing solution was butanol:water: acetic acid, 4:5:1, v/v/v (upper phase).

The circles designate metabolites that were positive to ninhydrin ( $0.25 \%$ in acetone). Color code: $P=$ purple, $B=b l u e$.

\section{Fraction}

1 IOAC $-1-1{ }^{14} \mathrm{C}$,

2 acetate-1-14 C,

3 IOAC $-1-14 \mathrm{C}$,

4 acetate $-1-14 \mathrm{C}$,

5 IOAC $-1-1{ }^{4} \mathrm{C}$,

6 IOAC $-1-14 \mathrm{C}$,

7 glutamic acid.

8 aspartic acid.

9 alanine. lst water wash.

lst water wash.

ammonium fraction, $1 \%$ formic acid elution.

ammonium fraction, $1 \%$ formic acid elution.

ammonium fraction, $5 \%$ formic acid elution.

ammonium fraction, 2, 3, 4 water washes. 


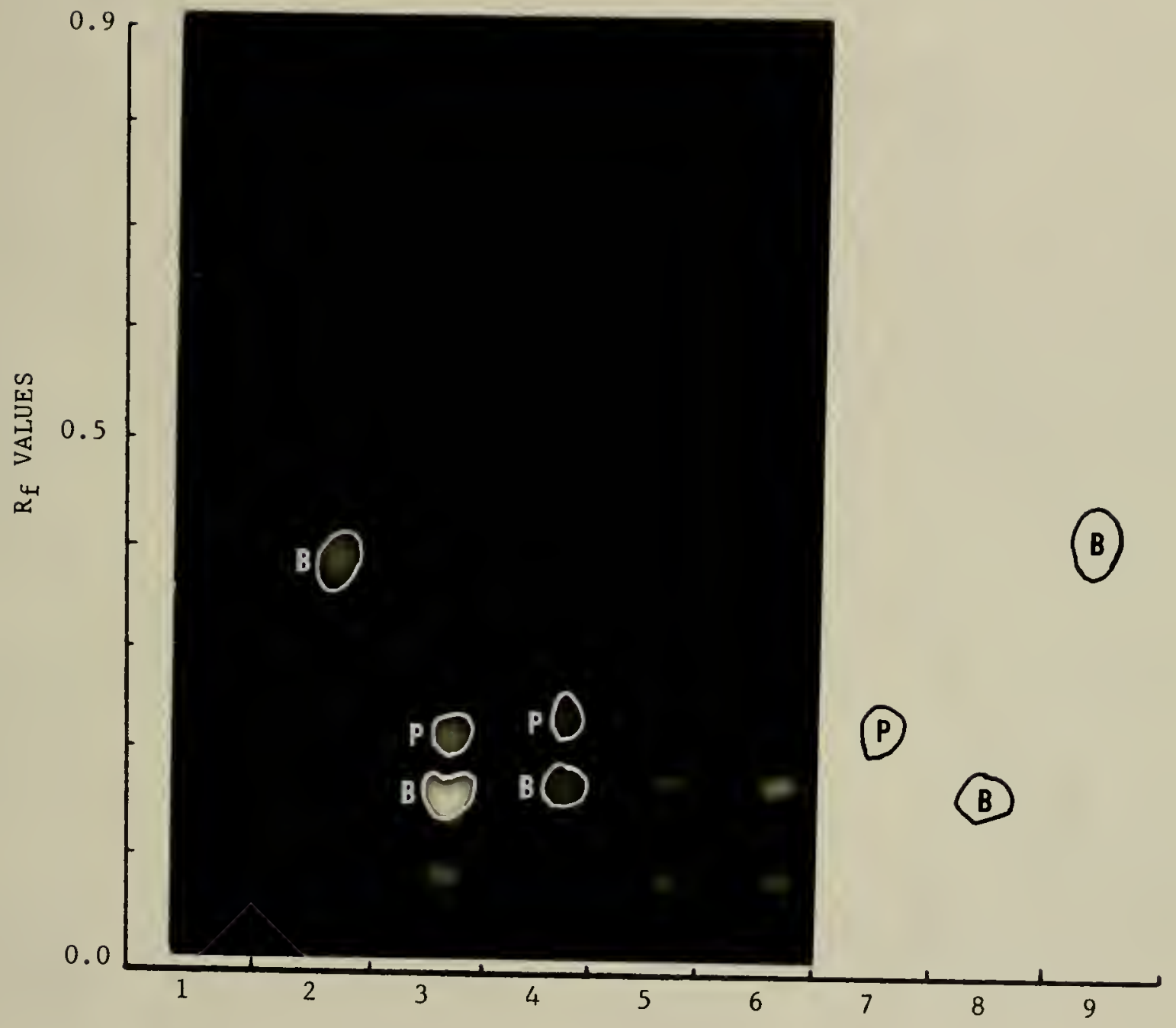


chromaphore for the 2 amino acids (blue for aspartic, and purple for glutamic). There were 2 other metabolites in this elution fraction that did not react to ninhydrin, but 1 of them corresponded closely to ninhydrin positive(Fig. 19, number 2) compound obtained from the metabolism of acetate by 'Pineapple' leaves. Two metabolites also were present in the $5 \%$ formic acid wash (Fig. 19, number 5) and these same 2 were in the combined water wash (Fig. 19, number 6). These did not react to ninhydrin even though 1 had an $R_{f}$ similar to aspartic acid. However, since it failed to react with ninhydrin and since it was eluted from the column later than aspartic acid, it would seem that it was a different compound. Metabolites Formed as a Result of Acetate- $1-14 \mathrm{C}$ Metabolism

Within the 2-hour uptake time interval of the experiment all of the acetate in the 'Pineapple' leaves had been metabolized, since subsequent separation of the extraction solution failed to detect any free acetate. However, approximately $75 \%$ of $14 \mathrm{C}$-acetate either was exchanged or was volatile in the solvent systems used. Thus, if any acetate was unmetabolized, it would probably be lost in the chromatography systems. Approximately $80 \%$ of the extracted radioactivity came through in the water wash of the Dowex 50-X8 column, indicating that the majority of the radioactivity was in acidic (if not acetate) or neutral compounds (Table 13). This was almost an exact reverse of the IOAC-14C metabolites since most of these were in the ammonium fraction. No substantial radioactivity remained behind in the leaf residue material. At least 2 metabolites were present in the water fraction (Table 17). There were also at least 3 (Table 17) labeled metabolites in the ammonium fraction from the Dowex 50-X8 column which had been, in turn, fractionated on a formate column. Two of these metabolites (in the ammonium fraction) were ninhydrin 
positive and corresponded to glutamic and aspartic acids, as did the IOAC $-{ }^{14} \mathrm{C}$ metabolites.

Thin-layer chromatography of the ammonium fraction (from the Dowe 50-X8 column) further eluted from a formate column, showed that 2 ninhydrin-positive, radioactive metabolites were present in the $1 \%$ formic acid eluting fraction (Fig. 19, number 4) with similar Rf values to those of glutamic and aspartic acids. The first water wash from the formate column also removed a radioactive, ninhydrin-positive metabolite (Fig. 19, number 2). However, the $R_{f}$ value was $\sim 0.36$ and the closest amino acid was alanine at 0.40 . The crude extract had previously been checked for phenolic amine activity. Since no phenolic amines were labeled, this metabolite with an $R_{f}$ of 0.36 could possibly be alanine. Thin-layer chromatography of the water fraction (from the Dowex 50-x8 column) further eluted from a formate column showed that at least 1 metabolite was present in the $5 \%$ formic acid elution and that this metabolite was probably acidic since it formed a yellow chromaphore with bromcresol green (Fig. 17, number 6). Another metabolite with almost the same $R_{f}$, but appearing in the $40 \%$ formic acid wash, was also acidic (Fig. 17, number 8).

Separation of the metabolites on a polystyrene column showed that there were 4 metabolites in the ammonium fraction from this column (Fig. 20). Two components (peaks $c$ and $h$ ) were common to both IOAC metabolism and acetate metabolism (compare Figs. 18 and 20 with Fig. 21 which was a scan of a composite sample). Therefore, since the metabolism of IOAC produced some compounds similar to those formed when acetate was metabolized, it would appear that some of the IOAC was metabolized as acetate. However, it was clear that there was a difference between the metabolism of IOAC and that of acetate in 'Pineapple' leaves. 


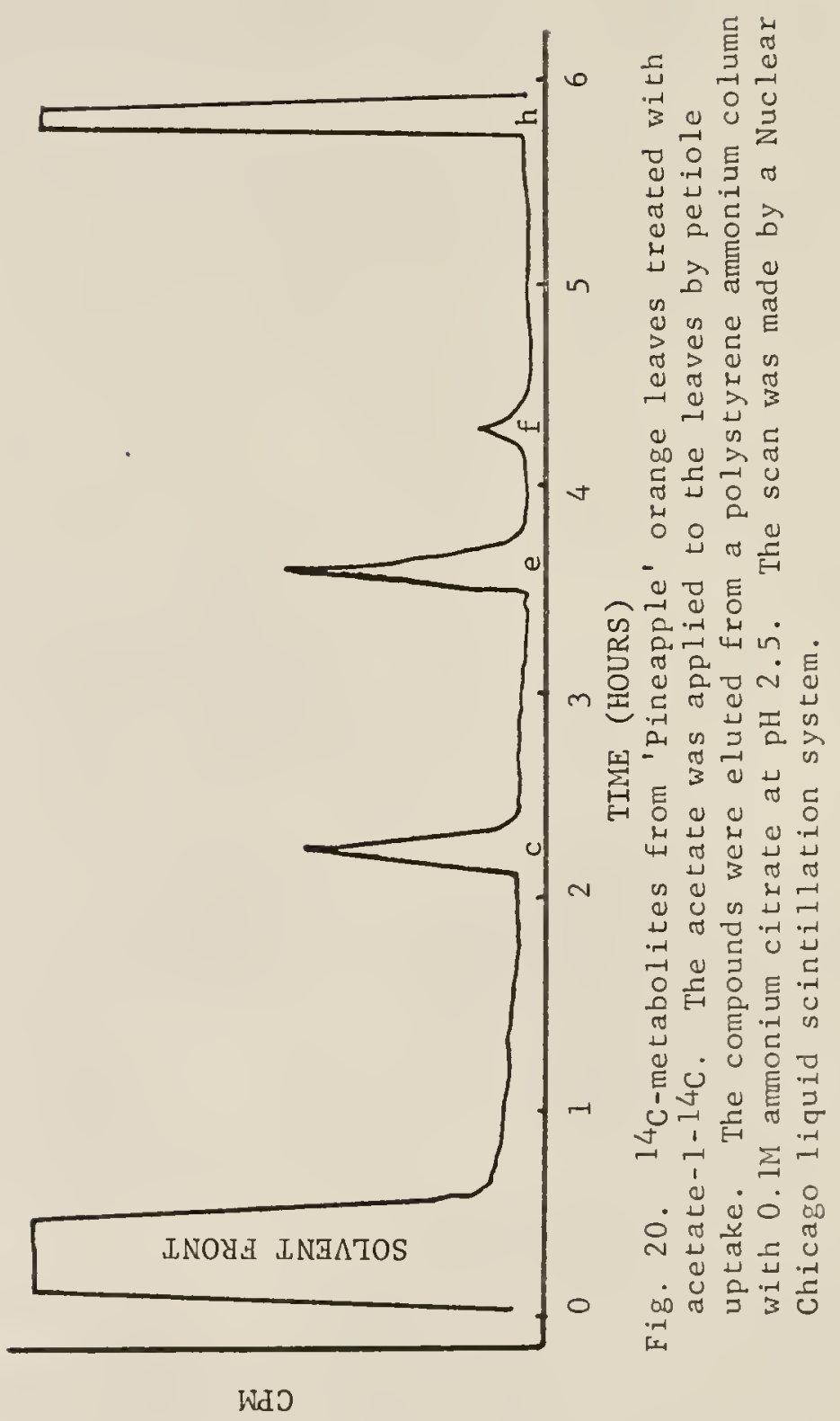




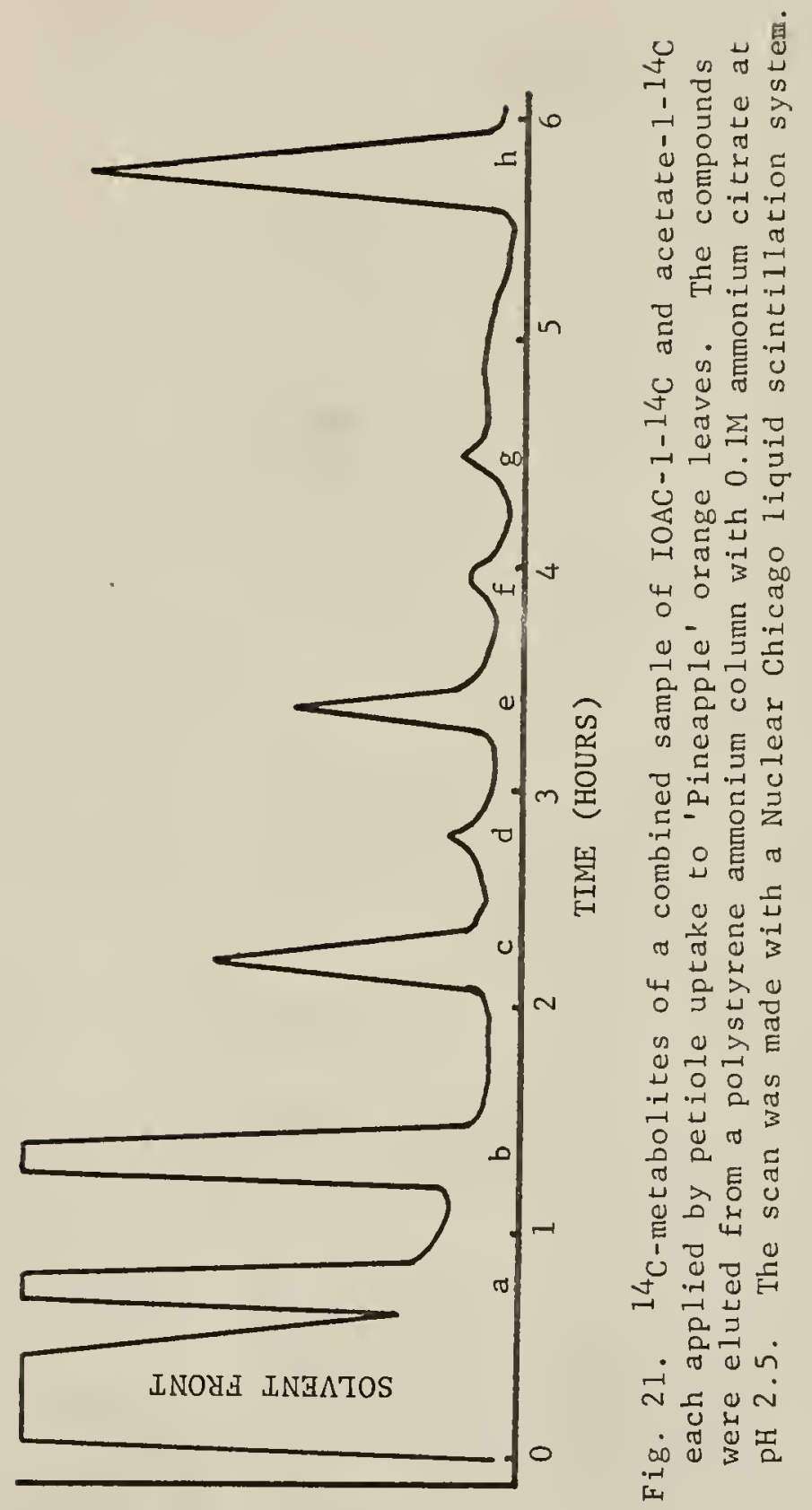

ผมว 
Metabolism of 131 IOAC

${ }^{131}$ IOAC treatment of 'Pineapple' leaves resulted in a compound with a different $R_{f}$ value that any formed in the IOAC-14 C metabolism (compare Table 20 to Tables 14, 15, and 16). This metabolite was not positive to ninhydrin. Almost all of the activity was present in the water fraction from the Dowex 50-X8 column and none in the ammonium fraction (Table 13).

Metabolism of $\mathrm{Na} 131$ I

Sodium 131I treated 'Pineapple' leaves resulted in a metabolite with an $R_{f}$ value similar to the 131 IOAC compound (Table 20). Approximately $30 \%$ of the activity was lost from the solution when the proteins and green pigments were precipitated. The remainder of the activity came through the Dowex 50-X8 column in the water fraction (Table 21). 
Table 20. $\mathrm{R}_{\mathrm{f}}$ values from paper chromatograms of metabolites formed by 'Pineapple' orange leaves treated with either 131IOAC or $\mathrm{Na} 131_{1}^{\mathrm{a}}$

$R_{f}$ values of labeled metabolites

Solvent systems

\begin{tabular}{lccc} 
Sample & 1 & 2 & 3 \\
\hline $\begin{array}{l}131_{\text {IOAC }} \\
\text { 'Pineapple' } 131_{\text {IOAC water }}^{\text {fraction }}\end{array}$ & .85 & $.70-.72$ & .64 \\
$\begin{array}{l}\text { 'Pineapple' Na131I water } \\
\text { fraction }\end{array}$ & $.34-.38$ & .60 & .26 \\
\end{tabular}

a The radioactive compounds were applied to the leaves by petiole uptake. Time of uptake was 1 hour, after which the leaves were transferred to water for an additional hour. The samples were fractionated from a Dowex 50-X8 column. They were then spotted on Whatman 非1.

$\mathrm{b}_{1}$ - Butanol:water:acetic acid, 4:5:1, v/v/v (upper phase).

2 - Methanol:water:acetic acid, 19:1:1, v/v/v.

3 - Phenol:water, $100: 20, \mathrm{v} / \mathrm{v}$, in $0.04 \%$-hydroxyquinoline. 
Table 21. Distribution of radioactivity in fractions from 'Pineapple' orange leaves treated with sodium $131_{\text {iodide and eluted from a Dowex }}$ 50-X8 column?

Fraction

$\%$ of total radioactivity

Ethanol precipitated

Water

63

Ammon i um

3

a The radioactive compound was applied to the leaves by petiole uptake. Time of uptake was 1 hour, after which the leaves were transferred to water for an additional hour. 


\section{DISCUSSION}

Both 'Pineapple' and 'Valencia' orange tissues will metabolize IOAC. In both instances, the patterns of labeled metabolites formed from IOAC- ${ }^{14} \mathrm{C}$ were the same. This was the case whether the IOAC was taken into the leaf through the surface or through the petiole. There was a greater quantity of IOAC $-14 \mathrm{C}$ absorbed into the tissues through the petiole than through the surface of the leaf. With the petiole uptake method, there was a concomitant increase in the quantity and the number of labeled metabolites. This increase in quantity and number found could be a consequence of the greater uptake. However, it might possibly be that the metabolism of IOAC in the petiole uptake tests was different in some respects simply because of the route of entry of the IOAC.

The reactions occurred over a relatively short period of time since only a very small percentage of the total radioactivity in the leaves remained as IOAC after only 2 hours. Also, the same results, namely, only a small percentage of free IOAC, were found with the surface application experiments. The duration of this test was 24 hours.

There was no significant incorporation of ${ }^{14} \mathrm{C}$ into cell wall materials, macromolecules, sugar compounds, or fats and it appeared that there were no phenolic compounds labeled. However, most of these determinations were made on extracts from leaves treated by surface application of $0.1 \mathrm{M}$ IOAC. Absorption rates of IOAC appeared to be slow under these conditions and not as much IOAC entered the leaves as with the petiole uptake tests. Since more labeled metabolites were 
found in the latter case, some of these unknowns might be either a sugar or a phenolic compound. No fats, proteins, or cellular debris left after ethanolic or water extractions were labeled in either case. Two of the labeled compounds formed in the leaves were identiffed as glutamic and aspartic acids. This was based on similarities of $\mathrm{R}_{\mathrm{f}}$ values and ninhydrin color reactions on chromatograms developed in 3 different solvent systems. These compounds were also retained on a Dowex 50-X8 column and appeared in the 1\% formic acid elution of a Dowex 1-X8 column (formate). Both facts indicated that the molecules were ionizable and could be amino acids.

These 2 amino acids were probably 2 of the major metabolites isolated from the leaf-surface application experiments. Electrophoresis showed that these were charged and compounds I and II reacted to ninhydrin. Also, paper chromatograms of these extracts showed 2 ninhydrin-positive, labeled metabolites were present with $\mathrm{R}_{f}$ 's similar to glutamate and aspartate.

Some of the unknowns were also bound to a Dowex 50-X8 column and eluted from a Dowex $1-x 8$ column (formate) with water or with various concentrations of formic acid. These were then organic cations but their exact nature was unknown. Possibly there were other labeled amino acids that were below the limit of detection by ninhydrin. Also, both methyl and carboxy $1{ }^{14} \mathrm{C}$ labeled IOAC treated orange leaves produced ${ }^{14} \mathrm{CO}_{2}$ in approximately the same patterns. This indicated that acetate was being metabolized and the most likely pathway would be through organic acids then to amino acids. Therefore, labeled organic and amino acids would seem to be the logical components to be produced. Glutamate and aspartate pools in the orange leaf are fairly large (148), which would lend support to this idea. 
The results indicated that some of the IOAC was metabolized similarly to acetate. Labeled acetate applied to orange leaves resulted in at least 2 to 3 of the same labeled compounds as did IOAC. Again, labeled glutamic and aspartic acids were present in both cases. Also, labeled alanine was tentatively identified as a component arising from acetate $-1-14 \mathrm{C}$ metabolism.

Other labeled compounds appeared with IOAC that were not present with acetate. A portion of the IOAC could have been metabolized differently, or could have affected metabolism, per se. However, it was clear from the $\mathrm{CO}_{2}$ pattern and the labeled metabolite patterns of acetate and IOAC that a large portion of the IOAC was broken at the I-C bond.

The metabolic patterns of ${ }^{13}$ IOAC and IOAC $-{ }^{14} \mathrm{C}$ indicated further that this disruption occurred in at least 90 to $95 \%$ of the IOAC in the tissue. The time of bond separation was not readily apparent. However, light was not the agent that catalyzed this reaction. Tests of $10 \mathrm{AC}-14 \mathrm{C}$ applied to a cellulose pad and kept in an acidic medium showed that no discernible radioactivity was lost from that surface during sunlighted or darkened exposures. Acetic acid would have been volatile under these conditions. IOAC does decompose in 1 ight but the rate is apparently very slow. It has been calculated to be $0.05 \% /$ hour (100). Therefore, the I-C bond was being reacted upon by some other agent. For glutamic and aspartic acids to form, it would seem logical that the I-C bond would have to be disrupted before the acetate was metabolized. This idea was supported by the capacity of the orange leaves to form the same iodinated compound from either ${ }^{131}$ IOAC or

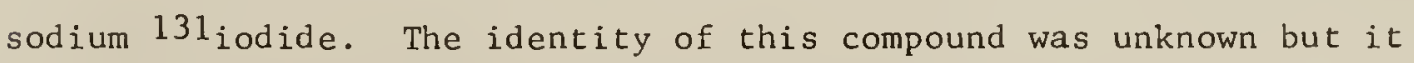

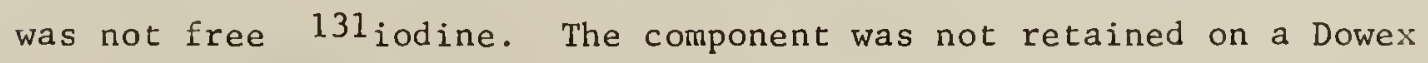


50-X8 column. About $30 \%$ of the radioactivity with ${ }^{13} 1_{\text {IOAC }}$ treated leaves was precipitated by alcohol. This could indicate that the

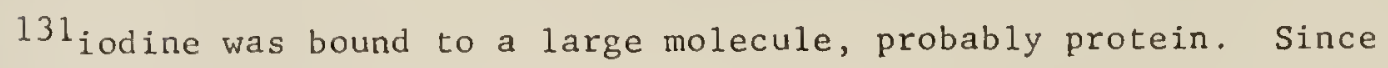
potassium iodide will promote orange explant abscission, it appears that the iodide portion of IOAC could be responsible for a portion of the abscission-accelerating activity. The IOAC may act as a better carrier for iodine since potassium iodide in a spray will not promote orange abscission but IOAC wil1. The iodide ion does not move readily into the leaf.

From previous work $(76,77)$, it has been shown that abscission of fruits of 'Pineapple' and 'Valencia' orange varieties are different when subjected to the same IOAC sprays. Yet, the data presented here show that there were no differences in the labeled metabolites formed from 'Pineapple' or 'Valencia' orange leaves treated with IOAC. However, there was approximately 3 to 4 times the amount of radioactivity in the 'Pineapple' leaves as that of the 'Valencia' leaves from the surface application experiments. This indicated either a greater uptake of the IOAC by 'Pineapple' leaves or a slower rate of translocation. A previous investigation on IOAC uptake (152) had shown a similar pattern and appearance of radioactivity in both varieties with time. It was concluded that there was no difference in translocation of labeled materials. From the present data on uptake of IOAC from surface applications vs petiole uptake, it would appear that the difference between 'Pineapple' and 'Valencia' in the abscission response was due to a difference in surface uptake.

Cross-sections of the leaves from both orange varieties were examined and no difference in the cuticle thickness was observed. In fact, the 'Pineapple' cuticle, though variable, appeared to be 
slightly thicker. Average values of a relative scale used to measure cuticle thickness were: 'Pineapple', 2.736; and 'Valencia', 2.464. Therefore, cuticle thickness cannot account for the observed differences in radioactivity in the leaves or in the differences with respect to abscission.

'Valencia' leaves also differed from 'Pineapple' leaves in the amounts of radioactivity in the residue. The amount of radioactivity in the 'Valencia' leaf residue decreased with time. This indicated that there was no significant synthesis of ${ }^{14} \mathrm{C}$ from IOAC to macromolecules occurring during this time. The reason for the difference in the radioactivity remaining in the residues after extraction between the 2 varieties is not known. However, the radioactivity in the residue was a small portion of the total radioactivity $(<0.1 \%)$.

Unfortunately, these metabolic studies did not indicate the mode of action of IOAC on orange fruit abscission. The IOAC was metabolized very quickly in the tissues; therefore, it would seem that the action on abscission, per se, was not entirely through the action of intact IOAC as an inhibitor of metabolism. However, both malonic acid and 2,4-dinitrophenol promoted orange abscission and these are both metabolic inhibitors. Also, it has been suggested that IOAC acts as an uncoupler of high-energy phosphate systems (47). Dinitrophenol acts similarly (46); therefore, the effect of some of the IOAC might be on high-energy transfer systems. Also, there could be an additive effect of the iodine and the unmetabolized IOAC.

Additions of sugars have been shown to inhibit abscission in many systems $(13,15,27,96,108)$, including the orange explant test (168, 169). This study yielded the same results, namely, that most sugars delayed abscission. Ascorbic acid was found to delay the rate of 
abscission of the orange explants. Other workers have found that ascorbic acid enhanced orange fruit abscission (48). Their test system was different from the orange explant test and the concentration tested in their investigation always exceeded $10^{-3} \mathrm{M}$.

Iodoacetic acid has also been shown to change the metabolic pathway of glucose from glycolysis to the pentose shunt $(55,90)$. Ribose slightly accelerated the rate of abscission of the orange explants, so this could suggest an involvement of the pentose shunt with abscission.

Certain amino acids have been shown to affect abscission. Alanine enhanced the rate of abscission of the orange explants as it does bean explants $(41,136,137,140)$. However, the effect of alanine in the bean explant bioassay was found to be related to ethylene production (137), but this has not been ascertained for citrus. Cysteine, also, slightly promoted orange fruit abscission. In conjunction with IOAC only a slight reduction in the abscission rate produced by IOAC alone was found. If IOAC acted as a sulfhydryl enzyme inhibitor, possibly flooding the tissues with sulfhydryl material might have reduced the effect of IOAC. There was no interaction between cysteine and IOAC on citrus fruit abscission.

Acetic acid applied as a spray on whole trees or in the explant test did not promote abscission. Therefore, the products of metabolism of the acetate portion of IOAC probably are not the active agents in initiating the events leading to abscission. Since some products from metabolism of IOAC were not found with acetate-treated leaves, these might be important. However, probably more important is the iodine compound or the fact that the iodine ion might exist. Potassium iodide will promote orange abscission in the explant test, 
but not when sprayed on trees (76). This suggests that the iodine was active in promoting abscission and that IOAC might act as a more effective carrier for the iodine into the leaf. Ethyl iodide and methyl iodide are not effective as promotors of orange explant abscission. However, diiodomethane did promote abscission. This may Indicate the relative ease of relcase of iodine from the chemical is a factor. 


\section{SUMMARY AND CONCLUSIONS}

Investigations were initiated to determine the patterns of metabolism of labeled IOAC in 'Valoncia' and 'Pineapple' sweet orange leaves, and to test various chemicals for their effects on the rate of abscission of orange explants. The following observations were made:

1. Both 'Valencia' and 'Pineapple' orange varieties had the same patterns of labeled metabolites when treated with either IOAC-1-14C or IOAC $-2-14 \mathrm{C}$. This was the case either with drops applied on the leaf surface or with petiole uptake.

2. Approximately 3 to 4 times as much foliar-applied IOAC got into 'Pineapple' orange leaves as compared to 'Valencia' orange leaves. This difference in uptake was not due to cuticular thicknesses.

3. A major portion of the IOAC ( 90 to $95 \%$ ) entering the leaf was metabolized in both varieties within a relatively short time. The I-C bond was apparently disrupted and the acetate portion of the molecule was metabolized to some of the same compounds as was acetate, i.e. glutamic and aspartic acids. The iodine portion was incorporated into only 1 compound that was detected. The nature of this compound remains unknown .

4. Na131 I applied to orange leaves resulted in the same radio-

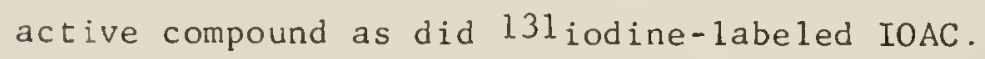

5. From the testing of chemicals in the orange explant test, ribose, malonic acid, L-alanine, cysteine, 2,4-dinitrophenol, potassium iodide, and diodomethane accelerated the rate of abscission. Methyl iodide, ethyl iodide, ascorbic 1 cid, and hexose sugars either retarded abscission or had no effect. 
It was concluded that the major portion of the IOAC was first dis $r$ upted at the I-C bond in the orange leaf. This apparently resulted in free iodine or iodide, and acetate. It appeared that a large portion of the action of IOAC on orange fruit abscission was via the iodine and that IOAC serves as a carrier for the iodine into the leaf. Another portion of the action of IOAC could be through the action of IOAC, per se, on metabolism since there were products of IOAC that were not present with acetate and since chemicals known to alter metabolism, e.g., 2,4-dinitrophenol, will hasten abscission. Thus, there could be an additive effect of IOAC and the iodine arising from IOAC metabolism.

Also, it appears that the apparent difference in uptake of IOAC through the surface of the leaves could be the basis for the varied response between the 'Pineapple' and 'Valencia' orange varieties. 


\section{LITERATURE CITED}

1. Abeles, F. B. and B. Rubinstein. 1964. Regulation of ethylene evolution and leaf abscission by auxin. Plant Physiol. 39: 963-969.

2. Addicott, F. T. 1961. Gibberellin and abscission. Calif. Agri. $15(9): 4$.

3. 1965. Physiology of abscission, p. 1094-1126. In W. Ruhland (ed.) Handbuch der Pflanzenphysiologie XV(2). Springer-Vertag, Berlin.

4. and R. S. Lynch. 1955. Physiology of abscission. Ann. Rev. Plant Physiol. 6:211-238.

5. , H. R. Carns, J. L. Lyon, O. E. Smith, and J. L. Means. 1964. On the physiology of abscisins. p. 687-703. Center National de la Recherche Scientifique 123, Paris.

6. O. E. Smith, and J. L. Lyon. 1965. Some physiological properties of abscisin II. Plant Physiol. (Suppl.) 40:XXVI -XXVII.

7. Barbour, R. D., D. R. Buhler, and C. H. Wong. 1958. Identification of and estimation of catabolic pathways of glucose in fruits. Plant Physiol. 33:396-400.

8. Barker, J. and L. W. Mapson. 1964. Studies in the respiratory and carbohydrate metabolism in plant tissues. XIV. The effect of certain enzymic poisons on respiration, sugar, and ascorbic acid of detached leaves. J. Exp. Bot. 15:272-283.

9. and M. E. Younis. 1965. Studies in the respiratory and carbohydrate metabolism of plant tissues. XVI. Further studies of the influence of iodoacetate as a stimulate of respiration in strawberry leaves. J. Exp. Bot. 16:59-73.

10. - 1965. Studies in the respiratory and carbohydrate metabolism of plant tissues. XVII. The effect of iodoacetate on the $\mathrm{CO} 2$ output, pathways of glucose respiration and contents of phosphate esters in strawberry leaves. J. Exp. Bot. $16: 74-85$.

11. Beevers, H. 1961. Respiratory metabolism in plants. Row-Peterson and Company, White Plains, New York. 232 p. 
12 . and M. Gibbs. 1954. The direct oxidation pathway in plant respiration. Plant Physiol. 29:322-324.

13. Biggs, R. H. 1957. Physiological basis of abscission in plants. Doctoral Dissertation. Purdue Univ. Lafayette, Ind.

14. and A. C. Leopold. 1956. A factor inducing abscission and its relation to defoliating agents. Plant Physiol. (Suppl.) $31: \mathrm{XX}$.

15.

1957. Factors influencing abscission. plant phystol. 32:626-632.

16. 1958. The two-phase action of auxin on abscission. Amer. J. Bot. 45:547-551.

17. Birch, A. J., R. A. Massey-Westropp, and C. J. Maye. 1955. Studies in relation to biosynthesis. VI. 2-hydroxy-6-methylbenzoic acid in Penicillium griseofulvum. Aust. J. Sci. 8:539:544.

18. and F. W. Donovan. 1953. Studies in relation to biosynthesis. I. Some possible routes to derivatives of orcinol and phloroglucinol. Aust. J. Sci. 6:360-368.

19. , P. Fritton, E. Pride, A. J. Ryan, Herchel Smith, and W. B. Whalley. 1958. Studies in relation to biosynthesis. Part XVII. Sclerotiorin, citrinin, and citromycetin. J. Chem. Soc. $4576-4581$.

20 . and E. Pride. 1962. Studies in relation to biosynthesis. Part XXVI. 7-hydroxy-4, 6-dimethylphthalide. J. Chem. Soc. 370-371.

21. A. J. Ryan, and Herchel Smith. 1958. Studies in relation to biosynthesis. Part XIX. The biosynthesis of helminthosparin. J. Chem. Soc. 4773-4774.

22. Block, R. J., E. L. Durrum, and G. Zweig. 1958. A manual of paper chromatography and paper electrophoresis. 2 ed. Academic Press, New York. 710 p.

23. Bonner, J. 1950. Plant Biochemistry. Academic Press Inc., New York. $573 \mathrm{p}$.

24. Bornman, C. H. and F. T. Addicott. 1965. Histological and histochemical effects of auxin and gibberellin in abscission. Plant Physiol. (Supp1.) 40:XXVII.

25. Brady, R. O. 1960. Biosynthesis of fatty acids. II. Studies with enzymes obtained from brain. J. Biol. Chem. 235:3099-3103.

26. Bray, G. A. 1960. A simple efficient liquid scintillator for counting aqueous solution in a liquid scintillation counter. Ana1. Biochem. 1:279-285. 
-27. Brown, H. S. and F. T. Addicott. 1950. The anatomy of experimental leaflet abscission in Phaseolus vulgaris. Amer. J. Bot. $37: 650-656$.

28. Brown, S. A., G. H. N. Towers, and D. Wright. 1960. Biosynthesis of the coumarins. Tracer studies on coumarin formation in Hierochoe odorata and Melilotus offinicinalis. Can. J. Biochem. and Physiol. 38:143-156.

29. Bryan, W. H. and E. H. Newcomb. 1954. Stimulation of pectin methylesterase activity of cultured tobacco pith by indoleacetic acid. Physiol. Plantarum. 7:290-297.

30. Buhler, D. R., E. Hansen, and C. H. Wang. 1957. Incorporation of ethylene into fruits. Nature. 179:48-49.

31. Burg, S. P. and Ellen A. Burg. 1961. Ethylene evolution and subcellular particles. Nature. 191:967-969.

32 .

1965. Ethylene action and the ripening of Eruits. Science. 148:1190-1196.

33. and K. V. Thimann. 1959. The physiology of ethylene formation in apples. Proc. Nat. Acad. Sci. 45:335-344.

34. - 1960. Studies on the ethylene production of apple tissue. Plant Physiol. 35:24-35.

35. Calo, N. and M. Gibbs. 1960. The site of inhibition of iodoacetamide in photosynthesis studies with chloroplasts and cel1 free preparations of spinach. Zeitschr. Naturforsch. 15 b (5): 287-291.

36. Canvin, D. T. and H. Beevers. 1961. Sucrose synthesis from acetate in the germinating castor bean: Kinetics and pathway. J. Biol. Chem. 236:988-995.

37. Carns, H. R. 1951. Oxygen, respiration and other critical factors in abscission. Doctoral Dissertation. Univ. of Calif., Los Angeles.

38. F. T. Addicott, K. C. Baker, and R. K. Wilson. 1961. Acceleration and retardation of abscission by gibberellic acid, p. 559-565. In R. M. Klein (ed.) Plant Growth Regulation. Iowa State Univ. Press. Anes, Iowa.

39. , and R. S. Lynch. 1951. Some effects of water and oxygen on abscission in vitro. Plant Physiol. $26: 629-630$.

40. Chatterjee, S. and A. C. Leopold. 1964. Kinetin and gibberellic actions on abscission process. Plant Physiol. 39:334-337.

41 .

1965. Changes in abscission processes with aging. Plant Physiol. 40:96-101. 
42. Chaudhri, S. A. 1957. Some anatomical aspects of fruit drop in citrus. Doctoral Dissertation. Univ. of Florida, Gainesville.

43. Cleland, R. and J. Bonner. 1956. The residual effect of auxin on the cell wa11. Plant Physiol. 31:350-354.

44. Coit, J. E. and R. W. Hodgson. 1919. An investigation of the abnormal shedding of young fruits of the Washington Navel Orange. Univ. of Calif. Pub. Agr. Sci. 3:283-368.

45. Conant, J. B. and W. R. Kirner. 1924. The relation between the structure of organic halides and the speed of their reaction with inorganic iodides. I. The problem of alternating polarity in chain compounds. J. Amer. Chem. Soc. 46:232-252.

46. Conn, E. E. and P. K. Stumpf. 1963. Outlines of Biochemistry. John Wiley and Sons, Inc., New York and London. 391 p.

47. Contreiras, J. de O. P. C. 1945. The effect of iodoacetate on the respiration of leaves of Hedera helix. Doctoral Dissertation. Univ. of Cambridge.

48. Cooper, W. C. and W. H. Henry. 1967. The effect of ascorbic acid on citrus fruit abscission. Citrus Industry. 48(6):5-7.

49. Coorts, G. D., J. B. Gartner, and J. P. McCollum. 1965. Effect of senescence and preservative on respiration in cut flowers of Rosa hydrida, 'Velvet Times'. Proc. Amer. Soc. Hort. Sci. 86:779-790.

50. Doyle, W. P. and C. H. Wang. 1958. Glucose catabolism in pepper fruit (Capsicum frutescens longum). Can. J. Bot. 36:483-490.

51. Eaton, F. M. 1955. Physiology of the cotton plant. Ann. Rev. Plant Physiol. 6:299-328.

52. and D. R. Ergle. 1953. Relationship of season trends in carbohydrate and nitrogen levels and effects of girdling and spraying with sucrose and urea to the nutritional interpretation of boll shedding. Plant Physiol. 28:503-519.

53. Esau, Katherine. 1965. Anatomy of Seed Plants. 2 ed. John Wiley and Sons, Inc., New York and London. 767 p.

54. Facey, V. 1950. Abscission of leaves in Frainus Americana L. New Phyto1. 49:103-116.

55. Faust, M. 1965. Physiology of anthocyanin development in 'McIntosh' apples. I. Participation of pentose phosphate pathway in anthocyanin development. Proc. Amer. Soc. Hort. Sci. 87:1-9.

56. Frankenburg, W. G. 1950. Chemical changes in the harvested tobacco leaf. Part II. Chemical and enzymic conversions during fermentation and aging. Adv. in Enzymol. 10:325-441. 
57. Gatenbeck, S. 1958. Incorporation of ${ }^{14} \mathrm{C}$-acetate in the phenolic substances in Penicillium isolandicum. (Suppl.) Acta Chemica Scan. 12:1985-1989.

58. - 1958. Incorporation of labelled acetate in emodin in Penicilium isolandicum. Acta Chemica Scan. 12:1211-1214.

59. and K. Mosbach. 1959. Acetate carboxyl oxygen (180) as donar for phenolic hydroxy groups of orsellinic acid produced by fungi. Acta Chemica Scan. 13:1561-1564.

60. Gaur, B. K. and A. C. Leopold. 1955. The promotion of abscission by auxin. Plant Physiol. 30:487-490.

61. Gawadi, A. G. and G. S. Avery, Jr. 1950. Leaf abscission and the so-called "abscission layer". Amer. J. Bot. 37:172-180.

62. Geismann, T. A. and T. Swain. 1957. Biosynthesis of flavonoid compounds in higher plants. Chem. and Ind. 984.

63. Gibbs, M. 1952. Triosephosphate dehydrogenase and glucose 6phosphate dehydrogenase in pea plant. Nature. 170:164-165.

64. metabolism. I. An enzyme study with pea root. Plant Physiol. $34: 529-532$.

65. Glasziou, K. T. 1957. The effect of indoleacetic acid on the binding of pectin methylesterase to the cell walls of tobacco pith. Aus. J. Biol. Sci. 10:337-341.

66. Halevy, A. H. 1963. Interaction of growth-retarding compounds and gibberellin on indoleacetic acid oxidase and peroxidase of cucumber seedlings. Plant Physiol. 38:731-737.

67. Hall, W. C. 1952. Evidence on the auxin-ethylene balance hypothesis of foliar abscission. Bot. Gaz. 113:310-322.

68. - 1952. Studies on the origin of ethylene from plant tissues. Bot. Gaz. 113:55-65.

69.

, F. A. Herrero, and F. R. H. Katterman. 1961. Leaf abscission in cotton. IV. Effects of a natural promoter and amino acids on abscission in cotyledonary node explants. Bot. Gaz. 123:29-34.

70. and H. C. Lane. 1952. Compositional and physiological changes associated with the chemical defoliation of cotton. Plant Physiol. 27:754-768.

71. and H. L. Liverman. 1956. Effect of radiation and growth regulators on leaf abscission in seedling cotton and bean. Plant Physiol. 31:471. 
72. Hansen, E. 1939. Effect of ethylene on certain chemical changes associated with the ripening of pears. Plant Physiol. 11: $145-161$.

73. Hartmann, H. T., M. Fad, and J. Whisler. 1967. Inducing abscission of olive fruits by spraying with ascorbic acid and iodoacetic acid. Calif. Agr. $21(7): 5-7$.

74. Heinicke, A. J. 1919. Concerning the shedding of flowers and Eruits and other abscission phenomena in apples and pears. Proc. Amer. Soc. Hort. Sci. 16:76-83.

75. Heinstein, P. F., F. H. Smith, and S. B. Tove. 1962. Biosynthesis of C14-1abeled gossypol. Fed. Proc. 21:399.

76. Hendershott, C. H. 1964. The effect of various chemicals on the induction of fruit abscission in 'Pineapple' oranges. Proc. Amer. Soc. Hort. Sci. 85:201-209.

77. 1966. The effect of iodoacetic acid on citrus fruit abscission. Citrus and Vegatable Magazine. 29:18-20.

78. Herrett, R. A., H. H. Hatfield, Jr., D. G. Grosby, and A. J. Vlitos. 1962. Leaf abscission induced by the iodide ion. Plant Physiol. $37: 358-363$.

79. Hield, H. Z., R. M. Burns, and M. J. Garber. 1965. Effect of gibberellin sprays on fruit set of 'Washington' Navel Orange trees. Hilgardia. 36:297-311.

80. Hodgson, R. W. 1918. An account of the mode of foliar abscission in Citrus. Univ. of Calif. Pub. (in Bot.) 6(15):417-428.

81. Huberty, M. R. 1948. Principles and methods of irrigation. Chapter X. In L. D. Batchelor and H. J. Webber (eds.) The Citrus Industry Vol. II. Univ. of Calif. Press, Berkeley and Los Angeles.

82. Humphreys, T. E. and W. M. Dugger, Jr. 1957. The effect of 2,4dichlorophenoxyacetic acid on pathways of glucose catabolism in higher plants. Plant Physiol. 32:136-140.

83. - 1959. Effect of $2,4-$ dichlorophenoxyacetic acid and 2,4-dinitrophenol on the uptake and metabolism of exogenous substrates by corn roots. Plant Physiol. 34:112-116.

84. Hutchinson, A., C. D. Taper, and G. H. N. Towers. 1959. Studies of phloridzin in Malus. Can. J. Biochem. and Physiol. 37:901-910.

85. Ibrahim, R. K. and G. H. N. Towers. 1960. Studies of hydrangerol in Hydrangea macrophylla. Ser. I. Isolation, identification and biosynthesis from Cl4 labelled compounds. Can. J. Biochem. and Physiol. 38:627-634. 
86. 1962. Studies of hydrangerol in Hydrangea macrophylla. Ser. II. Biosynthesis of hydrangerol from C14 labelled compounds. Can. J. Biochem. and Physiol. 40: $449-453$.

87. Jacobs, W. P., J. A. Shield, Jr., and Daphne J. Osborne. 1962. Senescence factor and abscission of coleus leaves. Plant Physiol. $37: 104-106$.

88. James, W. O. 1954. The use of respiratory inhibitors. Ann. Rev. Plant Physiol. 4:59-90.

89. Jansen, E. F., R. Jang, P. Albersheim, and J. Bonner. 1960. Pectic metabolism of growing cell walls. Plant Physiol. 35:87-97.

90. Kandler, O. and I. Liesenkotter. 1961. Effect of monoiodoacetic acid, arsenite, and dinitrophenol on the path of carbon in photosynthesis. Proc. Int. Congr. Biochem. 5 th Moscow. $6: 326-329$.

91. Key, J. I. 1962. Changes in ascorbic acid metabolism associated with auxin-induced growth. Plant Physiol. 37:349-356.

92. Kornberg, H. L. and H. A. Krebs. 1957. Synthesis of cell constituents from $\mathrm{C}_{2}$ units by a modified tricarboxylic acid cycle. Nature. 179:988-991.

93. Krezdorn, A. H. and M. Cohen. 1962. The influence of chemical fruit-set sprays on yield and quality of citrus. Proc. Fla. Soc. Hort. Sci. 75:53-60.

94. Laibach, F. 1933. Wuchsstoffversuche mit leben den orchidenpollinien. Berdtsh. Bot. Gaz. 51:386-392.

95. LaMotte, C. E., J. R. Mathur, and P. Brenner. 1965. Changes in pectin methylesterase activity associated with leaf abscission in Coleus. Plant Physiol. (Suppl.) 40:XXVII.

96. Lane, H. C. and W. C. Hall. 1952. The effect of applied sugars, light intensity and temperature upon the chemical defoliation of cotton. Science. 116:427-428.

97. LaRue, C. D. 1936. The effect of auxin on the abscission of petioles. Proc. Nat. Acad. Sci. 22:254-259.

98. Larsen, F. E. 1966. Potassium iodide induced leaf abscission of deciduous wood plants. Proc. Amer. Soc. Hort. Sci. 88:690-697.

99. Lee, E. 1911. The morphology of leaf-fa11. Ann. Bot. 25:51-106.

100. Lee, Pauline and F. H. Westheimer. 1966. Acetoacetate decarboxylase photochemical oxidation induced by iodoacetate. Biochem. 5: 834-837. 
101. Leopold, A. C. 1961. Senescence in plant development. Science. $134: 1727-1732$.

102. 1964. Plant Growth and Development. McGraw-Hill. New York. $466 \mathrm{p}$.

103. and C. A. Price. 1957. Sulfhydryls in plants. I. Reactions with growth regulators. Plant Physiol. 32(6):520-525.

104. Lieberman, M. and C. C. Craft. 1961. Ethylene production by cytoplasmic particles from apple and tomato fruits in the piesence of thiomalic and thioglycolic acid. Nature. 189:243.

105. and L. W. Mapson. 1962. Fatty acid control of ethane production by sub-cellular particles from apples and its possible relationship to ethylene biosynthesis. Nature. 195:1016-1017.

106. Lin, C. Y. and J. L. Key. 1964. Auxin-induced growth and its relationship to ascorbic acid metabolism. Plant Physiol. (Suppl.) 39:iii.

107. Liu, W. and H. R. Carns. 1961. Isolation of abscisin, an abscission accelerating substance. Science. 134:384-385.

108. Livingston, G. A. 1950. In vitro tests of abscission agents. Plant Physiol. 25:711-721.

109. Lloyd, F. E. 1916. Abscission in Mirabilis jalapa. Bot. Gaz. $61: 213-230$.

110. Lyons, J. M., W. B. McGlasson, and H. K. Pratt. 1962. Ethylene production, respiration and internal gas concentrations in cantaloupe fruits at various stages of maturity. Plant Physiol. $37: 31-36$.

111. MacDona1d, I. R. and P. C. DeKock. 1958. The stimulation of leaf respiration by respiratory inhibitors. Physiol. Plantarum. $11: 464-477$.

112. Marre, E. and O. Arrigoni. 1957. Metabolic reactions to auxin. I. The effects of auxin on glutathione and the effects of glutathione on growth of isolated plant parts. Physiol. Plantarum. 10:289-301.

113. Mason, T. G. 1922. Growth and abscission in 'Sea Island' cotton. Ann. Bot. 36:457-484.

114. Meigh, D. F., K. H. Norris, C. C. Craft, and M. Leiberman. 1960. Ethylene production by tomato and apple fruits. Nature. 186: 902-903.

115. Michaelis, L. and M. P. Schubert. 1934. The reaction of iodoacetic acid on mercaptans and amines. J. Biol. Chem. 106:331-341. 
116. Michener, H. D. 1938. The action of ethylene on plant growth. Amer. J. Bot. 25:711-720.

117. Morgan, P.W. and C. Ha11. 1962. Effect of 2,4-dichlorophenoxyacetic acid on the production of ethylene by cotton and grain sorghum. Physiol. Plantarum. 15:420-427.

118. - 1964. Accelerated release of ethylene by cotton following application of indole-3-acetic acid. Nature $201: 99$.

119. Muir, R. M. and J. G. Valdovinos. 1965. Gibberellin and auxin relationship in abscission. Plant Physiol. (Suppl.) 40:XXV.

120. Neish, A. C. 1960. Biosynthetic pathways of aromatic compounds. Ann. Rev. Plant Physiol. 11:55-80.

121. 1964. Major pathways of biosynthesis of phenols. p. 295-361. In J. B. Harborne (ed.) Biochemistry of Phenolic Compounds. Academic Press, London and New York.

122. Nelson, R. F. 1960. An investigation of a chemical mechanism of foliar abscission. Doctoral Dissertation. Iowa State Univ., Iowa City.

123. Nordby, H. E., J. F. Fisher, and T. J. Kew. 1966. Preparation of a firm polyamide absorbant for thin-layer chromatography. J. Chromatogr. 24:257-258.

124. Ordin, L., R. Cleland, and J. Bonner. 1955. Influence of auxin on cell-wal1 metabolism. Proc. Nat. Acad. Sci. 41:1023-1029.

125. Osborne, Daphne J. 1955. Acceleration of abscission by a factor produced in senescent leaves. Nature. 176:1161-1163.

126. - 1958. Changes in the distribution of pectin methylesterase across leaf abscission zones of Phaseolus vulgaris. J. Exp. Bot. 9:446-457.

127. and F. W. Went. 1953. Climatic factors influencing parthenocarpy and normal fruit set in tomatoes. Bot. Gaz. 114:312-322.

128. and S. E. Moss. 1963. Effect of kinetin on senescence and abscission in explants of Phaseolus vulgaris. Nature. 200:1299-1301.

129. Popjak, G. and J. W. Cornforth. 1960. The biosynthesis of cholesterol. Adv. in Enzymol. 22:281-335.

130. Portheim, L. 1941. Further studies on the action of heterauxin on Phaseolus vulgaris. Ann. Bot. 5:35-46.

131. Randerath, K. 1963. Thin-layer Chromatography. Academic Press, New York and London. 250 p. 
132. Rapkin, E. 1962. Measurement of $\mathrm{C}^{14} \mathrm{O}_{2}$ by scintillation techniques. Packard Tech. Bull. 非7.

133. Rasmussen, H. P. and M. J. Bukovac. 1965. Some chemical and physiological changes associated with abscission layer formation in Phaseolus vulgaris. Plant Physiol. (Supp1.) 40:XXV.

134. Reid, W. W. 1958. Biosynthesis of scopoletin and caffeic acid in Nicotiana tabacum. Chem. and Ind. 1439-1440.

135. Richards, J. H., and L. D. Ferretti. 1960. Tropolane biogenesis. Biochem. and Biophys. Res. Comm. 2:107-110.

136. Rubinstein, B. 1963. Analysis of the auxin control of bean leaf abscission. Plant Physiol. 38:262-267.

137. and F. B. Abeles. 1965. Relationship between ethylene evolution and leaf abscission. Bot. Gaz. 126(II): 255-259.

138. and A. C. Leopold. 1962. Analysis of the control of leaf abscission by auxin. Plant Physiol. (Suppl.) 37:XXXVI.

139. - 1964. The nature of leaf

abscission. The Quart. Rev. of Biol. 39:356-372.

140. - 1962. Effects of amino acids on bean leaf abscission. Plant Physiol. 37:398-401.

141. 1963. Analysis of the auxin control of bean leaf abscission. Plant Physiol. 38:262-267.

142. Scott, K. J., J. Daly, and H. H. Smith. 1964. Effects of indoleacetic acid and kinetin on activities of enzymes of the hexose monophosphate shunt in tissue cultures of Nicotiana. Plant Physiol. 39:709-711.

143. and A. C. Leopold. 1965. Petiole abscission as a localized cell senescence. Plant Physiol. (Suppl.) 40:XXV.

144. Shoji, K., F. T. Addicott, and W. A. Swets. 1951. Auxin in relation to leaf blade abscission. Plant Physiol. 26:189-191.

145. Siegel, S. M. and F. Porto. 1961. Oxidants, antioxidants, and growth regulation in plant growth regulation. p. 341-353. In R. M. Klein (ed.) Plant Growth Regulation. Iowa State Univ. Press, Ames, Iowa.

146. Simons, R. K. 1963. Anatomical studies of apple fruit abscission in relation to irrigation. Proc. Amer. Soc. Hort. Sci. 83:77-87.

147. Skok, J. 1943. Defoliation of tomato plant as a response to gaseous emanations from the fruit. Bot. Gaz. 104:486-489. 
148. Stewart, I. 1961. Nitrogen transformations in citrus trees. Proc. Soil and Crop Sci. Soc. of Fla. 21:272-282.

149. Stumpf, P. K. 1960. Lipid metabolism. Ann. Rev. Biochem. 29: $261-294$.

150. Swets, W. A., F. T. Addicott. 1955. Experiments on the physiology of defoliation. Proc. Amer. Soc. Hort. Sci. 65:291-295.

151. Tager, J. M. and J. B. Baile. 1957 Carboxylase and aldolase activity in the fipening banana. Physiol. Plantarum. 10:79-85.

152. Talton, J. H., Jr. and C. H. Hendershott. 1967. Absorption and translocation of iodoacetic acid in two sweet orange varieties. Proc. Amer. Soc. Hort. Sci. 90:117-122.

153. Terpstra, W. 1956. Some factors influencing the abscission of debladed leaf petioles. Acta Botanica Neerlandica. 5(2): $157-170$.

154. Thimann, K. V. 1951. Studies on the physiology of cell enlargement. 10th Symposium on Development and Growth, Growth Supplement. 15: $5-22$.

155. 1954. The physiology of growth in plant tissues. Amer. Scientist. 42:589-606.

156. and W. D. Bonner, Jx. 1948. Experiments on the growth and inhibition of isolated plant parts. I. The action of iodoacetate and organic acids on the Avena coleoptile. Amer. J. Bot. 35:271-281.

157.

1949. Experiments on the

growth and inhibition of isolated plant parts. II. The action of several enzyme inhibitors on the growth of the Avena coleoptile and on Pisum internodes. Amer. J. Bot. 36:214-221.

158. Thomas, R. 1961. Studies in the biosynthesis of fungal metabolites. 2. The biosynthesis of alternarial and its relation to other fungal phenols. Biochem. J. 78:748-758.

159. Tonzig, S. and E. Marre. 1961. Ascorbic acid as a growth hormone. p. 725-734. In R. M. Klein (ed.) Plant Growth Regulation. Iowa State Univ. Press, Ames, Iowa.

160. Underhill, E. W., J. E. Watkin, and A. C. Neish. 1957. Biosynthesis of quercetin in buckwheat. Can. J. Biochem. and Physiol. $35: 219-228$.

161. Valdovinos, J. and R. M. Muir. 1965. Effects of D and $L$ amino acids on foliar abscission. Plant Physiol. 40:335-339.

162. Van Overbeck, J. 1962. Endogenous regulators of fruit growth. p. 37-58. Plant Physiol. Sci. Symp. Campbell Soup Co., Camden, New Jersey. 
163. Van Steveninck, R. M. F. 1959. Factors affecting the abscission of reproductive organs in yellow lupins (Lupinus luteus L.) III. Endogenous growth substances in virus infected and healthy plants and their effect on abscission. J. Exp. Bot. $10: 367-376$.

164. Varner, J. E. 1961. Biochemistry of senescence. Ann. Rev. Plant Physiol. 12:245-264.

165. Walhood, V. T. and B. Counts. 1955. Effects of irrigation on the growth and yield of cotton. Calif. Agr. 9:9-11.

166. Watkin, J. E., E. W. Underhill, and A. C. Neish. 1957. Biosynthesis of quercetin in buckwheat. Part II. Can. J. Biochem. and Physiol. 35:229-237.

167. Weintraub, R. I., J. W. Brown, J. C. Nickerson, and K. N. Taylor. 1951-1952. Studies on the relation between molecular structure and physiological activity of plant growth-regulators. I. Abscission-inducing activity. Bot. Gaz. 113:348-362.

168. Wilson, W. C. 1966. Anatomy and physiology of citrus fruit abscission induced by iodoacetic acid. Doctoral Dissertation. Univ. of Fla., Gainesville.

169. and C. H. Hendershott. 1967. The effects of various chemical treatments on the rate of abscission of 'Hamlin' orange explants. Proc. Amer. Soc. Hort. Sci. 90:123-129.

170. Wright, L. D. 1961. Biosynthesis of isoprenoid compounds. Ann. Rev. Biochem. 30:525-548.

171. Yager, R. E. 1960. Possible role of pectic enzymes in abscission. Plant Physiol. 35:157-162.

172. and R. M. Muir. 1958. Amino acid factor in control of abscission. Science. 127:82-83.

173.

1958. Interaction of methionine and iodoleacetic acid in the control of abscission in Nicotiana. Proc. Soc. Exp. Biol. Med. 99:321-323.

174. Yamaguchi, S. 1954. Some interrelations of oxygen, carbon dioxide, sucrose, and ethylene in abscission. Doctoral Dissertation. Univ. of Calif., Los Angeles.

175. Zaitlin, M. and D. Coltrin. 1964. Use of pectin enzymes in a study of the nature of intercellular cement of tobacco leaf cells. Plant Physiol. 39:91-95. 
BIOGRAPHICAL SKETCH

Timothy Joseph Facteau was born in Tupper Lake, New York, on October 20, 1940. He received his secondary education at the Peddie School, Hightstown, New Jersey. He attended Rutgers, the State University of New Jersey, and received the degree of Bachelor of Science with a major in Pomology in June, 1963. He was also granted the degree of Master of Science with a major in Horticulture from Rutgers, the State University, in June, 1965.

In 1965 he was granted an assistantship from the Department of Fruit Crops, University of Florida and began study towards the degree of Doctor of Philosophy which was completed in December, 1967.

He is a member of Alpha Zeta honorary fraternity and a member of the American Society for Horticultural Science.

He is married to the former Alice Helen Bocchio and they have two children, Donald Michael and Elaine Michele. 
This dissertation was prepared under the direction of the chairman of the candidate's supervisory committee and has been approved by all members of that committee. It was submitted to the Dean of the College of Agriculture and to the Graduate Council, and was approved as partial fulfillment of the requirements for the degree of Doctor of Philosophy. December, 1967

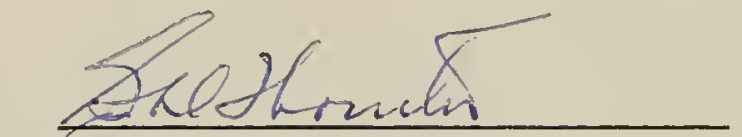

oman, College of Agriculture

Dean, Graduate School

Supervisory Committee:

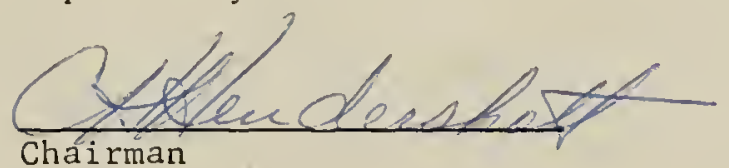

Chairman

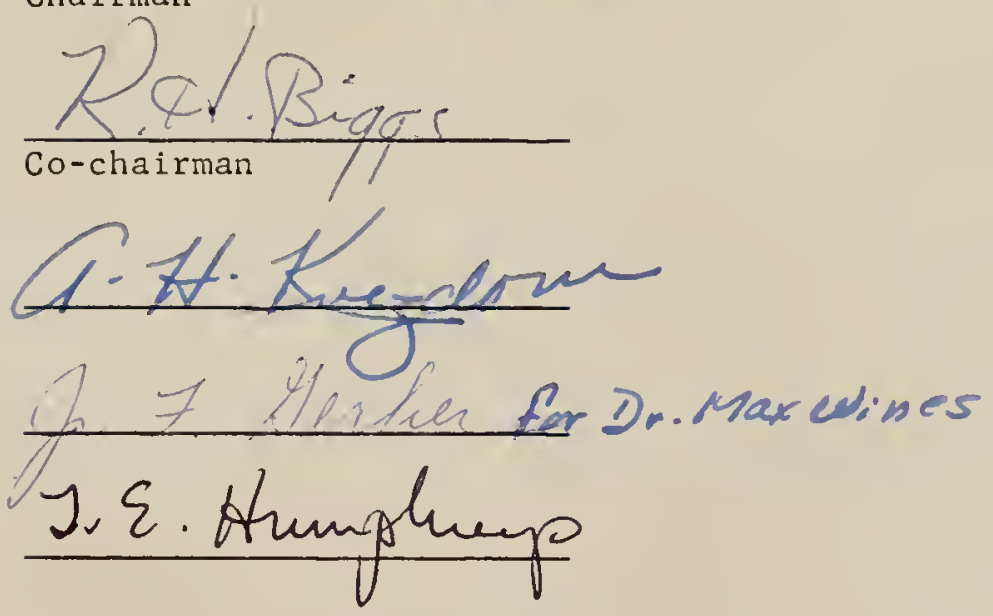


UNIVERSITY OF FLORIDA

31262085537768 